University of San Diego

Digital USD

2010-03-01

\title{
Examining Professional Development at the Organizational Level through the Lens of Teachers and Administrators
}

Lori Kelsey EdD

University of San Diego

Follow this and additional works at: https://digital.sandiego.edu/dissertations

Part of the Leadership Studies Commons

\section{Digital USD Citation}

Kelsey, Lori EdD, "Examining Professional Development at the Organizational Level through the Lens of Teachers and Administrators" (2010). Dissertations. 899.

https://digital.sandiego.edu/dissertations/899

This Dissertation: Open Access is brought to you for free and open access by the Theses and Dissertations at Digital USD. It has been accepted for inclusion in Dissertations by an authorized administrator of Digital USD. For more information, please contact digital@sandiego.edu. 
EXAMINING PROFESSIONAL DEVELOPMENT AT THE

ORGANIZATIONAL LEVEL THROUGH THE LENS OF

TEACHERS AND ADMINISTRATORS

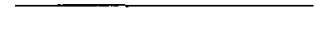 \\ by \\ Lori Kelsey \\ A Dissertation Submitted to the Faculty of \\ San Diego State University and the University of San Diego \\ in Partial Fulfillment \\ of the Requirements for the Degree \\ Doctor of Education \\ Dissertation Committee: \\ Douglas Fisher, Ph.D., San Diego State University \\ Barbara Moss, Ph.D., San Diego State University \\ Susan Zgliczynski, Ph.D., University of San Diego
}

March 2010 
Copyright (C) 2010

by

Lori Kelsey 


\section{DEDICATION}

This dissertation is dedicated to my husband Randy. Without his rational thinking, serene disposition, and independent nature, the completion of this project would have been

impossible. Thank you for the countless sacrifices and compromises you have made these past six years. I love you. 


\title{
ABSTRACT OF THE DISSERTATION
}

\author{
Examining Professional Development at the \\ Organizational Level Through the Lens of \\ Teachers and Administrators \\ by \\ Lori Kelsey \\ Ed.D. in Teaching and Learning \\ San Diego State University and the University of San Diego, 2010
}

The purpose of this evaluative case study was to explore teachers' and administrators' perceptions of the organizational capacity during an initial implementation of a systemic change in professional development at a K-8 school. Educational reform acts such as the No Child Left Behind Act of 2002 pressure public school systems to increase student achievement. School district personnel abide by making systemic changes in professional development. For organizations to make such systemic changes, first the culture must change. In an era of ongoing educational reform, it remains important to continually build upon the evidentiary body of literature so that the nation's students will potentially benefit from the highest quality of instruction provided by teachers working within a system of highly developed organizational capacity. Through application of Guskey's evaluation model, the researcher employed a mixed methodology approach that examined the following five critical aspects of organizational capacity: school vision and leadership, collective commitment and cultural norms, knowledge or access to knowledge, organizational structure and management, and resources. Data collection of the purposeful sample occurred in three phases and included a two-part teacher participant survey, teacher focus group interviews, and administrator semi structured interviews. Key findings emerged from cross case and within case data analysis. These key findings emphasized that perceptions of collective commitment and cultural norms may potentially influence other critical aspects of organizational capacity and therefore may potentially increase or decrease the complexities of systemic change during the initial implementation of a professional development program. Recommendations for future research include studies designed to explore the collective commitment and cultural norms of successful local schools' within the context of systems that sustain a continuous cycle of learning. Recommendations for future practice include assessing collective commitment and cultural norms prior to systemic change and during the life of a program. 


\section{TABLE OF CONTENTS}

PAGE

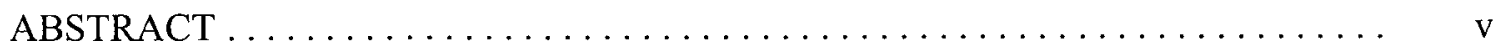

LIST OF TABLES $\ldots \ldots \ldots \ldots \ldots \ldots \ldots \ldots \ldots \ldots \ldots \ldots \ldots \ldots \ldots \ldots \ldots \ldots \ldots$

LIST OF FIGURES $\ldots \ldots \ldots \ldots \ldots \ldots \ldots \ldots \ldots \ldots \ldots \ldots \ldots \ldots \ldots \ldots \ldots \ldots \ldots$

ACKNOWLEDGMENTS $\ldots \ldots \ldots \ldots \ldots \ldots \ldots \ldots \ldots \ldots \ldots \ldots \ldots \ldots \ldots \ldots \ldots \ldots$

CHAPTER

1 INTRODUCTION $\ldots \ldots \ldots \ldots \ldots \ldots \ldots \ldots \ldots \ldots \ldots \ldots \ldots \ldots \ldots \ldots \ldots$

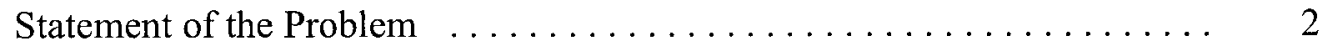

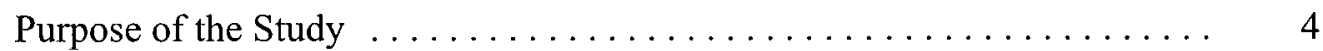

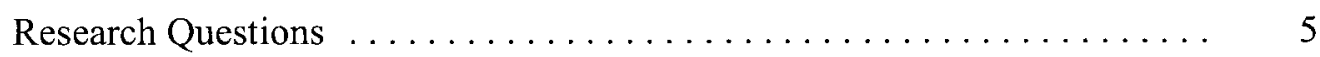

Definition of Terms $\ldots \ldots \ldots \ldots \ldots \ldots \ldots \ldots \ldots \ldots \ldots \ldots \ldots \ldots \ldots \ldots$

Organization of the Dissertation $\ldots \ldots \ldots \ldots \ldots \ldots \ldots \ldots \ldots$

2 REVIEW OF THE LITERATURE $\ldots \ldots \ldots \ldots \ldots \ldots \ldots \ldots \ldots \ldots \ldots \ldots$

Major Educational Reform $\ldots \ldots \ldots \ldots \ldots \ldots \ldots \ldots \ldots \ldots \ldots$

Systems and Systemic Change $\ldots \ldots \ldots \ldots \ldots \ldots \ldots \ldots \ldots \ldots \ldots$

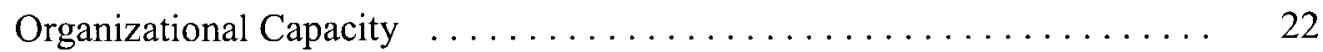

Vision and Leadership $\ldots \ldots \ldots \ldots \ldots \ldots \ldots \ldots \ldots \ldots \ldots \ldots$

Collective Commitment and Cultural Norms $\ldots \ldots \ldots \ldots \ldots \ldots . \ldots 32$

Knowledge or Access to Knowledge $\ldots \ldots \ldots \ldots \ldots \ldots \ldots \ldots \ldots$

Organizational Structures and Management $\ldots \ldots \ldots \ldots \ldots \ldots . \ldots \ldots$ 
Cultures and Subcultures $\ldots \ldots \ldots \ldots \ldots \ldots \ldots \ldots \ldots \ldots \ldots$

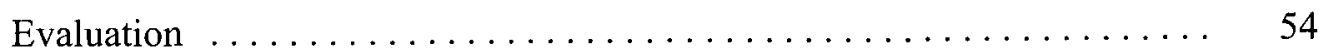

A Model of Evaluation for Professional Development ............ 59

Evaluative Projects Underway $\ldots \ldots \ldots \ldots \ldots \ldots \ldots \ldots \ldots \ldots \ldots \ldots \ldots \ldots \ldots$

The Complexities of Professional Staff Development $\ldots \ldots \ldots \ldots \ldots$

3 METHODOLOGY $\ldots \ldots \ldots \ldots \ldots \ldots \ldots \ldots \ldots \ldots \ldots \ldots \ldots \ldots \ldots \ldots$

Role of the Researcher $\ldots \ldots \ldots \ldots \ldots \ldots \ldots \ldots \ldots \ldots \ldots$

Context of the Case $\ldots \ldots \ldots \ldots \ldots \ldots \ldots \ldots \ldots \ldots \ldots \ldots$

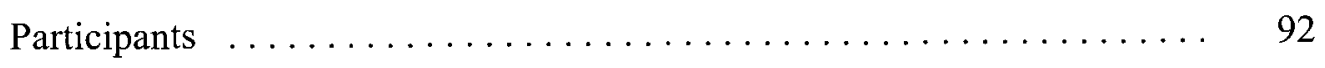

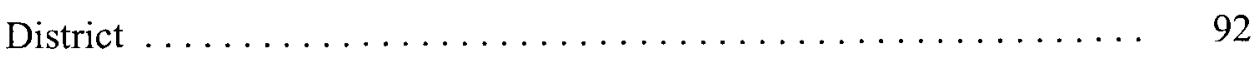

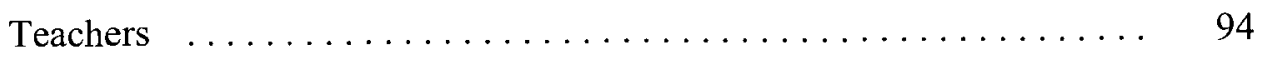

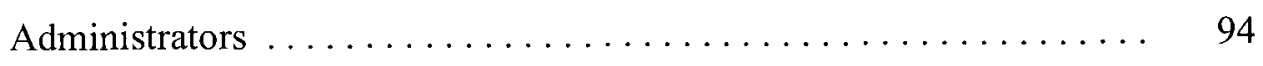

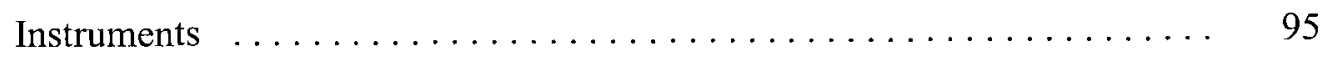

Teacher Survey $\ldots \ldots \ldots \ldots \ldots \ldots \ldots \ldots \ldots \ldots \ldots \ldots \ldots \ldots$

Focus Group Interviews $\ldots \ldots \ldots \ldots \ldots \ldots \ldots \ldots \ldots \ldots$

Administrator Interviews $\quad \ldots \ldots \ldots \ldots \ldots \ldots \ldots \ldots \ldots . \ldots \ldots$

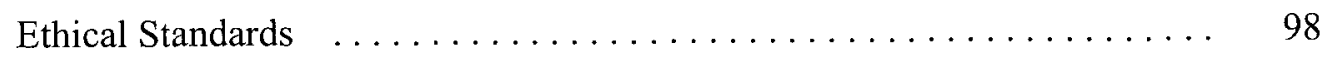

Validity and Reliability $\ldots \ldots \ldots \ldots \ldots \ldots \ldots \ldots \ldots \ldots \ldots$

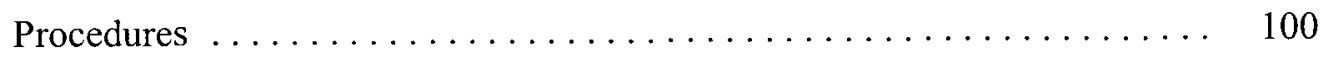

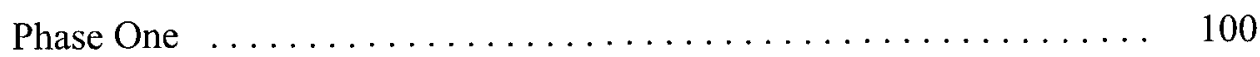

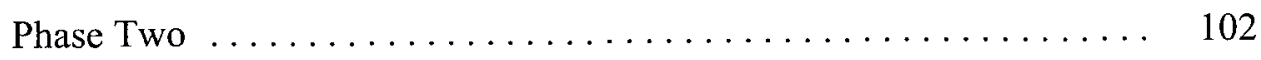

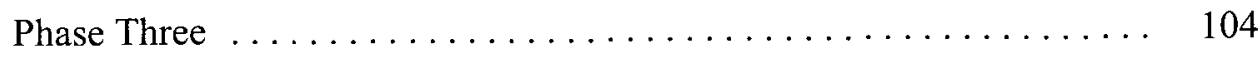

Limitations of the Study $\ldots \ldots \ldots \ldots \ldots \ldots \ldots \ldots \ldots \ldots \ldots \ldots$ 


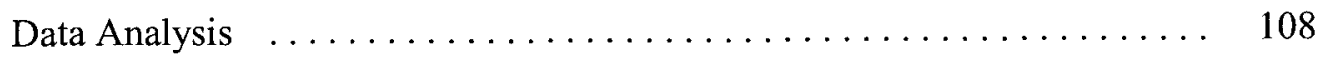

Quantitative .......................... 109

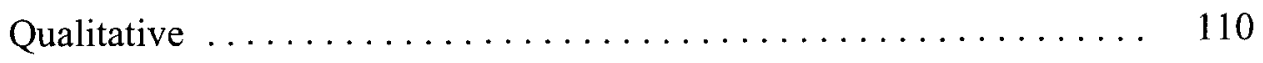

Data Management $\ldots \ldots \ldots \ldots \ldots \ldots \ldots \ldots \ldots \ldots \ldots \ldots \ldots \ldots \ldots \ldots$

Reading and Memoing $\ldots \ldots \ldots \ldots \ldots \ldots \ldots \ldots \ldots \ldots \ldots$

Describe, Classify, and Interpret $\ldots \ldots \ldots \ldots \ldots \ldots \ldots \ldots \ldots \ldots$

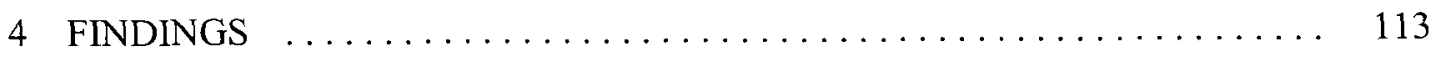

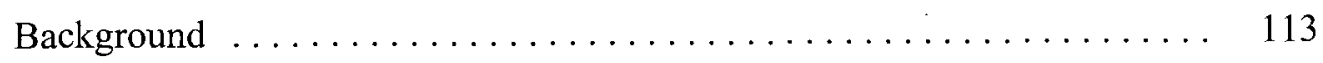

Participant Teacher Surveys $\ldots \ldots \ldots \ldots \ldots \ldots \ldots \ldots \ldots \ldots \ldots \ldots$

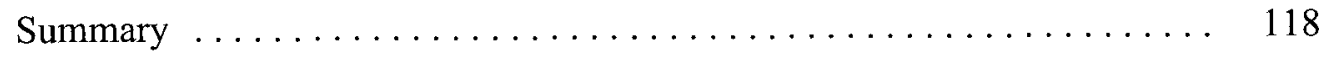

Overview of Focus Groups $\ldots \ldots \ldots \ldots \ldots \ldots \ldots \ldots \ldots \ldots \ldots \ldots$

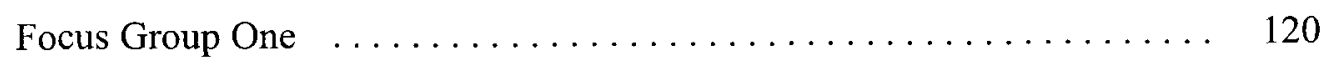

Focus Group Two $\ldots \ldots \ldots \ldots \ldots \ldots \ldots \ldots \ldots \ldots \ldots \ldots \ldots \ldots$

Focus Group Three $\ldots \ldots \ldots \ldots \ldots \ldots \ldots \ldots \ldots \ldots \ldots \ldots \ldots \ldots \ldots \ldots$

Focus Group Four $\ldots \ldots \ldots \ldots \ldots \ldots \ldots \ldots \ldots \ldots \ldots \ldots \ldots \ldots \ldots \ldots$

Focus Group Five $\ldots \ldots \ldots \ldots \ldots \ldots \ldots \ldots \ldots \ldots \ldots \ldots \ldots \ldots \ldots \ldots$

One on One Teacher Interview $\ldots \ldots \ldots \ldots \ldots \ldots \ldots \ldots \ldots \ldots \ldots \ldots$

Administrative Subgroup $\ldots \ldots \ldots \ldots \ldots \ldots \ldots \ldots \ldots \ldots \ldots \ldots$

Cross Case Analysis $\ldots \ldots \ldots \ldots \ldots \ldots \ldots \ldots \ldots \ldots \ldots \ldots \ldots \ldots$

Theme One: Strategies for Engaging Adult Learners: An Opportunity for Growth $\ldots \ldots \ldots \ldots \ldots \ldots \ldots \ldots \ldots \ldots$

Feedback and Follow Up Support . . . . . . . . . . . . . 194

Active and Interactive Learning $\ldots \ldots \ldots \ldots \ldots \ldots \ldots$ 
Differentiated Instruction $\ldots \ldots \ldots \ldots \ldots \ldots \ldots \ldots \ldots \ldots$

Time for Construction of New Knowledge . . . . . . . . . 200

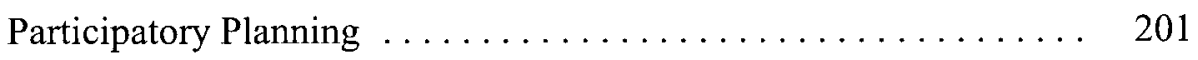

Theme Two: Structure and Management: Two Organizational

Policies That Present Challenges ................. 203

Theme Three: Identifiers of a Culture as Defined by Those

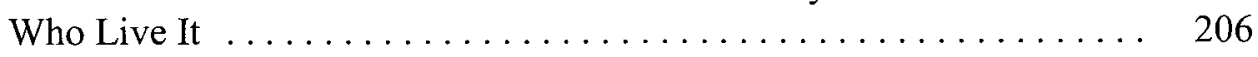

Fear: A Four-Letter Word Found in Culture . . . . . . . 206

A Norm of Continuous Improvement Exists $\ldots \ldots \ldots \ldots \ldots . \ldots 208$

The Push to Be Perfect? . . . . . . . . . . . . . . 211

Theme Four: A Learning Experience Worth Mentioning:

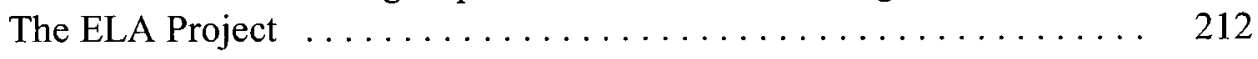

Theme Five: Institutional Roles Affect Attitudes, Beliefs,

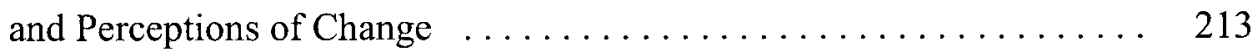

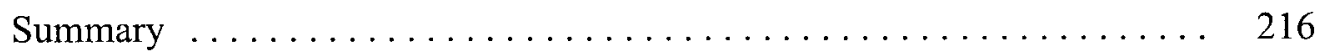

5 DISCUSSION, IMPLICATIONS, AND RECOMMENDATIONS $\ldots \ldots \ldots .217$

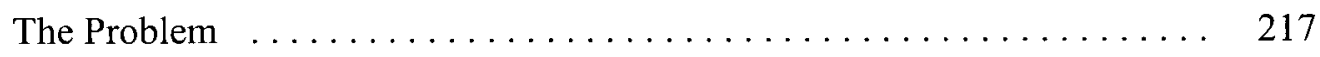

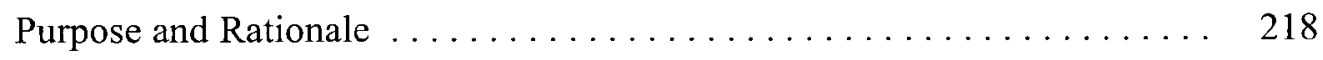

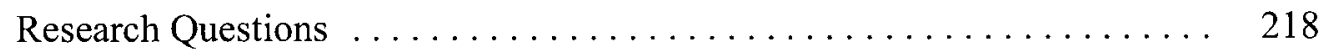

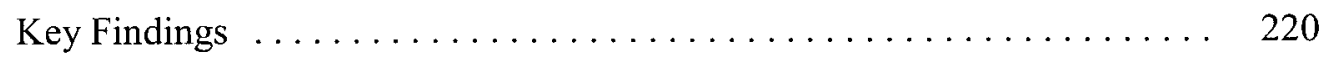

Perceptions of Organizational Structure and Management

May Create Unhealthy Cultural Norms $\ldots \ldots \ldots \ldots \ldots \ldots \ldots . \ldots 220$

How the Adult Learning Strategy of Participatory Planning Impacts Collective Commitment and Cultural Norms . . . . . . . 222

When New Knowledge Is Introduced, Expectations and Strategies of Support Differ $\ldots \ldots \ldots \ldots \ldots \ldots \ldots \ldots \ldots \ldots .223$ 
There Was Something About the ELA Project ............ 224

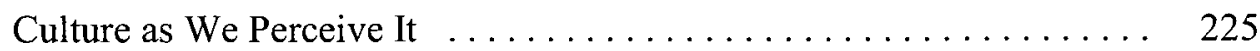

The Complexities of Systemic Change $\ldots \ldots \ldots \ldots \ldots \ldots \ldots \ldots 227$

Recommendations for Future Research $\ldots \ldots \ldots \ldots \ldots \ldots \ldots . \ldots 229$

Recommendations for Practice $\ldots \ldots \ldots \ldots \ldots \ldots \ldots \ldots \ldots \ldots \ldots \ldots \ldots \ldots$

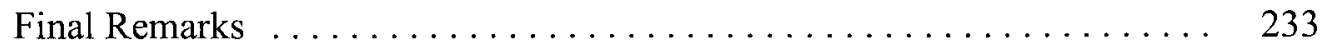

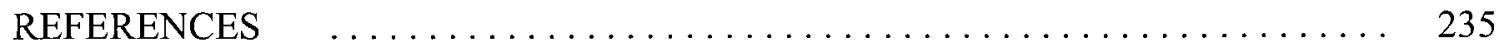

APPENDICES

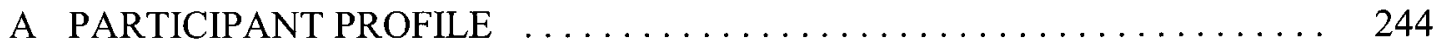

B QUESTIONNAIRE TO ASSESS ORGANIZATIONAL SUPPORT $\ldots \ldots \ldots 246$

C SCRIPT TO ADMINISTER THE SURVEY $\ldots \ldots \ldots \ldots \ldots \ldots \ldots \ldots \ldots .248$

D REFERENCE GUIDE FOR PARTICIPANT PROFILES $\ldots \ldots \ldots \ldots \ldots \ldots 250$

E PROTOCOL FOR FOCUS GROUPS' GUIDING INTERVIEW

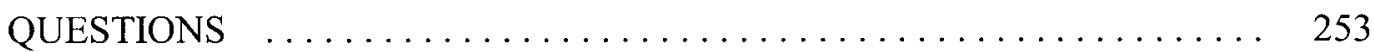

F ADMINISTRATOR INTERVIEW PROTOCOL ............. 261 


\section{LIST OF TABLES}

PAGE

Table 1. Strategies for Time for Professional Development $\ldots \ldots \ldots \ldots \ldots \ldots \ldots \ldots$

Table 2. Guskey's Five Levels of Professional Development Evaluation $\ldots . \ldots \ldots$. 61

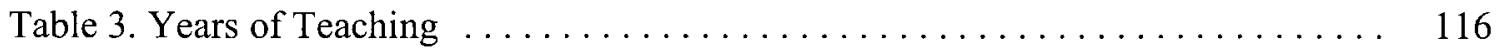

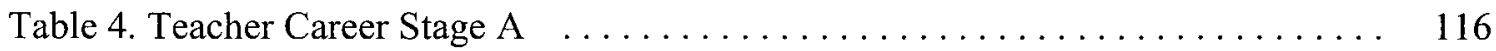

Table 5. Description Within Career Stage $\ldots \ldots \ldots \ldots \ldots \ldots \ldots \ldots \ldots \ldots \ldots$ 


\section{LIST OF FIGURES}

PAGE

Figure 1. The Teacher Career Cycle (adapted from Fessler \& Christensen, 1992)

Figure 2. Research design 


\section{ACKNOWLEDGMENTS}

I would like to thank Dr. Douglas Fisher, my chair, for his dedicated efforts throughout the life of this project. Without his guidance and encouragement, the dissertation may have gone unfinished ... the degree unearned. Dr. Fisher created a professional, collaborative environment that exemplified the optimal adult learning experience. Additionally, I would like to express my gratitude to my committee members, Dr. Barb Moss and Dr. Susan Zgyliczynski. Their inquiries, recommendations, and suggestions heightened my awareness as a researcher and ultimately strengthened the quality of the study. 


\section{CHAPTER 1}

\section{INTRODUCTION}

The bipartisan support of the No Child Left Behind Act of 2002 (NCLB) pressured public school systems to increase productivity by ensuring that all students score at the proficient level on state tests by the year 2014. Specifically, legislators demanded a change in the way educational systems implemented professional development. Schools were expected to strengthen teacher quality by improving and supporting individual teacher training and development. Schools were required to support and educate in-service teachers about scientifically based teaching methods that would improve instructional practices and raise student achievement in literacy and mathematics. Local districts would now have to demonstrate that all core academic teachers within the state were highly qualified (National Staff Development Council [NSDC], 2001). In addition, accountability would come in the form of state mandated annual academic achievement tests for students.

When institutions, such as schools, experience internal or external pressure to improve, they typically react and operate in three different ways. Institutions will attempt to improve by fixing a problem, fixing a process, or fixing the system ( $\left.\mathrm{O}^{\prime} \mathrm{Neill}, 2008\right)$. Of the three choices, fixing the system is the only one that can produce meaningful and sustainable change. In fact, Fuhrman (1994) reported that states which experienced the most success invested time needed for change at the system level. 
Fixing the problem, often viewed as a band-aid approach, takes precedence over fixing the process or fixing the system when institutions are pressed for results by policy makers. O'Neill (2008) reported that districts spend an exorbitant amount of resources on new initiatives and programs without creating processes and systems to support them.

According to Guskey (2000), many educational systems merely change the structure of the institution and fail to consider that for real change to occur, the culture of a school must also change. For the culture to change, educational systems at the organizational level must demonstrate the capacity to support participants' individual efforts to change.

School cultures differ greatly from other organizational cultures. Unlike many organizations in the 21 st century, the same employees (teachers) have worked together for years and consequently have firmly established fortresses of influentially powerful subcultures. This phenomenon makes professional development within the context of a systemic change more challenging (Peterson \& Deal, 1998). The kind of support needed by each subculture is vastly different. All subcultures existing within a school must feel that the change has meaning and matters to their particular group. Researchers emphasized that teachers respond differently to change depending on age, career stage, identity, and context of

their work (Barth, 1990; Fessler \& Christensen, 1992; Hargreaves, 2004; Huberman, 1993; Joyce, Showers, \& Fullan, 2002; Woods, Troman, \& Boyle, 1997).

\section{Statement of the Problem}

As each new school year begins, teachers are increasingly experiencing more nontraditional ongoing, job embedded, and district wide professional development programs. Local schools and districts are expected to support their staff through this systems' level 
change. However, in the absence of evaluation, it remains unclear how and at what level organizations are able to support staff during nontraditional professional development programs.

Preceding the legislative passing of the No Child Left Behind Act of 2002, educational systems across the nation reacted and planned for change in order for all students to meet or exceed the then newly developed state standards. Marriott (2003) suggested that the teaching profession needed to re-examine an array of educational conditions, contexts, and beliefs in hopes of improving student achievement.

One of the most important changes occurred in the way districts began to view and implement professional development. In the eyes of administrators, professional development conceptually changed from a standard operating routine procedure to important work. The days of recruiting one-hit wonders (Holly \& Mcloughlin, 1989) in the form of expert presenters occurred less often. Registering teachers in popular whole day off site "make-it, take-it workshops" (1989, p. 93) became less frequent. These types of traditional professional development programs simply did not meet legislators' demands. The programs were seldom based on scientific methods, results driven, and did little to improve instructional practices of teachers (Speck \& Knipe, 2005).

Historically, a district's ability to effectively implement and support high quality professional development programs has proved challenging. Educational systems, particularly those situated in lower socioeconomic neighborhoods, struggle to adequately fulfill the five critical aspects of organizational capacity: vision and leadership, collective commitment and cultural norms, knowledge or access to knowledge, organizational structures and management, and resources. 
Without evaluation, it remains unclear which critical aspects of organizational capacity need improvement during the system's level change necessary to successfully implement new professional development programs. It then becomes unclear if this new professional development is even making a difference by changing teachers' instructional practices which impact student achievement (Guskey, 2000). If a school's capacity to support teachers during new professional development programs is not evaluated, time and resources may be wasted. Most important, classroom instruction and student achievement may suffer.

Past efforts indicate that if program evaluation studies are conducted, data collection begins and ends at the participant reaction and learning level (Guskey, 2000). Historically, even this type of evaluation method was superficial and merely involved teachers responding to presentation type surveys (Sparks, 1994). For example, teachers would be asked to rate the presenter and identify one idea they could immediately use in their classroom. Even if programmatic evaluations attempt to gather meaningful evidence that indicates change at the participant level, Sparks (1996) reported that without evidence of the organization's capacity to support individual change, the education system's culture does not change, which after all is a major factor in true school reform.

\section{Purpose of The StUdy}

The purpose of this evaluative study is to systematically and deliberately investigate the capacity of a school to support and encourage the learning experiences of individuals during the first year implementation of a site-based, ongoing, job embedded professional development program. Through the lens of teachers and administrators, the researcher will examine the following five critical aspects of organizational capacity: school vision and 
leadership, collective commitment and cultural norms, knowledge or access to knowledge, organizational structure and management, and resources. The framework of the study draws heavily on Guskey's Five Levels of Professional Development Evaluation Model (2000) with a focus on level three, Organization Support and Change.

The evaluation approach of the study will attempt to determine the worth (Scriven, 1983) of a system's organizational capacity to support and encourage learning and change at the individual participant level. The approach then is that of a goal-free evaluation intended to supplement and complement future goal orientation evaluations.

Depending on whether district decision makers read the completed study, the findings may or may not have school-site based action consequences (Krathwol \& Smith, 2005). Although all evaluative studies are formative and summative by nature (Guskey 2002; Mertens, 2005; Stufflebeam \& Shinkfield, 2007), this study will involve the district site's decision makers only as participant volunteers in the study. Consequently, a more summative, opposed to formative, stance will be taken during the proposed research project. The intended audience is the researcher's chair, committee, and other researchers interested in exploring a school's capacity to support individuals during a new, ongoing site-based job embedded professional development program.

\section{RESEARCH QUESTIONS}

Two overarching and five sub questions will guide this proposed study.

1. How do teachers and administrators perceive the organizational capacity of a school to support the initial implementation of a site-based weekly job embedded professional development program? In what ways do they differ? In what ways are they the same? 
2. What are the different teacher subcultures' perceptions of the organization's capacity to support new learning during the initial implementation of a site-based weekly job embedded professional development program?

Several sub-questions, including the following, will provide a context for the study:

1. How is the school's vision and leadership supported by administrators? Colleagues?

2. How are collective commitment and cultural norms supported during the implementation of the new program?

3. How is knowledge and access to knowledge supported by the organization?

4. How does the organizational structure and management of operations support individual teachers?

5. How are resources allocated and used to support teacher knowledge and skills?

The first overarching question will allow the researcher to examine and describe a school's capacity to support individual learning during the first year of a nontraditional approach to professional development through the lens of those most affected by the change: administrators and teachers. The researcher will specifically explore the five critical aspects of organizational capacity by addressing the sub questions of the study. Similarities and differences between the perspectives of administrators and teachers will be teased out.

The second overarching question will allow the researcher to examine and describe, through focus groups, how different subcultures within a school's overall culture view the organization's capacity to meet the needs of each respective group. Specifically, the researcher will examine how each subculture perceives the five critical aspects of organizational capacity.

\section{DeFinITION OF TERMS}

Evaluation: The systematic investigation of merit and worth. 
Nontraditional professional development: Professional development that is district wide, site based, job embedded, and aligned to the revised National Staff Development Council's (NSDC) Standards for Staff Development.

Organizational capacity: The ability of an organization to support individual learning during systems level change through vision and leadership, collective commitment and cultural norms, knowledge or access to knowledge, organizational structures and management, and allocation of resources.

Perspective: The position from which something is considered.

Principal investigator: A term used by the Internal Review Board synonymous with the head, main, or lead researcher on any given research project.

School culture: A set of informal expectations and values developed over time and shaped by how personnel think, feel, and act on the school campus. It is a significant aspect of any educational system and influences everything that happens in schools. It can be positive or negative, uplifting or depressing (Peterson \& Deal, 1998).

Subculture: Homogenous groups formed within a culture that adopt a positive or negative disposition toward the organization.

Successful teacher: Through informal and formal measures, one who consistently demonstrates the ability to improve the learning of all students.

Traditional professional development: Professional development in the form of workshops, presentations, and trainings often held off site and not aligned to the revised National Staff Development Council's (NSDC) Standards for Staff Development. 


\section{Organization OF THE DisSertation}

Chapter 2, the literature review, follows the first introductory chapter of this proposal. In Chapter 2, the researcher will present a detailed and informative review of the literature including theories and studies related to the topic. Through the review of literature, the researcher will begin to build an evidentiary base (Steinaker \& Bustillos, 2007) for the discussion.

Chapter 3 will detail the methods in which the researcher will conduct the proposed study. The mixed methodology will include information about participants, instruments, procedures, and data analysis. In the procedures section, the researcher will detail how participants will interact with the instruments. The researcher will include a step-by-step process for the quantitative and qualitative analysis without findings in the data analysis section of Chapter 3 .

In Chapter 4, the researcher will present the findings of the proposed mixed-methods study. By presenting the findings, the researcher will add to the evidentiary base (Steinaker \& Bustillos, 2007) began in Chapter 2, review of the literature. In addition to clear, concise text the researcher will present quantitative data utilizing tables and figures (American Psychological Association [APA], 2002) as necessary to enhance the reader's understanding. Qualitative data will be presented in a detailed narrative form which collectively captures and blends participants' voices and is organized by themes around the research questions. In the fifth and concluding chapter, the researcher will link findings back to the two overarching and five sub questions of the proposed study through a reintroduction to the overall study that includes a review of the research problem, the purpose of the study, and a rationale for the study. Key findings and their implications will incorporate significant data from the literature 
review (2002). The researcher will continue with recommendations for additional research and practice. Final remarks, based on the project in its entirety will conclude this dissertation. 


\section{CHAPTER 2}

\section{REVIEW OF THE LITERATURE}

Through the discussion of relevant studies and theories, this review of the literature attempts to further construct the reader's knowledge of the problem. The content demonstrates that the proposed study is grounded in past research yet has the potential to expand upon current and future works. This review is organized into the following eight categories and five subcategories: major educational reform; systems and systemic change; organizational capacity (including the subcategories of vision and leadership, collective commitment and cultural norms, knowledge or access to knowledge, organizational structures and management, and resources); cultures and subcultures; evaluation; a model of evaluation for professional development; evaluative projects underway; and the complexities of professional development.

\section{MAJOR EdUCATIONAL REFORM}

By its very nature, the idea of reform evokes a negative connotation. One need only to conjure up the image of a reform school to revisit the stigma associated with the concept of reform. If individuals or organizations are pressured to reform their ways, then they are doing something defined by cultural norms and expectations as blatantly not right; or, what they are currently doing is not meeting a certain standard and must change. Such is the case of the American public school system and all those who dwell within it. 
The literature pertaining to major educational reform is abundant. Much has been written and published which narrates a journey filled with diagnoses and proposals of epic proportions toward a solution to whatever current crisis is overtaking public K-12 schools. Since the ringing of that first bell long ago on the first public school house steps, stakeholders have repeatedly questioned the efforts and ability of their local public school districts. However, it was Russia's 1958 successful endeavors into space, commonly known as Sputnik I and II that ignited the United States federal government to pass the National Defense Education Act (NDEA) of 1958. This act initiated the first movement for nationwide curricular reform (Speck \& Knipe, 2005).

Historically, educational reform efforts are reactionary to what society views as disturbing incidents, those that could lead to the permanent failure of America's schools and eventually the destruction of America, itself. When the Soviet Union rocketed a manned spacecraft into orbit, Americans panicked. The public began to question what other feats Russian scientists might accomplish with their advancements in science, math, and technology. Could they possess the knowledge and skills to inhabit and conquer space? If so, might they one day take over America and the rest of the world? Would America, land of the free, be forced into Communism by the Iron Curtain?

The alarm bell sounded by the nation motivated former President Eisenhower to provide $\$ 1$ billion in federal aid to schools through the passing of the NDEA. Mainly funds were applied to the math, science, and foreign language curriculums. However, monies also provided guidance and counseling for students and enhanced school libraries. In higher education, math and science scholarships were readily available and college students suddenly had access to low interest loans. The passing of the NDEA in 1959 foreshadowed 
what would become a permanent leading role of the federal government in future, more ambitious educational reform initiatives.

Another two decades passed before America's attention was drawn again to the happenings inside of public schools. This time the sounding of the alarm bell was in response to the publication of $A$ Nation at Risk, a controversial report authored by the National Commission on Excellence in Education in 1983. Although the data contained in the report could be legitimately interpreted in different ways, thus the controversy, an "overall troubling picture of achievement provoked widespread concern with K-12 education" (Fullan, 1993, p. 89). The quality of public education for America's students was not meeting the workforce's projected future global challenges. Again, the government answered the sounding of the alarm bell by recommending to states a large scale, top-down regulatory approach, requiring changes such as an increase in teachers' salaries, specifying and mandating of curriculum, student competency tests, teacher competency tests, and training for school leaders (Fullan, 1993).

According to Elmore (2004), just as the report A Nation at Risk was controversial so too were its results. Although the report may have resulted in few implemented, observed, or documented changes in the quality of education across classrooms in the nation, it did help promote and solidify a rising political movement in the south.

Southern politicians wanted states such as Arkansas, Florida, and South Carolina to be more involved in the country's political life. In a first of its kind meeting, during the Education Summit of 1989, the former President George Bush and the governors of those southern states, together, created a strategy for educational reform. The strategy involved giving local school districts jurisdiction on the education of its student body. At the federal 
and state level the focus would be on results, defined as student learning. "This idea [that originated from the Education Summit of 1989] was the kernel of what we now call education reform: that the government's job is to regulate and reward results, and it is the job of school people to produce them" (Elmore, 2004, p. 215).

From that first summit meeting in 1989, national education goals were created and the National Education Goals Panel (NEGP) was formed. The goals were termed national to signify that while the quality and accountability in education was a national concern, state and local entities still maintained control over student learning. The job of the NEGP was to track the eight goals to be accomplished by the year 2000 .

Up until the early 1990 s, educational reform efforts were not systemic. In other words, change at some level might be implemented in a particular district, a particular school, or a particular classroom. However, the Goals 2000: Educate America Act, passed in 1993 under President Clinton, introduced systemic reform in education. Nine years later, with President George W. Bush at the helm, the No Child Left Behind Act of 2002 was passed. This act adopted many of its programmatic goals from the Goals 2000: Educate America Act of 1993. More importantly, the federal government would now enforce performance-based accountability at the state and local level. The federal government in its newly found position as headmaster to the public school system changed everything. Reform was no longer a choice but something now measured through state test scores. "School people" (Elmore, 2004, p. 215) would now be held accountable. Beginning with the National Defense Act of 1958 and continuing well into the new millennium with The No Child Left Behind Act of 2002, federal reform efforts have continued, demanding change of a grandiose nature for employees of the educational system or "school people" as Elmore (2004, p. 215) referred to 
them. Professional development is one area in the educational system that has undergone many changes, at least on the surface, during federal and local reform efforts of the past 50 years. Sparks and Hirsh (1997) defined these changes as Professional Development Paradigm Shifts.

Brandt (1994) further emphasized the direct relationship between reform and professional development by stating, "Almost all school districts of any size routinely include a budget for staff development, and they seldom introduce a new educational initiative without a staff development outcome" (p. 3). Throughout their careers, teachers, working within the educational system, experience the emotional effects of these infinite mandated changes prompted by local, state, and federal reform. Hargreaves (2004) reported that onefourth of all teachers become fatigued by years of arbitrary change. They develop pessimistic beliefs about change resulting from reform agendas. Consequently, teachers often resist change, even when something new could potentially benefit students. However, this does not mean that reform efforts are incapable of producing change to benefit the system. In fact, findings from a study involving interviews with 50 teachers and supplementary focus groups suggested otherwise.

Researchers were interested in exploring teachers' emotions and educational change. The purposeful sample was gender mixed and included the youngest teacher, the oldest teacher, and an ethno cultural minority teacher. The sample $(N=50)$ was distributed across a total of 15 elementary and secondary Canadian schools. These schools varied in location and size. Researchers requested principals at each school to name a sample of up to four teachers. In total, 26 participants were high school teachers and the remaining 24 participants were 
elementary school teachers. In the design and methodology of the study, researchers did not state the total population of teachers employed by the 15 schools.

After asking teachers about their understanding of educational change, researchers then asked teachers to discuss an example of mandatory change and an example of a change made on their own. Researchers observed that positive emotional comments to mandatory change were few and very reserved. Positive responses to compulsory change came from new teachers, female teachers, and from teachers not teaching state tested subjects (Hargreaves, 2004). However, when teachers talked about changes made on their own, they discussed how satisfied and proud they were to overcome obstacles such as resistance from others and self doubt. Only 7 teachers out of the sample of 50 were unable to reflect upon self-initiated change.

Researchers reported that "a curious finding emerged concerning the commonly asserted contrast between self-initiated and mandated change" (Hargreaves, 2004, p. 301). The self-initiated changes that teachers discussed in the interviews, in reality, had stemmed from compulsory change reform efforts at the local and state level. In fact, 39\% (17/44) of examples described by teachers as self-change could be traced back to prior reform efforts. The researchers cautioned that this finding might be the result of so many large-scale reform efforts, which leave little time and opportunity for self-initiated teacher change. However, they also theorized that in an era of systemic school reform efforts, external change can and sometimes does lead to positive and productive teachers as long as that change includes a teacher's professional purpose and consequently is supported through organizational capacity which includes supportive administrators, organizational structures and management, resources, collective commitment and cultural norms. 
School reform is difficult. It is a struggle for the individual and it is a struggle for the organization. An idea for change, which affects the individual and the organization, is conceived in a place so very far away from where the idea actually becomes a living and breathing entity. Consequently, an idea may seem promising in the evolutionary stage, but by the time it reaches the schools and the people who matter most, the students, the idea often barely resembles what decisions makers originally had in mind in the way of change (Elmore, 2004; Fullan, 1993; Speck \& Knipe, 2005). For example, teaching to the test (Stiggins, 2007) most likely was not a desired outcome of the No Child Left Behind Act of 2002.

\section{Systems and Systemic Change}

In 1993, 10 years after the publication of the controversial report, A Nation at Risk, former President Clinton introduced the Goals 2000: Educate America Act. Unlike school reform efforts in the 1980s, Goals 2000 endorsed a systemic approach to school improvement (Lieberman \& Miller, 1999). The demands of the No Child Left Behind Act of 2002 forced school leaders to think about system wide interventions that could improve student achievement. In a state of crisis, many leaders knowingly and unknowingly began a series of quick fixes disguised as systemic change that failed. As Adelman and Taylor (2007) espoused, "The frequent failure to sustain innovations and take them to scale in school districts has increased interest in understanding systemic change” (p. 297).

The intended outcome of an intervention is to strengthen the system. It is important to remember that the intervention, itself, is also a system. Consequently, when the intervention is introduced into a system, the two systems, along with their many subsystems, interact. Because the topic of this current study evolved from a system-wide intervention of 
professional development, it is important to closely examine systems theory, systemic change, and systems thinking.

Ideas behind how systems operate were introduced by the German biologist Ludwig von Bertalanffy in 1936 (Pascoe, 2007). Bertalanffy, also a researcher in the fields of sociology, psychology, and philosophy, wrote that systems exist in all disciplines, not just the hard sciences. He emphasized that although diverse fields of study encounter systems differently, the general principals of systems theory remain applicable.

The German biologist turned philosopher and author was the first to view a system not as merely the sum of its parts. Bertalanffy theorized that a system was really about the relationship and interaction between its parts. Therefore, a system is comprised of its parts, the connection each part has to another, and problems, processes, and products that arise as a result of the interactions.

Everything and everyone are a part of not just one system but several. Focusing on only parts of an organization's system is often a costly mistake affecting the entire system and subsystems. Systems do not act alone; rather they interact and are often interdependent on other systems. In this way then almost all systems are also subsystems. Systems are not tools or products but a gradually developing process. As systems grow more complex in many disciplines, education being one of them, it is important to pay attention to systems theory.

One way to gain a better understanding of a system is to view it in entirety from different perspectives. Banathy (1992), another systems researcher, theorized that a system could be examined using three different lenses similar to a camera. Using a still picture lens, a researcher can examine the parts of the system. Viewing the system through a motion 
picture lens, a researcher can study the processes, relationships, and functions. Finally, peering at a system through a bird's eye view enables researchers to see how the system connects with other systems, which is a concept rarely considered in organizations.

Applying the systems perspective theory to just one school operating in the suprasystem (Banathy, 1992) of public education reinforces the complexity and importance of understanding systems theory. School leaders seldom use the motion picture or the bird's eye view lens. Instead, they tend to never get past the insular view of the still lens (Adelman \& Taylor, 2007). Most leaders who expected to produce change at the systems level just do not have a background in systems theory or the training to implement systemic change.

For systemic change to occur, change agents (e.g., Fullan, 1993) must begin to see their organization from all three perspectives: still, motion, and bird's eye view. Researchers of learning organizations and systems theory concurred that systemic change possesses the following characteristics (Adelman \& Taylor, 2007; Banathy, 1992; Cohen, 1995; Senge, 2006):

1. Adopts a holistic approach rather than piecemeal.

2. Examines the interrelationships among the parts of the system.

3. Recognizes that a fundamental change in one part will make it incompatible with other parts; therefore changes must be made simultaneously to those other parts.

4. Involves changes that amount to cultural shifts in institutional values.

5. Requires sustained attention from many workers at all levels of the system.

6. The big picture is presented in ways that are true to a shared vision and compatible with local culture.

Without applying systems theory through systems thinking, leaders will continue to only examine challenges within a certain area of the system and merely temporarily fix a 
problem. Systemic change requires a different, less self-centered way of thinking known as systems thinking. Systems thinking is the ability to see larger systems and forces at work in the world rather than the fragmented problems awaiting the individual on Monday morning. Senge (2006) defined systems thinking as the cornerstone of any learning organization. According to Senge, systems thinking encompasses the other four disciplines of a learning organization; personal mastery, mental models, shared vision, and team learning. Any of the other four disciplines in isolation will not create a learning organization. This way of thinking also requires individuals working within an organization to begin viewing one another not as helpless human beings capable of only reacting, but as active participants responsible for shaping the future. Stakeholders let go of assumptions and constantly question routine practices to decide how or even if the practices uphold core beliefs of the system.

Systems thinking is particularly challenging for schools. They are a system at the site level, yet each school site acts as a subsystem to the district level. The district level system is also a subsystem of the state. The state system then is a subsystem of the nation (LoucksHorsley, Love, Stiles, Mundry, \& Hewson, 2003). For leaders operating at each level, it is often difficult to envision their own system as not exclusively theirs - but part of another, larger system often with more jurisdictions. Aside from being part of a complex system, schools face the challenge of functioning as a public system. Stakeholders will always express a difference in priorities creating a list of competing interests. Many things in the system "favor the status quo by diverting energy to maintenance activities at the expense of devoting resources and attention to continuous improvement" (Fullan, 2008, p. 297).

All systems are driven by what is measured for accountability (Adelman \& Taylor, 2007). Since the No Child Left Behind Act of 2002, school accountability is annually 
measured by nationally published state, county, and district Academic Performance Index (API) scores. Consequently, the public school system is often driven by high stakes testing, making systems thinking challenging. Public education systems do not have the luxury of experimenting and cannot afford to take risks, which Senge (2006) explained is the reason why most schools are challenged to remain innovative learning establishments. Unlike in business where the bottom line of making a profit is clear, the criterion of evaluation for public schools remains subjective.

Joyce et al. (2002) advised that the success of implementing systemic initiatives in the public school system rests in the development of a "district wide synergy that relates training and support to the schools where the implementation takes place" (p. 143). The concept of synergy unfolds as such; first, administrators and teachers holding defined leadership roles (team level leader, literacy coach) must be visibly and genuinely vested in the change. Leaders must demonstrate the behavior of an "active consumer" (p. 143). Just as a teacher in a classroom must model the academic and character behaviors he or she desires from the learners, so too must leaders in a school model how and what they want their staff to accomplish. Second, allowing employees abundant opportunities for personal and professional growth must be an objective of any systemic initiative occurring in an organization.

Joyce et al. (2002) emphasized that studying and knowing the social climate of a school is critical in maximizing time for growth. Leaders must then be able to work toward establishing a positive school culture and engage employees, not officially in leadership roles, in collaborative governance processes. 
The concept of synergy along with systemic change does not create the immediate results desired by leaders in the midst of reform efforts. However, Fuhrman (1994) reported that it is the states that invest time needed for change at the system level that experience success. Fuhrman reported that data extracted from studies of reform in 19 states conducted by the Consortium for Policy Research in Education (CPRE), showed that two states, Vermont and Connecticut, took more years than planned to implement two reform efforts: Common Core of Learning in Vermont and Performance-based Assessment Tasks in Connecticut. Findings from that study revealed that "sufficient time assures quality and widespread participation from teachers who are more comfortable than they would have been otherwise" (Fuhrman, 1994, p. 6).

Across the private and public sector, two types of systems exist; systems that work and systems that do not work. Systems that do not work leave stakeholders functioning in survival mode. Zmuda, Kuklis, and Kline (2004) proposed a conceptual framework of incompetent and competent systems. In an incompetent system, educators make assumptions based on perceived realities. They also assume that the habitual practice is best. Just the opposite occurs in a competent system. Educators question what is, so that they can determine what might be. In other words, they are not exclaiming, "This is the ways things are." Competent systems require stakeholders to view the institution as a "complex living system with a purpose" (p. 46). Assumptions are replaced with systems thinking.

An incompetent system in a business can cause profits to decrease, layoffs to occur, and in dire cases, the corporation will cease to exist. However, when nonprofit institutions such as schools operate within an incompetent system, consequences directly affect the 
welfare of children and those who look after them. Incompetent systems cause a high level of stakeholder frustration, which affects student learning (Green \& Etheridge, 1999).

\section{Organizational Capacity}

In the educational system, capacity is defined as how a school helps its student population achieve high standards (O'Day, Goertz, \& Floden, 1995). An organization's capacity and an individual's capacity depend on one another. According to Elmore (2004), "Capacity is defined as the resources, knowledge, and skill that the teacher and student bring to the instructional core and the ability of the organizational surroundings-the school and the larger institutional environment-- to enhance and support the resources, knowledge, and skills of the teacher and student" (p. 222). In other words, members of the classroom, teacher and students, all have within themselves a certain innate level of capacity, which should be continually nourished by factors of external sources; organizational capacity.

In reviewing the literature, a relevant research study published in 2006 examined organizational capacity in terms of student achievement. In this study, researchers defined organizational capacity as "the measure of an institution's existing ability to meet the performance standards set" (Alexander, 2006, p. 400). Researchers defined a school's organizational capacity in terms of the percentage of students who scored proficient on the state assessments.

Researchers examined data drawn from a combined database of Massachusetts public schools, which included the eighth grade. Researchers did not identify the schools as K-8 schools, middle schools, or junior high schools. The combined database included school level demographics of the student population from the year 2000. Demographics included 
ethnicity, size, location, and socio economic status. Additionally, the database housed the percentage of eighth grade students at each school site who passed the Massachusetts state reading and math test during the years 1998 through 2001 .

The research team first conducted quantitative statistical analysis on the population at the state level. Then researchers conducted another analysis based on the schools' location. Statistical tests for non-inner city and nonrural schools were combined and reported as such. Statistical tests for inner city and rural schools were performed and reported separately. Because researchers were measuring the organizational capacity of schools not the students, they utilized unweighted statistics in their analysis (Alexander, 2006).

Major findings included the following:

1. Nonrural and non-inner city schools showed a higher percentage of students scoring proficientthan when the data was analyzed at the state level.

2. The percentage of students scoring proficient in rural schools also surpassed the statewide analysis.

3. The inner-city population "lagged significantly behind the rest of the state." (p. 420)

Researchers noted that the findings "highlighted the existence of large contextual differences between the organizational capacities of schools within the state, especially those serving the less privileged" (Alexander, 2006, p. 422). Because of this, all levels of administrators and policy makers working within the system should conduct school by school evaluative studies to assess the school's capacity to meet program goals. Researchers suggested, "There needs to be a greater emphasis on the contextual differences among schools" (p. 425). 
A strength and also limitation of the Massachusetts study was the type of evaluation and analysis researchers chose to conduct. An evaluative, quantitative study measuring student achievement is relevant to how schools are held accountable in the era of high stakes testing. Also, the method in which researchers first conducted a statewide analysis and then separate analysis of the state's public schools grouped by location allowed them to gather evidence exemplifying the challenge this country faces of providing an equal education for all children, regardless of their socioeconomic status. This way of working with the data also revealed that although a state may be considered on track for meeting the goals of a reform, individual schools and districts may be far from it. This warrants the question, if the system at the state level is considered on track by policy makers, but their subsystems (schools and districts) are failing, then is the system working?

Although organizational capacity as defined and measured by the researchers produced quantifiable data in the form of a highly sought after tangible product (student achievement), this definition of organizational capacity and quantitative analysis may be viewed as a limitation to the study. Because researchers did not examine or include in their study what others before (O'Day et al., 1995) them have defined as the five critical aspects of organizational capacity, vision and leadership, collective commitment and cultural norms, knowledge or access to knowledge, organizational structures and management, and resources, the findings are limited and tell little of the story behind each school.

Opportunities to explore and apply the potential lessons learned were lost. For example, because the five critical aspects of organizational capacity were not further explored even in the schools operating at a lower capacity, researchers were prevented from narrowing down and examining what specific aspects of organizational capacity contributed to the lower 
student achievement scores of the inner-city schools. If the specifics of what works and what does not work are not identified or described in evaluative studies on organizational capacity, then creating solutions to even out the playing field among contextually different schools may not be possible.

Researchers involved in the Massachusetts study concluded that schools which exhibit a high level of organizational capacity before a systemic reform are in a better position to implement and meet newly introduced programs such as NCLB. In other words, schools are not starting out on an equal playing field when the game of reform commences. Although underdog stories certainly exist in inner-city schools, they are far from the norm.

Another study relevant to the topic of this proposal was conducted by Lee (2006). The researcher's evaluative programmatic study shared characteristics very similar to this current proposal. Just like this proposal, Lee's study was a single case study, which focused on examining the organizational capacity of schools, including K-8 schools, to support the implementation of a new professional development program. Guiding questions included the following:

1. What is the organizational capacity of a school district, and how can it be conceptualized so that it can be assessed?

2. What is the organizational capacity of the Boston Public Schools to support the implementation of the Collaborative Coaching and Learning model in elementary and K-8 schools?

3. What assertions will $\mathrm{I}$ be able to make about the assessment of organizational capacity as a result of conducting this case study? (p. 6)

Although Lee's initial guiding questions are broader and appear more complex than the guiding questions of the current proposal, the methodologies of Lee's (2006) study and this current proposal are quite similar. For example, Lee collected data through interviews 
with administrators, teachers, and literacy coaches, along with examining primary documents. Lee used purposeful sampling and was interested in exploring if differences existed among the subgroups with regard to their perspectives on the organizational capacity of the Boston Public School District to support the implementation of a new professional development program.

Lee (2006) particularly addressed participants' perspectives on organizational structures, management systems, and support mechanisms, which essentially are broader terms for the five critical aspects of organizational capacity, vision and leadership, collective commitment to cultural norms, knowledge or access to knowledge, organizational structures and management, and resources, all of which the researcher of this current proposal will address. In contrast to the current proposal which is a case study involving one school, Lee's (2006) study is a case study of several schools in the Boston Public School District. This could make the findings less contextual than that of the current proposal. A limitation of Lee's study, as with all qualitative studies, is that the researcher acted as the primary instrument. Also, the researcher chose to write the study from the first person perspective, which seemed to emphasize rather than bracket potential researcher bias.

Because of the broad nature of Lee's (2006) initial research questions, extensive data collection, and detailed account of the findings, discussion, and conclusions, only the overall themes relevant to this current proposal will be highlighted. Lee's overall findings indicated that high levels of organizational capacity might contribute to higher levels of individual and collective capacity. The researcher also noted that the findings "emphasize a significant relationship exists between individual and organizational capacity" (p. 291), particularly in the case of school administrators. For example, Lee reported that the individual capacity of 
the principals, working within each participating school, positively or negatively impacted organizational structures.

If the researcher of the current proposal gathers evidence toward corroborating Lee's (2006) overall themes, then the findings of this current proposed study could significantly contribute to the evidentiary body of literature relevant to organizational, individual, and collective capacity. The findings of this proposal may also provide further data that schools located in affluent areas possess more initial quality resources in terms of human capital and materials. In other words, they have the advantage of already possessing a high level of organizational, individual, and collective capacity before they walk onto the field to compete in high stakes testing.

For example, affluent schools may experience less administrative and teacher turnover, offer higher salaries, provide more tangible resources, and house heavily invested stakeholders, such as parents, school board members, and the students themselves. If these conditions are present, then Lee's (2006) thematic finding of interconnectedness between organizational capacity and independent capacity will be strengthened and may lead toward further inquiries for all researchers and stakeholders in the educational system. For example, at the conclusion of the proposed study, what potential findings and lessons learned could educational stakeholders apply to strengthen organizational capacity to support individuals during a newly implemented professional development program?

Conditions in which teachers learn during professional development mirror the five scopes of organizational capacity. The National Staff Development Council's (NSDC) Context Standards for Staff Development also emphasize the importance of organizational capacity. The three context sub strands, learning communities, leadership, and resources all 
align to the five scopes of organizational capacity which include the following: vision and leadership, collective commitment and cultural norms, knowledge or access to knowledge, organizational structures and management, and resources.

\section{Vision and Leadership}

A vision is more than an eloquently written piece of prose splashed across a banner that adorns the archway leading into the school. A vision is also more than monogrammed words on a polo-shirt or artfully crafted sentences posted on a website. A vision is something that all workers within a system share and work toward. This scope of organizational capacity, vision and leadership, measures the ability of administrators and teachers working within the system to support one another toward a purpose (Guskey, 2000).

A theme that recurred in the literature was that visions, along with related ideas such as values and mission statements, bestow upon schools a combined sense of purpose, which contributes to the success and improvement of a school's organizational capacity. School visions, naturally, concentrate on improving student achievement through exemplary curriculum and instruction. Regarding curriculum and instruction, principals already hold the authoritative rights to oversee, manage, and intervene in the lives of teachers (Blasé \& Blasé, 2002).

An administrative leader must effectively convey the vision and rally collegial support for it by empowering and supporting teachers. To rally the troops, principals have to assess the culture of the organization, acknowledge the many subcultures, and establish different leadership approaches that fit the culture. Pennell and Firestone (1998) noted that particularly 
in one-on-one situations, principals, depending on whom they are leading and supporting, must adopt different personas.

A 3-year qualitative study that exemplified the importance of vision and leadership was conducted by researchers Green and Etheridge (1999). This study is important to the current proposal because it provides evidence of how vision and non-conventional leadership promote organizational capacity. The researchers concluded that, "When stakeholders [including leaders and teachers] can envision a positive difference between current conditions and a shared vision, they are likely to support change in order to acquire the perceived benefits to be derived from attaining the vision" (p. 824). Green and Etheridge also found that leaders set the tone of the eight participating school districts and were hired because of an all encompassing leadership style. In the study, all leaders were promoted within, built a common vision, and maintained a sense of continuity. The leaders did not operate from a topdown approach but rather adopted a shared leadership approach and encouraged collaboration among district personnel (Green \& Etheridge, 1999).

Conventional leadership, the top-down authoritarian model, may fail to support district employees and consequently weaken organizational capacity. One of the lessons learned during a 6-year evaluative study, commonly known as "Children Achieving, Philadelphia's Anneberg Challenge," was that administrators needed to work toward winning over teachers, not blaming them when things go wrong (Corcoran \& Christman, 2002). Researchers voiced the following: "Win over the teachers. You should not blame them for social ills they didn't create or accuse them of not caring or working hard just because test scores are low. Ultimately, success depends on their commitment and their sense of accountability" (p. 39). 
Researchers also noted that schools and districts continue to hire authoritative leaders who only possess the knowledge and skills of conventional leadership. They posited that providing, "conventional leadership solutions to exceptional leadership problems" (Corcoran \& Christman, 2002, p. 42) does not increase organizational capacity and that effective leadership should specifically promote the following four attributes:

1. Cross structural, cultural, and political barriers.

2. Build capacity within schools, communities, and systems.

3. Generate social capital and social equity.

4. Sustain performance through self-renewal. (Corcoran \& Christman, 2002, p. 42)

Through his examination of the PIM (Planning, Implementation, and Monitoring) Study, Reeves (2006) also emphasized the importance of leadership in organizational capacity when he challenged educators and leaders to ask, "When the external variables — governance, budget, union agreements, policies, and planning requirements-are constant, then which variables are most related to improvement in student achievement and educational equity" (p. 66)? Reeves, himself, formulated an answer to the question: teaching and leadership.

The data for the PIM Study came from the Nevada Clark County School District, a large school district servicing over 280,000 students. In response to Reeves' challenging question, it is important to note that most of the students in the PIM study attended schools located in rough urban settings, were classified as ethnic minorities, and were considered profoundly disadvantaged. The PIM Study gained recognition from researchers because despite the demographics of the population, leaders working within the Nevada Clark County School District were able to increase student achievement. Reeves' exploration of the PIM 
Study data is particularly important to this current proposal because it provides evidence that vision and leadership greatly matter in initial implementations and sustainability of new programs with the ultimate goal of improving student achievement.

In addition to the exploration of the PIM Study, Reeves also observed a way that school leaders can and do support teachers. Leaders must acknowledge that life outside the system exists. Within that life, school personnel are human beings experiencing the joys and disappointments in life. Reeves (2006) identified this idea of acknowledging life outside the system as passion. In other words, leaders who genuinely support colleagues will be passionate about school and the people working in the school. Because this current proposal will attempt to describe teacher subcultures' perceptions of organizational capacity, which includes the scope of vision and leadership, past observations, reports, findings, and theories providing evidence of the emotional relationship between leaders and teachers are valuable.

Ten years before Reeves' observation, Riehl and Sipple (1996) reported, “Teachers who reported high levels of support from principals were especially likely to express commitment to the goals of the school" (p. 883). However, they also reported that administrative support is not associated with increased effort. As early as 1978, researchers Berman and McLaughlin provided insight as to why teachers, although strongly supported by principals, might not increase on the job efforts: frequent administrative turnover, particularly that of the principal. Researchers also noted that it is often the poorer urban schools that experience the most turnover of administrators and teachers.

Hargreaves (2004) theorized that when less experienced teachers lose a good leader, they often are left alone to work through feelings of loss and insecurity. Eventually, as a new teacher becomes seasoned and experiences the loss of several leaders, and also the loss of the 
many new initiatives the leaders brought with them, teachers become very suspicious and hardened to any vision even if it could benefit them and the people they care most about, the students. Hargreaves' theory is important to this current proposal because it explains how at least one subculture of teachers may be formed within a school.

\section{Collective Commitment and Cultural Norms}

This scope of organizational capacity focuses on learning without fear, support from colleagues, and recognition of success. For professional educators, learning without fear means being able to implement a new teaching method without the risk of a bad evaluation or other negative consequences from teaching colleagues and administrators. Loucks-Horsley, Love, Stiles, Mundry, and Hewson (1998) emphasized that one of the ways a visionary leader supports staff is by encouraging risk taking in the classroom.

In a 3-year study, researchers Green and Etheridge (1999) found that teachers in all eight school districts, included in the purposeful sample, experimented without the fear of failing. These eight districts promoted a culture, established by visionary leaders, that actually encouraged risk taking so that more teachers felt comfortable trying out new practices and learning from feedback not failure when those new practices did not go as planned.

Preservice teachers experience the art of practicing teaching through coursework and student teaching assignments. This is not to say, however, that preservice teachers do not experience some level of fear. The fear for preservice teachers is different than the fear for inservice teachers. For example, preservice teachers may become nervous when presenting a lesson to classmates. Preservice teachers are not expected to be perfect in their practice. However, once teachers are in service, the opportunities to continue practicing new strategies 
in the midst of one's peers without fear occur infrequently. Loucks-Horsley et al. (2003) proposed coaching, demonstration, and mentoring as opportunities in which in service teachers can participate in practice sessions without fear.

Learning in the absence of fear requires educators to trust one another. Teachers, through reflection and feedback, should be able to speak candidly about their teaching practices. In fact, Speck and Knipe (2005) voiced that the school as a system will probably not make significant improvements without "productive interactions and trusting relationships among the teachers" (p. 66). Taking risks without fear of failure is one aspect that demonstrates collective commitment and cultural norms of an organization. Recognizing success among the school personnel is another measure of collective commitment and cultural norms.

When teachers complete a successful year, according to district expectations, how does the organization celebrate and recognize the success? Behind the closed door of the principal's office, a teacher might receive a handshake and be privately praised for a job well done. The principal may then ask the teacher to sign the written evaluation, which documents his or her achievements. The document is then photocopied, signed, and filed by both parties. However in terms of publicly recognizing that success, districts are often at a loss.

In supporting collective commitment and cultural norms, how can the organization recognize teachers' successes in a meaningful way? What seems to matter most to teachers is the success not of themselves but of their students. For this, teachers want to be recognized. This concept is not new. For over 30 decades now, research on teachers' perceptions of their success lead back to improved student behavior and academic achievement (Lortie, 1975). 
In addition to developing and recognizing successful students, Barth (1990) espoused that public, school wide recognition could renew and inspire teachers personally and professionally. However, Barth observed that when compared to district employees holding leadership positions, the school community provided little opportunity for public recognition of teacher success. Speck and Knipe (2005) reported that teachers are also motivated to continue successful endeavors by being recognized as professionals and treated accordingly. For example, recognizing teacher accomplishments publicly at school board meetings and granting teachers release time during the school year are ways to honor teachers as professionals.

Qualitative data gathered through teacher interviews in an evaluative study conducted by Miller (2006) provided evidence that schools may be starting to provide more opportunities to publicly recognize teachers. For example, in this study, teachers were recognized by receiving the "Board's Director of Education Award" (p. 203). Also, teachers received "Years of Dedicated Service" (p. 203) award pins. From an intrinsic view, teachers in this study also commented that they enjoyed teaching the new strategies and observing the difference in students' behavior and academic performance. When asked about financial rewards, teachers did not expect to earn extra money based on a successful evaluation.

Unlike numerous other professions, teaching is an atypical profession in which salary increase is unrelated to successful job performance. Number of years of service is the dominant factor in determining increases in teachers' salaries, regardless if they are successful or unsuccessful. However, all 50 states do offer some sort of financial incentive for advanced degrees and National Board Certification. For example, many California school districts offer monetary incentives for teachers earning additional credits and advanced 
degrees. Other states, such as Pennsylvania, finance teachers' tuition toward advanced degrees such as a Master's but do not offer an increase in salary once the degree is earned. Additionally, some districts may reward teachers' accomplishments by providing supplemental materials related to district training or technological equipment such as new computers (Speck \& Knipe, 2005).

The teacher salary scale does not disenchant preservice teachers. Individuals do not enter the teaching profession with hopes of growing rich from success. Beginning teachers can view a district's pay scale and determine exactly what their future monetary potential for growth: years of service and the district's rewards on continuing education.

\section{Knowledge or Access to Knowledge}

Graduates of the American education system have always intuitively known what researchers have shown, that the quality and knowledge of the teacher directly affects the motivation and achievement of students (NSDC, 2001). This scope of organizational capacity, knowledge or access to knowledge, defines teachers' access to knowledge once formal education is completed and they are on the job. In 1996, several years before the passing of NCLB, a national report was published entitled, What Matters Most: Teaching for America's Future (National Commission on Teaching and America's Future [NCTAF], 1996). The report focused on improving teacher education programs and professional development.

Five years later in 2001, again before the passing of NCLB, another prominent report entitled, Investing in Teaching (National Association of Manufacturers [NAM], 2001), was released by the NAM. What is important to note about this report is that it was a yearlong 
analysis that involved data from business leaders, administrators, college professors, policy makers, and teachers. The report emphasized the need to treat the art of teaching as a profession. One recommendation relevant to quality teachers in classrooms was to create a rigorous new model for teacher preparation and professional development (NAM, 2001). Despite these recognized milestone publications and various programs and initiatives summoning a strengthening of teacher quality, increasing the knowledge of veteran teachers did not emerge as a top priority among school districts until the passing of the 2002 No Child Left Behind Act.

Since NCLB, some school districts such as Mountain Brook in Alabama have begun to offer incentives for teachers to continue building their knowledge beyond the mandated staff development programs. Mountain Brook offers stipends to teachers who participate in summer institutes. In $2004,85 \%$ of the teaching population attended summer institutes. The district also has a staff development committee where teachers can apply for in house grants to complete projects toward school improvement (Newman, 2006).

Another method districts are increasingly utilizing to strengthen teachers' knowledge is ongoing, site-based professional development (NSDC, 2001). This type of on-campus training makes the work place an environment that can sustain new knowledge. However, Bernfield, Blasé, and Fixsen (2006) cautioned that merely training teachers on evidence based instructional practices is not enough to produce the end result: an increase in student achievement. Glover and DiPerna (2007) suggested that teachers be given opportunities for "guided practice by expert teachers and/or consultants as well as opportunities to discuss issues with implementation" (p. 641). Although site based professional development provides a common meeting place and time, according to Hiebert, Gallimore, and Stigler (2002): 
Most teachers who continually develop knowledge about their own practice have seldom accumulated and shared their knowledge. They have learned from each other only in the most haphazard way. As much as they might benefit from the knowledge of their colleagues, most teachers have not accessed what others know and must start over, creating this knowledge anew. (p. 11)

In contrast, teachers voiced (O’Day et al., 1995; Riehl \& Sipple, 1996) that they do indeed turn to one another for support in learning new teaching practices. Teachers also made very clear that the ability and commitment to use new knowledge and skills often depended on the support of colleagues. Riehl and Sipple (1996) concurred that; "Teachers who received help from others experienced stronger feelings of goal commitment" (p. 884). They also spent more time on schoolwork when they reported receiving help from other teachers.

Effective professional development must also provide teachers with a network to support new knowledge. For example, teachers might require more than a one-day training seminar to implement a new writing model. Researchers theorized that it takes on average 3 to 5 years for teachers to fully adopt and implement a new strategy (Loucks-Horsley et al., 2003).

Hiebert et al. (2002) theorized that teachers participating in ongoing site-based professional development could benefit from an "archived professional knowledge base" (p. 3). This national knowledge base would allow teachers Internet access to the latest advancements in the field, practitioner and research oriented. It would provide teachers working in all 50 states with a professional knowledge system, similar to what others professionals such as dentists and optometrists have been utilizing for years. Researchers Speck and Knipe (2005) concurred that the potential benefits of the Internet continue to remain unchartered territory for the professional learning of teachers. Local Internet versions of what may be packaged as a teacher knowledge base often exist district and countywide. 
Due to lack of quality control, these websites often contain fragmented, inaccurate information and outdated lesson plans with links to sites that no longer exist (Hiebert et al., 2002).

Elmore (2004) challenged that to improve the individual capacity of teachers (and therefore students), the educational system must heavily invest in providing teachers with knowledge. This means that the system must commit to allocating resources and providing support structures to deepen and update educators' methods of practice.

Teachers are not blue-collar workers or white-collar workers but "knowledge workers" (Pava, 1986, p. 208). Knowledge is the main tool that teachers utilize to educate their students. Recognizing this, the tool needs to be constantly improved and updated just as tools used by other professional are constantly being refined. For example, an eye doctor would not continue to perform corrective eye surgery using a scalpel when he has the knowledge and skills to perform laser surgery.

In the area of building teachers' knowledge, education may benefit from theories applied in the corporate world. For example, the late Pava, an educator, consultant, and expert of office design developed specific actions in 1986 to improve knowledge work in office environments on the frontier of the informational age (Speck \& Knipe, 2001). Later these three actions were adapted to the teaching profession. They are as follows:

1. Give teachers timely access to the information they need to do their work.

2. Give teachers frequent access to the experts who have the information they need.

3. Improve the work procedures, processes, and equipment that support teachers doing their work. (p. 230) 
Just as in the corporate world, these three actions cannot consistently occur in schools without quality organizational structures and management in place.

\section{Organizational Structures and Management}

Any organization seeking to support and nurture individual change during an implementation of a new program attempts to structure time for employees to attend training sessions. Schools are no different but must be creative in restructuring the traditional school day to include time for professional development. Guskey (2000) stated, "One of the most crucial aspects of organization support and change is the provision of adequate time for professional development" (p. 162).

Before the new millennium and shortly after the 1993 introduction of Goals 2000, the government assigned the National Education Commission to examine the relationship between time and learning (National Education Commission on Time and Learning, 1994). Upon the Commission's examination, authors developed the following metaphor. "Learning in America is a prisoner of time and time is learning's warden" (p. 5). The Commission found that the American public school system is and has been (over the past 100 years) dominantly controlled by the two most common measures of time: the clock and the calendar. Researchers named the 180-day school year as an "unacknowledged design flaw in American Education" (p. 7). Furthermore, researchers proposed that America's learning system "sits on a foundation of sand" (p. 8) and involves many assumptions, which educators know to be untrue. One premise, relating to the provision of time is as follows: "It is a myth that schools can be transformed without giving teachers the time they need to retool themselves and reorganize their work" (p. 8). 
As the Commission's exploration on the relationship between time and learning continued, researchers located a document written in 1894 by then Commissioner of Education William T. Harris. In this over a century old publication, Commissioner Harris disputed the reduction of school days from 193.5 to 191 . Additionally, he was opposed to the discontinuation of Saturday school, the lengthening of summer vacations, and the introduction of new holidays. In his 1894 report, Harris also indicated that in terms of time spent accomplishing work in school; America could learn much from Germany and France (National Education Commission on Time and Learning, 1994).

Evidence throughout history indicates that educators could grow weary in the battle of clock and calendar. However in this era of accountability, public schools cannot afford to grow weary. The only way an organization will lose the battle of finding time will be to cease trying new strategies to preserve the hours in a day for what matters most.

Time reserved for professional development matters but must not be too costly or too disruptive in the academic lives of students. Guskey (1998) noted six common ways, all with different risks and benefits that schools can make time for professional development.

Guskey's recommendations included the following: add professional development days to the school year, add professional development hours to the school day, hire permanent substitute teachers to allow for teacher release time, change the weekly school schedule, implement block scheduling, and change the school or class daily schedules. The perks and drawbacks of each are summarized in Table 1. 
Table 1. Strategies for Time for Professional Development

\begin{tabular}{|c|c|c|}
\hline Strategy & Cost & Disruption \\
\hline $\begin{array}{l}\text { 1. Add professional development days to the school year } \\
\text { - Number of teaching days remains the same but more days } \\
\text { are added to teachers' contracts } \\
\text { - Funds are needed to pay for the additional days }\end{array}$ & High & Low \\
\hline $\begin{array}{l}\text { 2. Add hours to the school day for professional development } \\
\text { - Number of teaching days remains the same, but more time } \\
\text { is added to teachers' daily schedules } \\
\text { - Per-hour funds are needed to pay for the additional time }\end{array}$ & Medium & Low \\
\hline $\begin{array}{l}\text { 3. Add professional staff to allow additional release time } \\
\text { - Substitute teachers are hired on a permanent basis } \\
\text { - Teachers are released for classroom observations or } \\
\text { planning } \\
\text { - Additional money is needed to pay for the substitute } \\
\text { teachers }\end{array}$ & Medium & Low \\
\hline $\begin{array}{l}\text { 4. Alter the school weekly schedule } \\
\text { - One-half hour is added to Monday through Thursday } \\
\text { - Students go home early on Friday (no lunch) } \\
\text { - Per-hour funds are needed to pay for the additional time }\end{array}$ & Medium & Medium \\
\hline $\begin{array}{l}\text { 5. Block Scheduling with provision for shared planning } \\
\text { periods } \\
\text { - Schedules are arranged for shared planning } \\
\text { - Typically easier in middle and high schools } \\
\text { - Requires extensive planning in the elementary schools }\end{array}$ & Low & Medium \\
\hline $\begin{array}{l}\text { 6. Change school or class daily schedules } \\
\text { - Requires flexible assignmenbt of special subject teachers } \\
\text { (e.g., art, music) and paraprofessionals } \\
\text { - Requires much planning, coordination, and team teaching }\end{array}$ & Low & High \\
\hline
\end{tabular}

Source: Guskey, T. R. (2000). Evaluating professional development. Thousand Oaks, CA: Corwin Press. 
In theory models such as Guskey's, which demonstrate strategies for restructuring the traditional school day, may appear logical and applicable. However, researchers conducting a state-wide comprehensive study on professional development gathered evidence indicating that theory does not always transfer easily into practice (NSDC, 2001). Researchers gathered and analyzed evidence through interviews, focus groups, and examination of relevant school documents. Findings indicated that principals lack the knowledge and skills to "create schedules for this purpose [time for professional development] and many do not know how to collaborate with their teachers to ensure the best use of additional time for professional development" (p. 90). Even if principals and other administrators have the knowledge and skills to structure time designated for new learning, it is seldom uninterrupted protected time.

Regardless of their profession, logically individuals are more productive if they are not interrupted during their work. "Just a quick question," or "I need a minute of your time," interjected by colleagues and clients can quickly invite the thieves of time, attention, and energy into a workspace. Before one knows it, he or she is exhausted from all of those quick questions and one minute of your time proposals. Corporate Managerial positions often align personnel to field these so called interruptions.

Individuals employed by a school district are often not so fortunate, and it is not logical to expect individuals working with children to be well protected from intrusions all of the time. However, just as teachers in classrooms decide how to field interruptions and maximize student learning, organizational structures and management in schools can either create a culture that limits or invites intrusion into the adult learning environment. For example, if a school district restructures its day by sending students home early and holding professional development in the afternoon, how often might a teacher or administrator be 
pulled out to address a student or parent concern? A knock on the door by Sally who forgot her lunchbox in the classroom could potentially lead to more than a minute away. A principal may just as likely be called away by Mrs. Brooks demanding that her son be given back his Ipod this instant. Miller (2006) found that it took a collaborative effort from all those involved working on a school site to protect one another from intrusions. The data in the study also showed that school personnel were very respectful of one another's time and events scheduled on the master calendar were sacred.

According to Riehl and Sipple (1996), teachers who were buffered from intrusions experienced a stronger sense of goal commitment. Teachers who work in orderly schools are more committed to the organization's goals. Commitment is enhanced if teachers and administrators work together to create policies and procedures for managing student behavior.

Policies at the school, district, regional, state, and national level affect organizational capacity. However, it is the school and district policies that can either promote or impede the individual learning of teachers. What happens when members of the organization work toward implementing a new program with aspirations of improving student achievement but certain aspects of the program or in extreme cases the entire program itself conflicts with organizational policy? Just as in medicine, prevention is often easier than treatment. In order for organizations to support individual learning, careful thought must be devoted to the contents of professional development (Guskey, 2000). The relationship (and potential conflict) between what is being learned, site based policy, and district policy must be explored before teachers are introduced to the new endeavor. 
While Guskey proposed that policy is strongly related to an organization's capacity to support individual learning and change, researchers Newman, King, and Youngs (2000) conducted a study that warranted otherwise. The 2-year mixed methods study involved nine elementary urban schools. The team of researchers theorized that all scopes of organizational capacity should support professional development. Researchers first visited all nine schools and interviewed staff members, observed professional development sessions, and examined achievement, demographic, and financial documents.

From the initial visit, researchers selected to conduct follow-up visits to seven out of the nine schools based on the following criteria: the schools selected planned on sustaining professional development aimed at key aspects of capacity and represented different state and district policy contexts.

In follow-up visits to the seven schools, researchers continued to use the same methods of data collection. At the conclusion of the study, researchers found that “comprehensive professional development was most strongly related to the school's initial level of overall organizational capacity and principal leadership" (Newman et al., 2000, p. 291). The relationship between policy support and professional development was described as "weak and unclear" (p. 291). In spite of this, researchers did gather evidence from the seven schools that district and/or state policies can positively or negatively affect what schools are trying to accomplish through district and site based professional development programs. Researchers warned that policy support can make a difference but programs are very contextual. They suggested a more flexible approach in state and district policy in order to strengthen a school's organizational capacity to support teacher learning in professional development programs. This included less rigid local policies for allocating resources. 
Although resources come in many shapes and sizes, if organizations do not have an abundance of 6 inch by $21 / 2$ inch rectangular shaped green and white papers technically named Federal Reserve notes, then they have no resources. The capacity of any organization to provide adequate, substantial resources (human capital and tangible resources) for the work to get done comes down to funding. This is especially true of nonprofit organizations such as schools. While conducting an evaluation of professional development applying Guskey's model of professional development, Miller (2006) reported that "significant financial support was invested in the initiative" (p. 180) and that the wealth of resources provided by the district reflected the philosophy of approach. Participants in the study commented that the quality of the resources and the expedience in which they received resources made them feel supported during the implementation of the new professional development program.

All school districts possess itemized budgets that allocate funds for resources in various categories. For example, a school budget will allocate a certain amount of money toward technology, which may include mobile computer labs, new software, etc. According to the NSDC (2001), 10\% of a school's budget should be allocated toward professional development.

Oftentimes, districts lack the necessary state funding to even provide schools with the basics such as updated curricular materials and a textbook for every child. In 2007, teachers working in the Chicago public school system reported purchasing tissue products for student classrooms and bathrooms (Long, 2007). However, school districts located in areas where parental involvement and community participation are high, frequently receive funds through established foundations. For example, Black Mountain School District, located in Alabama, 
received $\$ 800,000$ from a district wide community foundation for staff development (Newman, 2006). Other schools may partner with a university for a specific study and receive grants provided by private and federal institutions.

Speck and Knipe (2001) proposed that the concept of "on-demand resources" (p. 230) could strengthen organizational capacity to support teachers in self-directed learning. For teachers in content areas such as science and social studies, the potential of on-demand resources is infinite in terms of what teachers are able to offer students in the classroom. Speck and Knipe provided an example of utilizing on-demand resources to teach students about global weather systems. Information, as long as Internet connections are working, can be quickly accessed by teachers and students before, during, and after instructional practice.

Speck and Knipe (2005) also theorized that current and future "on demand resources" could provide a feasible, efficient, and effective method to strengthen professional development programs in this era of accountability. VoiceThread is one such on demand resource that demonstrates the potential for a paradigm shift in professional development. A VoiceThread allows group conversations to be collected and shared in one place, from anywhere in the world (Burden \& Atkinson, 2008). A VoiceThread can house most types of media: images, documents, and videos. This online program enables users to post comments using voice, text, audio file, or video. Contributors can choose to share their newly formed projects with anyone. User generated materials can also be archived and viewed offline on a DVD.

In reviewing the literature on the scopes of organizational support a dominant theme emerged. All scopes of organizational capacity, vision and leadership, collective commitment and cultural norms, knowledge or access to knowledge, and organizational structure and 
management are only as strong as their resources, regardless if those resources come in the form of minutes added to the clock, people added to the payroll, new textbooks in student backpacks, or working computers in classrooms.

\section{Cultures and Subcultures}

School culture, much like an old home, is characterized by all human beings who have ever lived, passed through, or worked within its physical architectural boundaries. No matter how much new owners change certain attributes of the dwelling to make the newly purchased house a home, remnants of previous owners can always be found secretly decorating the walls and napping underneath the foundation of the house. How true this is of school culture as well. Throw open the gates, doors, and windows of the school and one can literally feel the various underlying vibrations, new and old of the school.

Peterson and Deal (1998) defined culture as "the underground stream of norms, values, beliefs, traditions, and rituals that has built up over time as people work together, solve problems, and confront challenges" (p. 28). In exploring this definition of culture, the phrase "as people work together" separates schools from other nonprofit and profit organizations.

After earning tenure, it is not uncommon for teachers, assuming they stay in the profession, to remain in one district their entire teaching career, which could span well past four decades. For this reason, few other professions exist in the $21^{\text {st }}$ century with the potential to create a culture similar to the culture of a school district. Within the overall school culture, many subcultures unique only to schools exist. Researchers Fessler and Christensen (1992) captured these many subcultures through their Dynamics of the Teacher Career Cycle 
framework (Figure 1), which intertwines personal environment, organizational environment, and career cycle. The components that comprise the personal environment are life stages, family, positive critical incidents, crises, individual disposition, and avocational outlets. Organizational environments include regulation, management style, public trust, societal expectations, professional organizations, and union. A teacher's career cycle includes preservice, induction, competency building, enthusiastic and growing, career frustration, career stability, career wind-down, and career exit. All of these elements within the three domains are constantly interacting with one another and in the case of the public school system working toward developing numerous subcultures within the population. Because of the nature of the second research question, this part of the literature review will focus on the third dynamic, career cycle, of Fessler and Christensen's model. According to the model, teachers may experience up to eight stages during their career (Fessler \& Christensen, 1992):

1. Preservice-This stage is the period of preparation for a specific professional role. Typically, this would be the period of initial preparation in a college or university. It might also include retraining for a new role or assignment, either by attending a higher education institution or as part of staff development within the work setting.

2. Induction - This stage is generally defined as the first few years of employment, when the teacher is socialized into the system. It is a period when a new teacher strives for acceptance by students, peers, and supervisors. The teacher attempts to achieve a comfort and security level in dealing with everyday problems and issues. Teachers may also experience this stage when shifting to another grade level, another building, of when changing districts completely.

3. Competency Building-During this stage, the teacher is striving to improve teaching skills and abilities. The teacher seeks out new materials, methods, and strategies. Teachers at this stage are receptive to new ideas, attend workshops and conferences willingly, and enroll in graduate programs through their own initiative. Their job is seen as challenging, and they are eager to improve their repertoire of skills. 


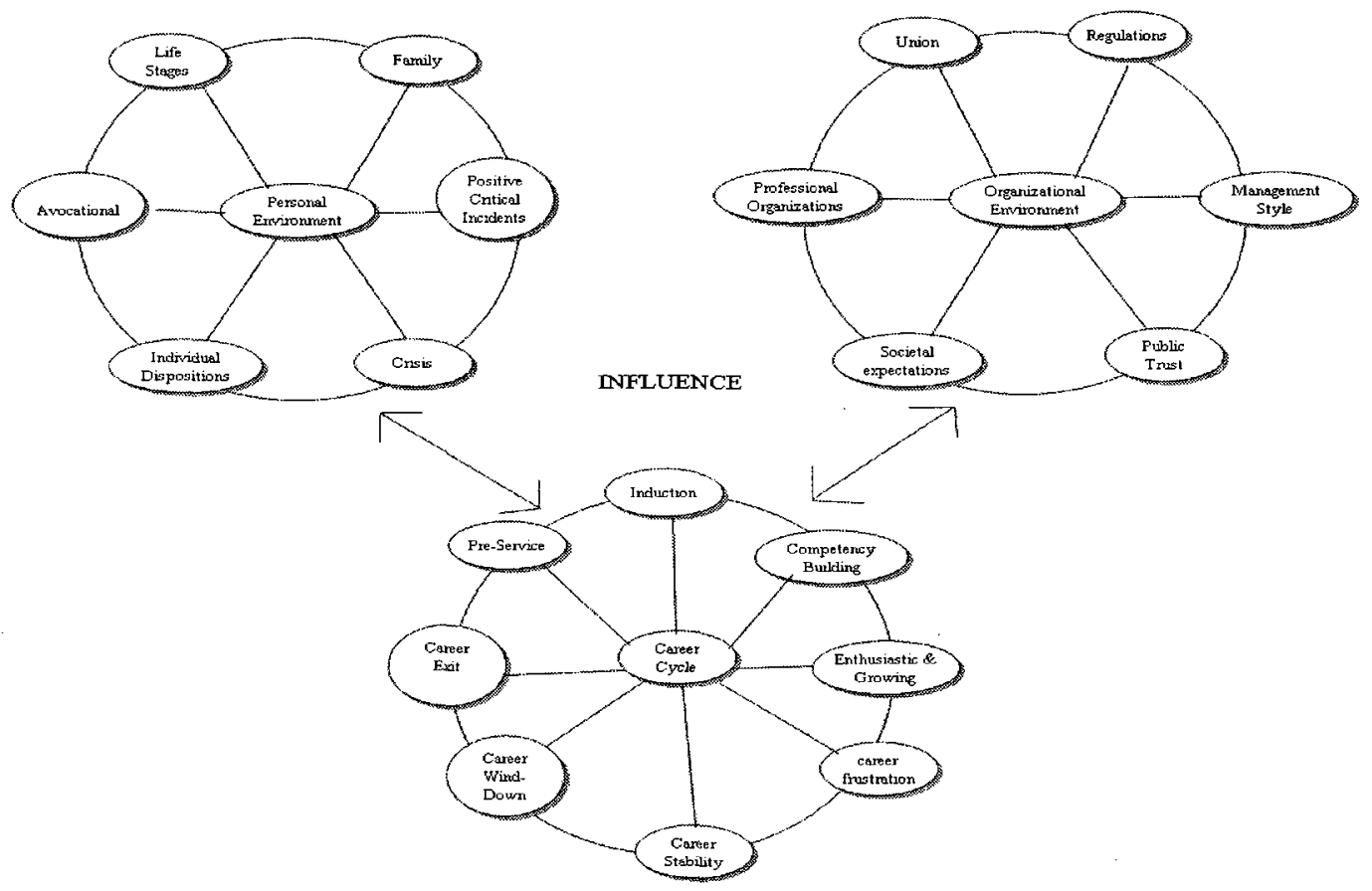

Figure 1. The Teacher Career Cycle (adapted from Fessler \& Christensen, 1992).

4. Enthusiastic and Growing--At this stage, teachers have reached a high level of competence in their job but continue to progress as professionals. Teachers in this stage love their jobs. They look forward to going to school and to the interaction with their students. Teachers are constantly seeking new ways to enrich their practice. Key ingredients here are enthusiasm and high levels of job satisfaction. These teachers are often supportive and helpful in identifying appropriate inservice education activities for their schools.

5. Career Frustration - This period is characterized by frustration and disillusionment with teaching. Job satisfaction is waning, and teachers begin to question why they are doing this work. Much of what is described as teacher burnout in the literature occurs in this stage.

6. Stability-At this stage, teachers have resigned themselves to putting in a fair day's work for a fair day's pay. They are doing what is expected of them but little 
more. These teachers are often fulfilling terms of their contracts but see little value in professional development programs. They participate in activities only at a surface level and are passive consumers of in-service efforts at best.

7. Career Wind-Down-This is the stage when a teacher is preparing to leave the profession. For some, it may be a pleasant period in which they reflect on the many positive experiences they have had and look forward to career change or retirement. For others, it may be a bitter period, one in which a teacher resents the forced job termination or, perhaps, cannot wait to get out of an unrewarding job. A person may spend several years in this stage, or it may occur only during a matter of weeks or months.

8. Career Exit-This stage of a teacher's career represents the period of time after the teacher leaves the job but includes other circumstances than simply retirement after many years of service. It could be a period of unemployment after involuntary or elective job termination or a temporary career exit for child rearing. It could also be a time of alternative career exploration or of moving to a nonteaching position in education such as administration. (pp. 41-42)

When graduating teachers accept their first assignment and become inducted into the profession, school culture can and does affect them, personally and professionally. McGinnis, Parker, and Graeber (2003) conducted a qualitative 2-year case study involving five new mathematics and science teachers. The participants all worked within the same school district but at different school sites. Researchers documented the experiences and perceptions of these teachers as they attempted to implement reform based mathematics and science practices they had studied as undergraduates. Researchers found that the new teachers' perceptions of their school culture was a significant factor in whether the reform based methods the teachers had learned in their undergraduate work were successfully implemented during their first two years of teaching. When the inductees viewed their school culture as unwilling to provide support, the new teachers showed resistance, moved on, or in two cases quit the profession. 
The study is important to the current study because it documents several implications regarding the new teacher career stage (induction) and the power of school culture. In the words of the researchers, "The affordances and constraints teachers perceived they encounter on a daily basis, particularly from individuals with potential coercive power over their work lives, are noticed by beginning teachers and influence their curricular, instructional, and assessment actions" (McGinnis et al., 2003, p. 743). Researchers suggested that new teachers should be made aware of the intricacies of school culture in their preservice years. At the very least, new comers to the field should be educated on career options other than leaving the profession.

Teachers may experience a stage several times throughout their careers or not all. For example, the frustration stage of the teacher career cycle is one that teachers can enter into and exit at any time during their career (Fessler \& Christensen, 1992). Age and years spent teaching may not always relate to teachers experiencing the frustration stage. In other professions if an individual becomes frustrated, he or she may choose to look for employment inside or outside the profession. Depending on years of service and the district's salary schedule, a frustrated tenured teacher, may not find it so easy to leave the district or the profession all together. Consequently, school districts may potentially house many frustrated employees. It does not take long for a very powerful subculture to form, a subculture that has no difficulty in recruiting new members by the minute.

Researchers Joyce et al. (2002) referred to individuals existing within an organizational culture(s) as "the most important element in the equation of staff development" (p. 129). They also noted how much time staff development planners worry about the behavior and action of individuals to whatever change is forthcoming. A 
framework to assist professional development program planners in working with organizational culture(s) was developed by Joyce et al. during a longitudinal study of staff development and school improvement practices in California.

The goal of The California Staff Development Study (Joyce, Bush, \& McKibbin, 1982) was to describe professional development opportunities experienced by teachers. Researchers surveyed 2,000 teachers and also generated case studies involving an additional 300 teachers working in 21 districts across seven counties. Data was collected in three areas: formal, peer generated, and personal domains, depending upon the kind of professional development activity teachers attended. Researchers theorized that ultimately it was the disposition of the individual that made the difference in professional development growth. They found that the disposition of an individual is developed over time and becomes habitual in nature. Results of the study encouraged the researchers to develop prototypes that would offer insight into the behavior patterns of individuals engaged in professional development opportunities. The prototypes are centered on the levels of activity collected from the three domains (formal, peer generated and personal) in the original study. Characteristics of the three prototypes are as follows:

1. Gourmet Omnivore-These individuals are members of a culture who possess the ability to investigate an environment and either cultivate or exploit it. They are deemed very mature, persistent, and highly active people professionally and personally. In the workforce, these people crave knowledge and are capable of giving and taking energy from individuals within their own and other subcultures of the organization. In their private lives, Gourmet Omnivores are very aware and enthusiastic about a particular activity or activities. They often encourage or force others to join in the fun. For example, a person might be an avid photographer and encourage friends to engage in the hobby. This group will also transfer ideas and lesson learned from their personal life into the classroom.

2. Passive Consumer-These individuals are members of a culture that goodnaturedly conforms to the social context of their environment. In a sense they are 
like chameleons adapting to whatever subculture is in close proximity. Professionally and personally their activity level depends on where and with whom they are spending time. For example, in the schoolyard, a passive consumer might find himself/herself partner teaching with a gourmet omnivore. The passive consumer suddenly becomes highly productive and is somehow able to successfully implement the new reading program, report card format, and character education program. However, the next year teaching assignments change and now the passive consumer disguised as a gourmet omnivore has been assigned to partner teach with another passive consumer in the hopes of strengthening the newcomer's instructional practices and ... nothing happens. Two good-natured teachers go about their business in the usual way.

3. Reticent Consumer-These individuals are members of a culture that use time and energy constructing a wall between themselves and opportunity for growth. Figuratively, this wall is often built from the bricks of reluctance, blame, and suspicion using negativity as mortar. In their professional and personal endeavors reticent consumers view themselves as oppressed by the system, whatever it may be. For example, in the workforce, individuals belonging to this culture will often loathe the supervisors and acquire a strong distaste and distrust toward gourmet omnivores. Reticent consumers view amicable colleagues as naïve. An extremely reticent consumer may even refuse opportunities for decision making viewing the opportunities as attempts from the evil system to win them over. In their personal lives, reticent consumers find excuses for not being active. For example a reticent consumer who lives far out in the country will argue that although they would like to watch the city's annual fourth of July fireworks display, the drive is far, gas is expensive, and they will be tired for work the next day. If a reticent consumer is a city dweller, they are likely to argue that trying to find a parking spot would be a night mare, paying for parking would be too expensive, and the park would be crowded and the lines too long. This prototype is an expert at finding the negative, regardless of the angle. For professional development planners, if the overall culture of the organization is positive and contains a good number of gourmet omnivores, the reticent consumer is less likely to voice their negativity and will positively engage in activities.

From the California Staff Development Study, Joyce et al. (2002) classified approximately $70 \%$ of their participants as passive consumers, $10 \%$ of the sample matched the profile of the gourmet omnivore, and another $10 \%$ were categorized as the reticent consumer prototype. Researchers did not report on the characteristics of the remaining $10 \%$ of the sample.

The structure of teacher salary schedules also creates subcultures unique only to the public school system. A simple formula exists for teachers to receive a monetary increase: 
years spent working in the district plus level of education. A monetary increase is not related to the amount of hours that any one teacher devotes to the job. Soon enough yet another subculture begins to form. Throughout their careers, some initially dedicated, hard working teachers come to the realization that the person working next door to them is not doing much work at all yet continues to reap the annual monetary rewards of years of service plus educational credits. The once dedicated passionate teacher has now migrated from a positive subculture to a "toxic" (Peterson \& Deal, 1998, p. 28) subculture. Fullan and Hargreaves (1992) cautioned members of subcultures, toxic or not, to be aware of balkanization. The concept of balkanization can be found among subcultures when members of the group are so loyal to their own kind that the whole group develops groupthink (Janis, 1972) and begins to exhibit hostile behaviors toward other subcultures, without hesitation. As Barth (2002) stated, "It [culture] is the historically transmitted pattern of meaning that wields astonishing power in shaping what people think and how they act" (p. 6). It is no wonder then that school culture commands center stage in many aspects of school, including school reform, which often affects professional development (Guskey, 2000; McCabe, 2001). Ongoing job-embedded professional development asks all subcultures thriving within the main culture of the school to find common ground and work together to create quality education for all. However, it remains unclear whether subcultures in schools can meet this challenge without examining their perspectives on the organizational's capacity to support them during a change process.

\section{EVALUATION}

From the day human beings are born, they begin to collect a repertoire of experiences. As the brain matures, individuals develop the ability to start remembering their experiences. 
With further growth, people begin to practice the art of reflection. Naturally, this reflection process leads to an evaluation of the experience. In some circumstances, people might evaluate their experience as it unfolds. Individuals might also give careful consideration to a potential experience - using their assessment of the situation to decide if they, indeed, want to engage in the experience. For the human race, evaluation is a natural process. For working professionals employed by profit and nonprofit organizations, evaluation is a necessity. For savvy decision makers and stakeholders working particularly in federally funded public service programs, the necessity of evaluation is not novice.

In reviewing the literature, the concept of evaluation has existed for over a century. According to Stufflebeam, Madaus, and Kellaghan (2000), in the 1800s the United States government contracted outside inspectors for evaluations of hospitals, prisons, and other programs serving the public. In the early 1930 s, Ralph Tyler, known as the father of evaluation, invented the term, educational evaluation (Stufflebeam \& Shinkfield, 2007). He worked toward developing an approach that focused on objectives. To Tyler, evaluation was synonymous to determining if objectives were met within a program. His definition required evaluators to aid school curriculum developers in clarifying student behaviors that would occur through the implementation of a certain curriculum.

What is known as the Progressive Education Movement offered Tyler the chance to capitalize on his theories of educational evaluation and dominate educational program evaluation for the following 25 years. As political leaders tried to optimistically steer America out of its financial dilemma during the Great Depression, educational leaders such as John Dewey were also trying to breathe life back into a starving public education system. Consequently, Tyler was summoned to direct the research of what is now known as the 
seminal Eight-Year Study. This highly visible study explored the effectiveness of innovative curricula and teaching strategies in thirty schools throughout the country (Stufflebeam \& Shinkfield, 2007).

Historically, it was the proposal of a program referred to as the Great Society (Kaplan, 1986) by then President Lyndon Johnson in the 1960s that placed evaluation as a profession on the map and challenged Tyler's local approach (Mertens, 2005; Stufflebeam \& Shinkfield, 2007). Great Society (Kaplan, 1986) legislation focused on helping disadvantaged Americans by offering federal funds to support public education (such as the 1965 Elementary and Secondary Education Act, bilingual education, special education, Head Start, loans, grants, and scholarships for college) and provide healthcare (such as Medicare and Medicaid) to the elderly. Legislators required that evaluation would be a necessary component of any and all new federally funded programs. Previously, most educational evaluation had been initiated by local school districts. They had the decision making power to conduct evaluations or not to conduct them.

Because the federally mandated large-scale evaluations were new, many evaluations were poorly done and not cost effective. To rectify this "embryonic program evaluation movement" (Stufflebeam \& Shinkfield, 2007, p. 85), efforts included developing standards and principles for assessing and strengthening evaluations.

Institutions such as schools that received federal dollars needed guidance in measuring the effectiveness of such programs. Practitioners realized this and in 1975, one year prior to America's bicentennial celebration, 15 people from established educational organizations gave birth to the Joint Committee on Standards for Educational Evaluation. 
The committee set about to compose standards to guide educational evaluation in the areas of cost effectiveness, usefulness, and ethical procedures (Stufflebeam \& Shinkfield, 2007).

Decades later the Committee has now published three different sets of standards: program evaluation standards, personnel evaluation standards, and student evaluation standards. The program evaluation standards, first published in 1981 and revised in 1994, are listed under four categories: utility, feasibility, propriety, and accuracy (The Joint Committee on Standards for Educational Evaluation, 1994). The utility standards promote that evaluations will serve the information needs of intended users. Feasibility standards uphold that evaluations will be realistic, prudent, diplomatic, and frugal. Propriety standards uphold that evaluations will be conducted legally and ethically. Accuracy standards uphold that evaluation will reveal and convey technically adequate information about the features that determine worth or merit of the program being evaluated.

The standards are considered a living document and members of the Joint Committee on Standards for Educational Evaluation ask for feedback from professionals applying the standards to evaluative procedures (Stufflebeam \& Shinkfield, 2007). Although the Joint Committee on Standards for Educational Evaluation document is clearly most relevant to this proposal, it is important to note that two other organizations have published documents providing guidance for professional evaluators, which may be applied to evaluative studies in education. The American Evaluation Association (AEA) created Guiding Principle Standards that apply to many service oriented institutions and are not as detailed as the Joint Committee's Program Evaluation Standards. A third set of standards, the Government Auditing Standards, was produced by a United States Government Accountability Office special project team and applies to auditors (2007). 
Researchers advocated that educational programs must be critically evaluated utilizing the standards to determine impact. Guskey (2000) voiced that "a systematic plan to collect data, analyze it, and make changes based on the significance of the data should inform professional development planners" (p. 88).

Not only do educational evaluators need a systematic plan, they often must discuss with school administrators the type of evaluation best suited for the program. Evaluations can be classified into three categories: planning, formative, and summative. These three kinds of evaluation were born out of the three broad purposes of evaluation (Guskey, 2000, 2005; Stufflebeam \& Shinkfield, 2007).

Planning evaluation gives stakeholders an idea of what is to be accomplished, what procedures will be used, and how stakeholders will know if the plan was successful. Formative evaluation happens during the program and guides decision makers. This type of evaluation gives parties responsible for the implementation of new programs, ongoing information about the program. For example, are things moving along as planned? Is progress being made as expected? Formative evaluation can take place many times throughout a program. Evidence gathered during formative evaluations can help program implementers revise certain aspect of a program as needed. In this way, major shortcomings of a particular program can be addressed before the program and the people involved in it fail.

Summative evaluations gather information for decisions makers at the end of a program implementation. A summative evaluation describes what was accomplished, the positive and negative consequences, and the final results. Decision makers can learn from a summative evaluation if a program should be continued, expanded, modified, or terminated. 
These three types of evaluation can be equated to the words, before (planning), during (formative), and after (summative). Although all evaluations in some capacity include all three types, most evaluators and stakeholders will determine from the onset the major purpose of the evaluation to be conducted. Educational evaluators and stakeholders will then determine what model of evaluation to follow.

\section{A Model of Evaluation for Professional DEVELOPMENT}

As identified by the researcher through the review of the literature, seven different models of evaluation exist (Guskey, 2000; Stufflebeam \& Shinkfield, 2007). They are as follows:

1. Tyler's Evaluation Model

2. Metfessel and Michael's Evaluation Model

3. Hammond's Evaluation Model

4. Scriven's Goal-Free Evaluation Model

5. Stufflebeam's CIPP Evaluation Model

6. Kirkpatrick's Evaluation Model

7. Guskey's Evaluation Model

However, it is Guskey's model of evaluation that will be applied to this evaluative study. Before exploring Guskey's model, it is critical to first closely examine an evaluation model which originated in corporate America: Kirkpatrick's model. His model was first utilized in business to evaluate supervisory training programs. This business model contained four levels of evaluation: reaction evaluation, learning evaluation, behavior evaluation, and results evaluation (Guskey, 2000). 
1. Reaction evaluation. Focuses on how participants feel about the program. Because training programs in business and industry are generally designed to help those who participate, it is important to determine how satisfied they are with the product they receive.

2. Learning evaluation. Measures the knowledge, skills, and attitudes that participants acquire as a result of the training. Because most training programs are trying to increase knowledge and skills or change attitudes, evaluation at this level centers on how effectively the program accomplished these learning objectives.

3. Behavior evaluation. Considers the extent to which the on-the-job behavior of participants changed because of the training. The focus at this level is on how much and what type of change actually took place in job performance.

4. Results evaluation. Designed to assess the bottom line in business and industry. Evaluation at this level assesses such things as improved productivity, better quality, lower costs, meeting deadlines, reduced accidents, improved morale, lower turnover, and ultimately, more profits or better service. (p. 55)

Kirkpatrick's model is user friendly. It is practical and simple, making it "the foundation of training program evaluations in businesses around the world" (Guskey, 2005, p. 13).

However, in the field of education, critics of the model argued that it was not robust in explanatory power (Alliger \& Janak, 1989; Holton, 1996). Despite rejection among his colleagues, Guskey continued redesigning the model to improve its robustness well into and beyond the new millennium.

Guskey adapted Kirkpatrick's business model for educational evaluation purposes. Guskey's design includes five hierarchical levels as displayed in Table 2. Each level becomes more complex, requires more time and resources for data gathering, and builds on the previous level. Table 2 contains the levels in detail starting with the simplest level, Participant Reactions, and progressing to the most complex level, Student Learning Outcomes. 
Table 2. Guskey's Five Levels of Professional Development Evaluation

\begin{tabular}{|c|c|c|c|c|}
\hline $\begin{array}{l}\text { Evaluation } \\
\text { Level }\end{array}$ & What questions are addressed? & $\begin{array}{l}\text { How will information } \\
\text { be gathered? }\end{array}$ & $\begin{array}{l}\text { What is measured or } \\
\text { assessed? }\end{array}$ & $\begin{array}{c}\text { How will } \\
\text { information be used? }\end{array}$ \\
\hline $\begin{array}{l}1 \\
\text { Participants' } \\
\text { Reactions }\end{array}$ & $\begin{array}{l}\text { * Did they like it? } \\
\text { * Was their time well spent? } \\
\text { * Did the material make sense? } \\
\text { * Will it be useful? } \\
\text { * Was the leader } \\
\text { knowledgeable and } \\
\text { helpful? } \\
\text { * Were the refreshments fresh } \\
\text { and tasty? } \\
\text { * Was the room the right } \\
\text { temperature? } \\
\text { * Were the chairs } \\
\text { comfortable? }\end{array}$ & $\begin{array}{l}\text { * Questionnaires or } \\
\text { surveys administered at } \\
\text { the end of the session. }\end{array}$ & $\begin{array}{l}\text { * Initial satisfaction } \\
\text { with the experience. }\end{array}$ & $\begin{array}{l}\text { * To improve program } \\
\text { design and delivery. }\end{array}$ \\
\hline $\begin{array}{l}2 \\
\text { Participants' } \\
\text { Learning }\end{array}$ & $\begin{array}{l}\text { * Did participants acquire the } \\
\text { intended knowledge and } \\
\text { skills? }\end{array}$ & $\begin{array}{l}\text { * Paper and pencil } \\
\text { instruments. } \\
\text { * Simulations } \\
\text { * Demonstrations } \\
\text { * Participant reflections } \\
\text { (oral and/or written). } \\
\text { * Participant portfolios. }\end{array}$ & $\begin{array}{l}\text { * New knowledge } \\
\text { and skills of } \\
\text { participants. }\end{array}$ & $\begin{array}{l}\text { To improve program } \\
\text { content, format, and } \\
\text { organization. }\end{array}$ \\
\hline $\begin{array}{l}3 \\
\text { Organizational } \\
\text { Support and } \\
\text { Change }\end{array}$ & $\begin{array}{l}\text { * Were sufficient resources } \\
\text { made available? } \\
\text { * Were problems addressed } \\
\text { quickly and efficiently? } \\
\text { * Was the implementation } \\
\text { advocated, facilitated, and } \\
\text { supported? } \\
\text { * Were successes recognized } \\
\text { and shared? } \\
\text { * Was the support public and } \\
\text { overt? } \\
\text { * What was the impact on the } \\
\text { organization? } \\
\text { * Did it affect organizational } \\
\text { climate and procedures? }\end{array}$ & $\begin{array}{l}\text { * Minutes from follow-up } \\
\text { meetings. } \\
\text { * Questionnaires. } \\
\text { * Structured interviews } \\
\text { with participants and } \\
\text { district or school } \\
\text { administrators. } \\
\text { * District and school } \\
\text { records. } \\
\text { * Participant portfolios }\end{array}$ & $\begin{array}{l}\text { * The organization's } \\
\text { advocacy, support, } \\
\text { facilitation, and } \\
\text { recognition. }\end{array}$ & $\begin{array}{l}\text { * To document and } \\
\text { improve } \\
\text { organizational } \\
\text { support. } \\
\text { * To inform future } \\
\text { change efforts. }\end{array}$ \\
\hline $\begin{array}{l}4 \\
\text { Participants' } \\
\text { Use of New } \\
\text { Knowledge } \\
\text { and Skills }\end{array}$ & $\begin{array}{l}\text { * Did participants effectively } \\
\text { apply the new knowledge and } \\
\text { skills? }\end{array}$ & $\begin{array}{l}\text { * Questionnaires. } \\
\text { * Structured interviews } \\
\text { with participants and } \\
\text { their supervisors. } \\
\text { * Participant reflections. } \\
\text { * Participant portfolios. } \\
\text { * Direct observations. } \\
\text { * Video or audiotapes. }\end{array}$ & $\begin{array}{l}\text { * Degree and } \\
\text { quality of } \\
\text { implementation. }\end{array}$ & $\begin{array}{l}\text { * To document and } \\
\text { improve } \\
\text { implementation of } \\
\text { program content. }\end{array}$ \\
\hline $\begin{array}{l}5 \\
\text { Student } \\
\text { Learning } \\
\text { outcomes }\end{array}$ & $\begin{array}{l}\text { * What was the impact on } \\
\text { students? } \\
\text { * Did it affect student } \\
\text { performance or achievement? } \\
\text { * Did it influence students' } \\
\text { physical or emotional well- } \\
\text { being? } \\
\text { * Are students more confident } \\
\text { as learners? } \\
\text { * Is student attendance } \\
\text { improving? } \\
\text { * Are dropouts decreasing? }\end{array}$ & $\begin{array}{l}\text { * Student records } \\
\text { * School records } \\
\text { * Questionnaires } \\
\text { * Structured interviews } \\
\text { with students, parents, } \\
\text { teachers, and/or } \\
\text { administrators. } \\
\text { * Participant portfolios. }\end{array}$ & $\begin{array}{l}\text { * Student learning } \\
\text { outcomes. } \\
\text { * Cognitive. } \\
\text { * Affective. } \\
\text { * Psychomotor. }\end{array}$ & $\begin{array}{l}\text { * To focus and improve } \\
\text { all aspects of } \\
\text { program design, } \\
\text { implementation, } \\
\text { and follow-up. } \\
\text { * To demonstrate the } \\
\text { the overall impact of } \\
\text { professional } \\
\text { development. }\end{array}$ \\
\hline
\end{tabular}

Source: Guskey, T. R. (2005). Taking a second look at accountability. Journal of Staff Development, 26(1), 14. 
When Guskey first designed the model he intended for evaluators to begin at level 1 and progress through the different levels. He cautioned against the idea that success at one particular level would indicate or imply success at the following level. However, in 2005, Guskey applied the idea of backward planning to his original model. Evaluators would begin at level 5, Student Learning Outcomes, and end at level 1, Participants' Reactions. He emphasized the importance of backward planning because decisions made at one level would greatly affect decisions made at the next level.

With educational reform focusing on accountability through systemic change, level 3 of Guskey's model Organizational Support and Change becomes critical for evaluators. The evidence gathered and investigated at this level proves essential to all stakeholders of a newly implemented program. The findings at this level are used to inform future change initiatives. This type of information is crucial in the field of education as reform efforts are infinite.

Evaluating Organizational Support and Change provides the opportunity for decision makers to reflect upon the level of support the organization offers during a reform movement and how that level of support might be modified to make the next reform effort more constructive and beneficial to all.

\section{Evaluative Projects Underway}

The researcher has included this section of the literature review to demonstrate and visualize how the current proposal might extend or connect to the research of studies already underway. According to Krathwohl and Smith (2005), it is important for researchers to recognize and explore how a proposal compares and contrasts to current studies in the field. 
Evaluative studies measuring the effects of new educational programs and interventions have vastly increased since the passing of NCLB in 2002 (Institute of Educational Sciences [IES], 2008). The federal government along with private institutions and individuals continue to offer grants in educational evaluative research. These grant awards provide mounting evidence of an escalating interest and need for more school districts to conduct evaluations.

The Institute of Educational Sciences (IES), an agency of the United States Department of Education, advocates "improving education depends in large part on using evidence generated from rigorous research to make education decisions" (IES, 2008, About $U s$, section para 2). The Institute makes clear that schools cannot afford to wait for scientific research to validate programs and policies, rather schools and the people working in them must be at the forefront in the evaluation process. IES is working toward educating school leaders at the state and district level in the development of rigorous evaluations of their policies and programs. For example, in the spring of 2008, IES sponsored a workshop in evaluation, which further emphasized the need for school administrators to think seriously about conducting more district and site based evaluations.

The IES contains four branches: National Center for Education Research (NCER), National Center for Education Statistics (NCES), National Center for Education Evaluation and Regional Assistance (NCEE), and the National Center for Special Education Research (NCSER). The National Center for Education Research (NCER), the first branch of the Institute, believes in rigorous research that, "contributes to the solution of significant education problems in the United States" (IES, 2008, About Us, section para 2). One program of NCER, the Teacher Quality Research Program, focuses on identifying and evaluating 
strategies that help new and veteran teachers improve instructional practices. Five goals of the Teacher Quality Research Program exist. They are as follows:

1. Identify the characteristics or practices of teachers that are associated with better student outcomes in reading or writing in kindergarten through Grade 12; and identify programs and practices for teacher professional development that are associated with better student outcomes in reading or writing from kindergarten through Grade 12, as well as mediate and moderate the relationships between student outcomes and these teacher characteristics, programs, or practices.

2. Develop new programs and practices for teacher professional development that will eventually result in improving teacher practices for teacher professional development that will eventually result in improving teacher practices and through them student learning and achievement.

3. Evaluate the efficacy of programs and practices for teacher professional development for improving teacher practices and through them, student learning and achievement.

4. Evaluate the effectiveness of teacher professional development programs that are implemented at scale and intended for improving teacher practices and through them student learning and achievement. Develop and validate new assessments of teacher quality or validate existing assessments for teachers at any grade level from kindergarten through high school against measures of student achievement. (NCER, 2008, Description section, para 1)

All five of these goals are clearly associated with organizational and individual capacity. For example, NCER's goal number one, "Identify the characteristics or practices of teachers," rephrased as a guiding question for a study might become, how are levels of individual capacity related to student outcomes? Continuing on with goal number one, “identify programs and practices for teacher professional development that are associated with better student outcomes," could lead researchers to explore the organizational capacity of the programs and practices that are associated with better student outcomes (NCER, 2008).

In fact, the guiding questions and sub questions of the current proposal could be applied to many grant awarded studies in NCER's Teacher Quality Research Program. 
Researchers involved in current NCER grant awarded studies could not only evaluate a professional development program, but also assess the organizational capacity of each institution to support individuals experiencing the program. By addressing the five critical aspects of organizational capacity, vision and leadership, collective commitment to cultural norms, knowledge or access to knowledge, organizational structures and management, and resources, researchers may gain a better understanding of how and why some districts, implementing the same professional development program, produce more highly qualified teachers than others. Researchers could also gain perspectives from stakeholders on how the overall culture of a school and subcultures within each school work for or against the goals of NCER to promote highly qualified teachers.

In March of 2008, the IES announced that its annual NCER 2009 competition would continue to award grants in Education Research Training such as the Teacher Quality Research Program, and also offer grants in two new programs: Statistical and Research Methodology in Education and Evaluation of State and Local Education Programs and Policies (IES, 2008).

The two new programs added to the annual NCER 2009 competition, Statistical and Research Methodology in Education and Evaluation of State and Local Education Programs and Policies, are also relevant to this current study. The purpose of the newly added Evaluation of State and Local Education program award is to emphasize the importance of evaluation by providing funding to state and local school sites who conduct their own evaluations of their own programs (NCER, 2008). For example, in relevance to this current proposal, a district would conduct a rigorous evaluation of organizational capacity to support a new site based, job embedded weekly professional development program. Depending upon 
the design and methods a district might employ to conduct the evaluation, it may also be eligible for the Statistical and Research Methodology in Education financial award. This new program addition to the annual NCER 2009 competition seeks to emphasize the importance of methods and statistical analyses in the following areas: methods that would improve the ability of researchers to conduct IES funded studies, improvements in evaluation methods to increase the generalizability of studies, improvements in evaluative studies to increase statistical power, improvement of single case study statistical analyses and design, and methods or tools to assist researchers at the National Assessment of Educational Progress (NAEP) to make interpreting data less challenging for education leaders (NCER, 2008).

Current projects with the goal of development funded by IES under various branches include: The Influence of Collaborative Professional Development Groups and Coaching on the Literacy Instruction of Upper Elementary Special Education Teachers, Teaching Teachers to Teach Critical Reading Strategies (CREST) through an intensive Professional Development Model, Evaluation of Principles-Based Professional Development to Improve Reading Comprehension for English Language Learners.

The National Center for Education Evaluation and Regional Assistance (NCEE), another division of the Institute, evaluates programs and practices, which are financially supported by federal dollars. These types of evaluations are done on a large-scale basis and include well-known programs such as Reading First and Title I (NCEE, 2008a). Studies funded by this division focus on gathering scientific evidence in an attempt to answer the following three questions:

1. What is the impact of the federal program on the intended outcomes?

2. Is the program model effective? 
3. Is a specific intervention (or class of interventions) effective?

The NCEE division has approximately 30 ongoing projects in the following domains: Literacy, Mathematics, Teacher Quality, Choice, English Language Learning, Effectiveness of Educational Technology Interventions, Supplemental Educational Services, After-School Programs, School-Based Violence Prevention Program, Adult Education, Student Mentoring Program, Random Mandatory Drug Testing Study, Career and Technical Education, Upward Bound Program, Comprehensive Technical Assistance Centers, Magnet School Assistance Program, Technical Assistance, and Special Education (NCEE, 2008d).

In reviewing the literature, out of the 18 domains, evaluation studies on Teacher Quality (nine evaluations underway) are drawing the most attention. The domain of Literacy places a distant second with five evaluation projects underway. The nine Teacher Quality evaluation studies focus on teacher preparation and professional development (NCEE, 2008d). Two evaluative studies measuring professional development are of interest to this current proposal.

The first study, The Impact of Professional Development Strategies on Teacher Practice and Student Achievement in Math (NCEE, 2008c), is guided by the overarching research question: What is the impact of teacher knowledge, teacher practice, and student achievement of providing seventh grade teachers with intensive professional development that focuses on common student misconceptions in the areas of fractions, decimals, percent, ratio, and proportion?

Researchers were contracted to select, develop, and evaluate a math professional development program. The model consisted of a 3-day seminar in the summer, 5 day-long sessions throughout the academic school year, and 10 days of additional coaching support 
throughout the school year. Three districts piloted the program during the 2006-2007 school year (NCEE, 2008c).

The evaluative study was conducted during the 2007-2008 academic school year. Eighty-eight middle schools across 12 districts were randomly assigned to receive the treatment or to a control group. Participants (seventh grade math teachers) in the control group received the professional development planned by the district. Data collection includes measures of professional development implementation, teacher knowledge and practice, and student achievement. Researchers began data collection at the beginning of the 2007-2008 school year. Data will continue to be collected during the 2008-2009 school year. The study, which technically began in 2005 , is expected to be completed by the year 2010 (NCEE, 2008c).

This current study differs from the above study in many ways. First, it will not measure the impact of a particular professional development program. Rather this proposed study will evaluate the organizational capacity of a school to support individual learning during a newly implemented district mandated professional development program. Second, this study will examine the perceptions of subcultures, within the school, of the organization's capacity to offer support. Third, this evaluative study will not include a control group. Fourth, participants for the proposed study will include kindergarten through eighth grade teachers in all content areas, not just math as in the above study sponsored by the NCEE (2008c). Fifth, the sample for the proposed study will be selected from a one-schooled district. A final, important distinguishing feature of this current study is that the program will not be federally funded. 
Although many aspects of the NCEE (2008c) study, The Impact of Professional Development Strategies on Teacher Practice and Student Achievement in Math, differ from this current proposed study, in some ways the studies do connect and have the potential to create a proposal for a third study. First, researchers could revise the second guiding question of this proposal, "What are the different teacher subcultures' perceptions of the organization's capacity to support new learning during the initial implementation of a sitebased weekly job embedded professional development program?" to explore relationships between a school's capacity and professional development from the perspectives of subcultures of the overall school culture.

Contextually, all participants in both studies will be exposed to some kind of professional development program. Participants in the treatment group of the NCEE study (2008c), The Impact of Professional Development Strategies on Teacher Practice and Student Achievement in Math, and participants in the proposed study will be exposed to new, intensive programs. All of these teachers will be a part of a subculture existing within the overall school culture. These teachers also will fit into different phases of the teacher career cycle (Fessler \& Christensen, 1992) and therefore are expected to hold different perspectives of the new programs and the schools' capacity to support them.

In the Impact of Professional Development Strategies on Teacher Practice and Student Achievement in Math (NCEE, 2008c), one of the dependent variables of the study is teacher knowledge and practice, which is also one of the five critical aspects of Organizational Capacity. Teacher knowledge or access to teacher knowledge includes available resources, collegial support, and administrative support (O'Day, Goertz, \& Floden, 1995). Lessons learned from and analysis in the NCEE's study (2008c) and the current 
proposed study could be explored and used as a springboard for an additional study. For example, a proposal for a third study might include evaluating the organizational capacity of the 12 districts from the NCEE study to support the individual learning of seventh grade math teachers during the professional development programs. Guiding questions may include the following: what did those 10 days of additional coaching support look like? How did the districts support this? Were teachers in the 88 schools encouraged to practice new math concepts in the absence of fear? Did they receive adequate resources including time, personnel, and materials? How did the district recognize teachers' success in using the new methods? Evaluators in a proposed third study may want to continue utilizing Guskey's evaluation model or explore other models of evaluation. Researchers may also in their programmatic evaluations explore the differences between professional development programs that are federally funded and programs that are not federally funced.

The Impact of Professional Development Models and Strategies on Teacher Practice and Student Achievement in Early Reading (NCEE, 2008b) is a second NCEE funded study of interest to this current proposal. Researchers in this federally funded study evaluated the impact of two professional development programs on instructional practices and student growth in early reading. Methods consisted of two treatment groups and one control group. Treatment group A received a 5-day content-focused summer program supported by three follow-up days scheduled throughout the school year. Treatment group B in addition to receiving everything equal to Treatment Group A, also received support by an onsite reading specialist trained in a coaching (2008b).

The Impact of Professional Development Models and Strategies on Teacher Practice and Student Achievement in Early Reading (NCEE, 2008) is examining two types of 
professional development programs that were implemented during the 2005-2006 academic school year across six districts. Three of the districts used one type of reading curriculum and the remaining three districts used a second type of reading curriculum. Within each district, an average of 15 socioeconomically disadvantaged elementary schools were randomly assigned so that five schools received Treatment A, five schools received Treatment B, and five schools acted as control groups by receiving only the normal professional development offered by each district. A grand total of approximately 90 schools participated in the study. All second grade teachers working in the treatment schools were given the chance to attend the professional development sessions. Researchers collected data during the implementation year of the two reading professional development programs and one year after the initial implementation to examine sustainability (2008b).

This current proposal differs from the NCEE-sponsored study, The Impact of Professional Development Models and Strategies on Teacher Practice and Student Achievmenet in Early Reading, in several ways. First, researchers in the NCEE study (2008b) are evaluating the impact of professional development programs. They are evaluating two separate professional development programs in early reading. The current proposal does not focus on impact but rather attempts to evaluate the organizational capacity of a district to support individuals experiencing the impact of a single newly designed professional development program not focused on a particular content area such as literacy or math.

Second, the research design differs greatly from the research design of The Impact of Professional Development Models and Strategies on Teacher Practice and Student Achievement in Early Reading (NCEE, 2008b). The research design of the current proposal does not contain a control group. The NCEE study (2008b) contains two treatment groups 
and one control group. It is a large-scale study involving second grade teachers working in 90 different socioeconomically disadvantaged schools. The current proposal involves teachers working in grades kindergarten through eighth under one roof in an affluent neighborhood. In schools receiving the treatment from the NCEE study (2008b), teachers were given the choice to receive the professional development. The professional development program in the proposed study was mandatory for all teachers.

The proposed study could constructively connect with The Impact of Professional Development Models and Strategies on Teacher Practice and Student Achievement in Early Reading (NCEE, 2008b) in terms of the proposed study's second guiding question, What are the different teacher subcultures' perceptions of the organization's capacity to support new learning during the initial implementation of a site-based weekly job embedded professional development program? For example, in the NCEE funded study, researchers could examine the perspectives of defined subgroups of each three groups (Treatment A, Treatment B, and the control group) in supporting the treatments and regular professional development. Researchers may want to deeply explore the teacher demographics and subcultures thriving among and within the 60 schools involved in the study. Researchers may want to consider and apply the Teacher Career Cycle Model (Fessler \& Christensen, 1992) and the three consumer prototypes (Joyce et al., 2002): gourmet omnivore, passive consumer, and reticent consumer in their exploration.

Although evaluative studies are highly contextual in nature, investigating how the proposed study differs and also connects with current projects underway could work toward extending and improving the body of literature on evaluative studies. Comparing and contrasting this current proposal to research underway might also work toward fulfilling a 
goal of NCER (2008), to improve evaluation methods for an increase in the generalizability of studies. As Shaha, Lewis, O'Donnell, and Brown (2004) stated, "As a caution, too often those [individuals] undertaking evaluations from which results might be shared allow their perceptions regarding the smallness of a district or its unique ethnic mix to undermine their capability of impacting the broader educational arena by sharing their findings" (p. 4).

As interwoven and indicated throughout this section of the literature review, Evaluative Projects Underway, components of this current study Examining Professional Development at the Organizational Level Through the Lens of Teachers and Administrators are similar yet different to many of the evaluative projects underway. The selected case is "worthy of study" (Creswell, 1998, p. 63) because it is contextually situated at the local level, has recently undergone a systemic change in professional development to increase the quality of teacher instruction, and the institute's flat structure promotes an "in depth picture" (Creswell, 1998, p. 63). It is by nature that an institution with a flat structure such as this case lends itself to a less complex process in terms of gathering data soon after a systemic change has occurred which has the potential to make the participants' experiences better remembered, resulting in potentially more scholarly recommendations for practice and future research.

\section{The Complexities of Professional Staff DEVELOPMENT}

Thousands of years ago, individuals banded together to cooperatively hunt and fish for survival. These prehistoric people shared a common purpose larger than themselves. Man instinctively knew or quickly learned that the consequences of living in isolation eventually meant death by succumbing to vicious attacks, starvation, or the brutal harshness of their 
environment. Prehistoric men also seemed to understand that the capacity of the group depended on the knowledge and strength of each member. As cruel as it may seem in this modern age, people who had their own personal agenda, became maimed or too old to contribute to the overall mission of the tribe, were frequently killed or left behind. How can it be that these cavemen operating with fewer neuronal connections than modern day man still were extremely cognizant of the interdependent relationship between the group and the individual?

In the $21^{\text {st }}$ century workforce, organizational capacity and individual capacity continue to remain interdependent; however, they often fail one another in the continuous professional development of educators working in the public school system. With decades of educational reform efforts behind them, public schools should know and be able to implement meaningful professional development programs. However, researchers in the field continue to explore and gather evidence demonstrating the daunting, endless challenge of professional development, particularly since the passing of the No Child Left Behind Act of 2002 (Guskey, 2005; Killion, 2002; Newman et al., 2000; O’Day et al., 1995; Sparks \& Hirsh, 1997; Speck \& Knipe, 2005).

Professional staff development pertains to the advancement of an idea, plan, design, or procedure to increase practitioner knowledge toward a main goal of increasing student achievement. However, improving student achievement is left to chance unless professional staff development and organizational performance improve (Loucks-Horsley et al., 2003). High quality professional development, in the words of researchers Speck and Knipe (2005), is a "sustained collaborative learning process that systemically nourishes the growth of educators through adult-learner-centered, job-embedded processes"' (p. 4). 
The concept of a job-embedded approach to professional development is not new.

Decades ago, Little (1993) described a teacher development model of professional

development that would be embedded in the life of a teacher and a school. Gaining teacher knowledge and skills would be an ongoing process as teachers reflected on their practices. Specifically, Little's model recommended that professional development should offer the following six attributes:

1. Meaningful intellectual, social, and emotional engagement with ideas, materials, and colleagues.

2. Take explicit account of the contexts of teaching and the experiences of teachers.

3. Offer support for informed dissent.

4. Place classroom practice in the larger contexts of school practice.

5. Prepare teachers (as well as students and parents) to employ the techniques and perspectives of inquiry.

6. Involve governance that ensures a balance between the interests of individuals and the interests of the institution. (p. 138)

Six years after Little's proposed job-embedded model, Cohen and Ball (1999) noted that professional development which embedded learning into the daily work of teachers was slowly emanating into the public school system. This type of professional development was providing opportunities for teachers to learn "in and around their practice" (p. 4). By the year 2007, Hall voiced that teachers were experiencing less traditional forms such as expert presentation and workshop approaches to professional development and more non-traditional site-based, district-wide and individually directed approaches.

Researchers concur that professional development planners must rethink present and future professional development by exploring the following critical aspects: continuous, 
differentiated learning through the cycle of inquiring centered around similar values, motivation of teachers, sustainability when leadership changes, current measure of organizational capacity, school culture and subcultures, teacher career cycles, tools for teachers, and the change process of teachers (Guskey, 2002; Loucks-Horsley et al., 2003; Sparks \& Hirsh, 1997; Speck \& Knipe, 2005).

All stakeholders experience change during the implementation of new professional development programs. Change is difficult for everyone involved in the process, regardless of his or her role. Since the passing of the No Child Left Behind Act of 2002, school administrators must plan high quality programs that meet the demands of state officials. Those in leadership roles are expected to unveil flawless programs that increase student achievement and in turn produce high state test scores. Principals must answer to the superintendent. The superintendent must answer to the school board. The school board must justify to parents time and resources designated toward professional development. Change driven by professional development is especially difficult for teachers as proposed by Guskey (2002).

To fulfill the goal (increasing student achievement) of all professional development initiatives, ultimately it is the teachers who must alter their beliefs and attitudes toward new instructional approaches. Depending on what stage teachers occupy in the teacher career cycle model (Fessler \& Christensen, 1992), new professional development initiatives can be extremely stressful, unmotivating, risky, and challenging. Particularly, in the hearts and minds of teachers, change means potentially risking what they care about the most: the welfare and achievement of their students (Guskey, 2002). 
Guskey (2002) developed a model of teacher change that encourages professional development planners to rethink the process of teacher change. Most programs are based on the premise that teachers' attitudes and beliefs change first. This leads those in leadership roles to include teachers in planning the program. Sometimes, professional development planners will conduct surveys in order to align programs to teachers' needs and desires. Guskey's model suggests that this inclusion of teachers may create buy in on the surface, but does little good when it comes time for teachers to implement new instructional approaches in the classroom.

For teachers' attitudes and beliefs to change, first they must be encouraged or mandated to try the new instructional approach. During this time of risk taking, teachers must continue to practice the implementation until they feel secure with the new strategy. Feelings of security and confidence come with evidence of student achievement. If teachers continue to see students improving, it is only then that their beliefs and attitudes change. This process is slow and arduous. According to Robb (2008), it takes 3 to 5 years for a teacher to successfully implement a new methodology. Guskey's teacher change model then is the antithesis of most professional development program designs.

Researchers and policy advocates such as Sparks (2002), Guskey (2000), and LoucksHorsley et al. (1998) compiled a list of the five most common professional development models: Individually Guided Observation, Assessment of Teaching Practices, Collaboration Through Involvement in a Development or Improvement Process, Training, and Action Research. The Individually Guided Model is based on the premise that individuals have the ability to identify a need in their practice. They possess the capacity to plan, act, assess, modify, and finally achieve a goal. For example, a teacher may decide that he or she needs 
more knowledge and skills to provide students with authentic and meaningful experiences in nonfiction reading. The teacher may decide to attend a seminar or enroll in a university course. Throughout the learning experience, a savvy teacher will reflect upon practices and ask for feedback from others, which leads to the next model of professional development: the Observation and Assessment of Teaching Practices.

The Observation and Assessment of Teaching Practices Model provides opportunities for teachers to be observed in their practice without experiencing feelings of fear or other repercussions associated with formal evaluations. Reflection, sharing of information, and working together are outcomes most likely associated with this model. For example, after a teacher independently acquires the knowledge of teaching nonfiction reading, he or she may then ask a literacy coach or other colleagues for coaching in relation to skill mastery.

Collaboration Through Involvement in a Development or Improvement Process is a third model. In this model, groups of individuals form teams and work together toward identifying and solving a particular problem. This type of model makes people feel important because of ownership. It also allows them to be involved in the decision making process. An example of the Collaboration Through Involvement in a Development or Improvement Process Model would be if teachers recognized that middle school students were not applying supposedly mastered grammar skills in their writing. In collaborating with one another, the teachers recognized that they were still teaching grammar in isolation and needed to learn a different approach. The collaborative group may research different methodologies, visit other schools, and eventually propose a new model for grammar instruction.

The fourth model, Training, is probably the most utilized in education (Spicer, 2008); it is cost effective and efficient. Ideas can be shared with large groups of teachers. For 
example, Language Arts teachers may receive training on a new writing program. Staff may first watch a video about the program, and then they may do some role-playing. An outside representative may come to the school once a week to provide ongoing training in the newly adopted writing curriculum.

The fifth model, Action Research (teacher as researcher), entrusts teachers to develop a hypothesis regarding their practice and use a scientific approach toward formulating a conclusion. For example, a teacher may want to explore if using classic mentor texts as opposed to contemporary mentor texts produces stronger writers. The teacher conducts an experiment using a control and experimental group. This type of model, Action Research, can be implemented alone, in a group, or with a partner.

All five of the models demonstrate the potential to incorporate the job-embedded approach. All five of the models have the potential to increase the skills and knowledge of teachers. All five of the models have the potential to increase student achievement. All five of these models require a certain level of organizational capacity for success (Berry et al., 2003). All models, even the Individual Learning Model, require vision and leadership, collective commitment and cultural norms, knowledge or access to knowledge, organizational structures and management, and resources. To what extent do any of these five models impact the quality of classroom teachers and improve student achievement remains unclear without programmatic evaluation to explore the organization's capacity for supporting individual change.

Researchers from the Southeast Center for Teaching Quality Center (Center) and the Applied Research Center of Georgia State University (GSU) came together to investigate the capacity of districts and schools to support teacher practices that would increase student 
achievement (Berry et al., 2003). Because this study explored many critical aspects of organizational capacity in low, average, and high performing schools, it is significant to the current study and will be reviewed extensively. It is important to note that each institution reported the study's findings separately and this discussion includes only the findings available during the time this literature review was conducted.

Researchers wanted to know what conditions would promote effective professional development. This was a mixed methods study involving 24 schools located in 12 school districts across six different southeastern states. Researchers at GSU used quantitative methods and the Center utilized the qualitative methodology of case studies to explore the issue. Researchers from the Center collected qualitative data at the district level through interviews of human resource personnel and professional development administrators. Researchers also explored testing information and professional development archives. In each of the 24 schools studied, researchers conducted 60-minute interviews with eight teachers, for a total of over 150 interviews. Vice principals and assistant principals were also interviewed. The researchers coded the data by teachers' responses to the following categories: organizational capacity to support teacher learning, state and local accountability, curriculum and instruction, and perceptions of student learning. Researchers then organized the teacher responses that occurred the most into 24 case memos.

Teachers reported in interviews that "their professional development had been improving as of late with less emphasis on the one shot deals and more increased emphasis on hands on learning about how to teach to the state curriculum standards" (Berry et al., 2003 , p. 36). However, even in the high performing schools, through observation and examination of documents, researchers could not find evidence that the professional 
development experienced by these same teachers showed characteristics of what the body of literature on the topic has deemed effective or high quality. For example, little evidence could be found in any of the low or high performing schools to support a systematic professional development and only a few examples of teachers studying together or teachers observing and providing feedback to one another were uncovered by researchers.

Although the professional development seemed to be improving by focusing more on state standards through the eyes of the teachers, researchers reported that especially in lower performing schools, teachers and administrators were often confused about state test data and professional development lacked the content to help teachers interpret data and change or expand upon instructional practices toward increasing student achievement (Berry et al., 2003).

During professional development experiences, teachers valued two critical scopes of organizational capacity, resources and leadership support, across all 12 districts. Not surprisingly, researchers noted what common sense reveals: that the higher performing schools had more financial resources to allocate toward professional development opportunities. They also noted these high performing schools contained leaders who were influential rather than authoritative in gaining support from their teachers on new initiatives in professional development. Leaders working in high performing schools realized that change is a slow process and the focus should be only on a few concepts. Consequently, teacher and administrator relations were much stronger in the high performing schools and a higher level of trust was noted. These relationships in lower performing schools were weak at best- due to high turnover of teachers and administrators coupled with the pressures placed on both to improve state test scores (Berry et al., 2003). 
Findings from this joint study indicated that the level of organizational capacity, especially leadership and resources, can and does make a difference in professional development, regardless of the model. In the words of the researchers, "Inequities in organizational capacity were evident and profound" (Berry et al,. 2003, p. 15). The high performing schools did indeed receive the best of everything. For example, teachers working in these schools received better resources, taught more affluent students, controlled their own professional learning, experienced more opportunities for formal and informal learning, and were treated professionally by stakeholders. Although the lower performing schools did receive additional state funds, the quality and impact [of the money] was very limited.

In a national report, Designing Effective Professional Development: Lessons from the Eisenhower Program, researchers Garet, Birman, Porter, Desimone, and Herman (1999) surveyed 1,000 teachers to gather evidence from their perspectives on models of professional development that proved most beneficial in classroom practices. These 1,000 teachers were participants in a federally sponsored program called the Eisenhower Program (Office of Educational Research and Improvement, 1994). The program focused on developing the knowledge and skills of mainly science and mathematics educators. As part of this national report, researchers also utilized the case study method by conducting 16 case studies in five states.

Through analysis of the data, researchers identified the following three contextual structural features for professional development: form (sparked by a reform activity), duration, and participation. Additionally, researchers also identified the following features that characterized the processes during professional development experiences: content focus, active learning, and coherence. The analyses also included exploring the relationship between 
teacher outcomes and professional development characteristics, while holding constant the following variables: subject taught, school socioeconomic status, percentage of minority students, school grade levels, teacher certification, years of experience, and gender. Researchers hypothesized that teachers who were engaged in active work, acquired content knowledge, and experienced coherency during professional development would improve classroom practices and increase student achievement.

The most significant finding in relation to this current study is that the model, form, process, and context are all far less important than the number one factor in designing professional development that works: time. This is why perhaps that reform models take credit for success, because they are usually longer and therefore can provide many other attributes conducive to effective professional development such as content, coherence, and active learning (Garet et al., 1999).

Effective professional development is not only complex in theory but remains even more of a complexity in its implementation. The very institutions specializing in academic development continuously struggle with the professional development of its adult life long learners: teachers. 


\section{CHAPTER 3}

\section{METHODOLOGY}

The purpose of this evaluative research study was to systematically and deliberately investigate the capacity of an organization to support and encourage individual participants' learning during a system wide implementation of a site-based, ongoing, job embedded professional development program. Two overarching questions guided the design and methodologies of the study:

1. How do teachers and administrators, working in a small school, perceive the organizational capacity of a school to support the initial implementation of a sitebased weekly job embedded professional development program? In what ways do they differ? In what ways are they the same?

2. What are the different teacher subcultures' perceptions of the organization's capacity to support new learning during the initial system wide implementation of a site-based weekly job embedded professional development program?

Additionally, five sub questions provided a context for the study:

1. How is the school's vision and leadership supported by administrators? Colleagues?

2. How are collective commitment and cultural norms supported during the implementation of the new program?

3. How is knowledge and access to knowledge supported by the organization?

4. How does the organizational structure and management of operations support individual teachers?

5. How are resources allocated and used to support teacher knowledge and skills? 
The past, present, and future experiences of human beings are often defined first by numbers. For example, an individual might begin describing an experience by saying, "When I was 12, wow that was 28 years ago, in 1980 right after the Cold War ended . ." or a person might say, "By the time I am 50, in 2018, I plan to ...." Although human beings may use numbers to make sense of things and put things into perspective, numbers alone are meaningless without an interpretation. To make some sort of logic out of the numbers, rich descriptions of experiences must follow. It also works the other way around. For example, how often does an individual recall an experience without adding some statistics? A person may say, "I will never forget when we eloped! Now that was in 1996-12 years ago." Or, "Look at this picture of me-in that tacky prom dress ... who was I trying to be, Madonna - well yes it was long ago-24 years!" To make better sense out of rich descriptive experiences, numbers are often added. Meaningful evidence of a life cannot be gathered without both approaches. As topics continue to be explored and studies continue to be conducted, it is suggested that the same could be said of research (Seltzer \& Rose, 2006).

Evaluative research studies may be conscientiously and thoroughly explored using quantitative and qualitative methods. An example of the importance of using both methods in evaluation is supported by a situation involving the Kalamazoo school system in the 1970s. The Kalamazoo school system implemented a complicated system of accountability that, in the beginning, received renowned recognition from the nation (Perrone \& Patton, 1976).

The then newly implemented program held the school system accountable by giving fall and spring achievements tests and creating student performance objectives. Additionally, teachers were rated by students, parents, other teachers, and administrators. The Kalamazoo Education Association (KEA) did not agree with the positive attention bestowed upon the 
program. With the help of the Michigan Education Association and the National Education Association, the KEA surveyed the teachers in the accountability program to obtain their perspectives. When results from the closed ended portion of the survey indicated that the majority of teachers surveyed did not feel positive about the new system, the school board dismissed it from the view that the objective of the accountability system was not to make teachers happy.

School board members also accused the teacher's union of influencing teachers' perspectives. In response to this, the school officials were asked to read the teachers' comments to two open-ended questions, which also appeared on the survey. The rich descriptive qualitative data forced Kalamazoo school officials to rethink and value the effect of the accountability system on teachers. The superintendent resigned, and the data was used the following year as a baseline to start anew.

The evaluative nature of the study lends itself to a mixed methodology. According to Patton (1997), "A consensus has emerged in the profession that evaluators need to know and use a variety of methods in order to be responsive to the nuances of particular evaluation questions and the idiosyncrasies of specific stakeholder needs" (p. 267). Utilizing the mixed method approach enabled the researcher to better understand and contextualize data.

Researchers Seltzer and Rose (2006) suggested that a mixed methodology actually contributes to a researcher's thoughtfulness and thoroughness when designing studies. They proposed that a restriction to traditional methods could negatively affect a study by not allowing the researcher to use "analytic thoughtfulness" (p. 477).

The researcher combined three inquiry approaches in the collection of data (Guskey, 2000). These three approaches explored participants' assessments and perceptions of the 
school's organizational capacity to support teachers' individual learning during the implementation of a system wide change to create an ongoing job embedded professional development program.

The three inquiry approaches consisted of teacher participant surveys, teacher focus group interviews, and site administrator interviews. The two-part survey was administered to teachers in order to gather quantitative data that was then analyzed to form homogenous teacher focus groups and to guide the qualitative interview process for each of the teacher focus groups. Additionally, administrators were interviewed to gain evidence and insight on their perceptions of the school's organizational capacity to support the individuals during the newly implemented professional development program. Figure 2 illustrates the research design. From the overall design structure, detailed methods of the three pieces will be discussed.

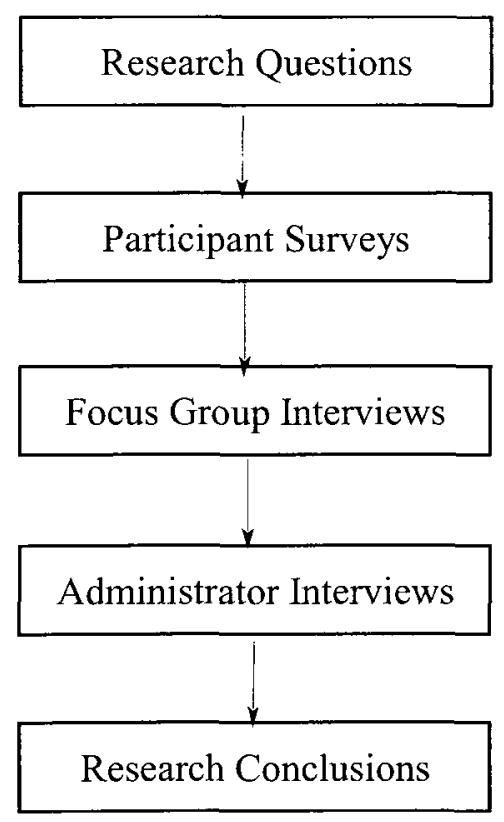

Figure 2. Research design. 


\section{ROLE OF THE RESEARCHER}

Since the researcher, also referred to as the principal investigator throughout this methods section, was employed by the school as a seventh grade teacher during the year (2007-2008) of implementation, she along with other staff experienced the system wide change. However, during the life of this research project the following year (2008-2009), the researcher was extra cautious in ensuring that her new role as researcher in 2008-2009 would have a limited impact on the study. At the recommendation of the dissertation committee, the researcher managed this in several ways.

First, the researcher hired an outside source, Dr. Percy, a professor of teaching and learning. Dr. Percy was objective during all contact with the district and its employees. Because Dr. Percy was unfamiliar with the school district or its staff, he was able to approach the project objectively. Additionally, Dr. Percy was not affiliated with any particular school district in any working capacity such as a classroom teacher or administrator during the timeframe of this study. Consequently, he was able to professionally administer surveys, conduct interviews, and lead the focus groups without biases for or against participants' job assignments. For example, during the focus group interviews and administrator interviews, Dr. Percy could and did not agree, disagree, sympathize, or empathize with how participants responded to the semi structured interview questions. He followed the interview protocol and sometimes asked follow up questions based on participants' responses. Finally, because Dr. Percy's scholarly, research based interests did not include professional development or organizational capacity during the timeframe of this case, he was able to view the topic of study objectively. For example, it is unlikely that Dr. Percy approached the research questions or data collection with a preconceived theory or hypothesis. However, if he did, as a 
professional hired to work on a project, it is unlikely that Dr. Percy would allow his theories to influence his objectivity.

The second way the researcher managed potential impact was to not physically be present on campus during any periods of data collection involving the participants. Third, the researcher trained and employed outside sources to assist the researcher in reviewing, coding, and analyzing the data. These outside sources were employees of a well established creditable business called Elance.com. Jodi Thermozi, experienced in qualitative and quantitative data collection and analysis, acted as team lead. Fourth, to protect participants' identities, the researcher did not listen to the digital recordings generated from the focus group interviews. This qualitative data was emailed to the researcher following the transcription and only after all names had been changed. The three administrators were not identified by their names or positions in Dr. Percy's interview notes. Rather he referred to them as interview 1, interview 2, and interview 3.

\section{Context of The Case}

Certificated teachers and administrators at this small (700 students) kindergarten through eighth grade public school experienced a radical change in their professional development program during the 2007-2008 academic school year. In previous years, professional development assumed the more traditional approach of one-day workshops and seminars scheduled at the beginning and end of the school year. In contrast, this new systemwide method of professional development became a school wide weekly ongoing job embedded endeavor for the teachers and administrators. 
In 2005-2006, 2 years before implementation of this system wide change in professional development, the assistant superintendent and K-4 principal discussed the need for a strategic plan or road map that outlined the school's mission. This became known as the Visions, Values, and Mission (VVM) campaign. The concept of the VVM was discussed at the administrative level for a year. Then in December of 2006, the administrative team began asking for feedback from the staff, by distributing a "How Are We Doing Survey?" in the hopes of better creating a strategic plan for the school. One of the things that came out of that survey was that teachers wanted more time to plan and work together. Although teacher collaboration is one of the attributes of successful schools, time for planning and collaboration was previously not a high priority for this district under past administrators.

In the hopes of beginning to build an organizational culture that would someday support teacher collaboration, an educational consultant conducted a 2-day seminar entitled Collective Leadership in December of 2006. The following topics were presented during the 2-day workshop: school culture, school values, tools of collective leadership, boundary conflicts, and academic visions. Through the work accomplished in the seminar combined with other feedback, it became clear that teachers and administrators desired a vision that would lead to a system wide change in professional development which included teacher collaboration.

In late January of 2007 , the assistant superintendent contacted a few outside facilitators to help with the implementation of VVM. A parent, who was also a consultant, volunteered his services and the formal process began. The original VVM team consisted of 12 people (four administrators, three teachers, three parents, one classified staff, and one board member). This team was responsible for creating the original vision and values of the 
school that later appeared on the school website, $t$-shirts, and banners. As Whyte and Whyte (1991) phrased it, "Although a culture cannot be created by fiat, it is important for an organization to write down and disseminate the basic elements of its culture so as to provide behavioral guidance for members and reference points for further study and debate" (p. 295).

Once the values and visions were created, additional employees joined the team on a volunteer basis. The team was then split into an execution team and a communication team. At the end of the 2006-2007 school year, 16 teachers and 8 parents comprised the VVM. The summer prior to the start of the 2007 school year, the team met to discuss the beginnings of a system wide change in the professional development program that would be more aligned with the schools' values, visions, and mission statement. Specifically the team wanted to create a system wide change that would foster consistent blocks of time when teachers could collaborate. It was decided that the assistant superintendent would step into the role of professional development planner.

The district's vision and values mission statement; "We are committed to learning through active participation in an engaging, inspiring, and rigorous educational experience," provided an overall focus for the professional development program. The program plan included a wide range of topics for exploration during that first year including student goal setting, creating a caring school community, exploring the new English Language Arts framework, analyzing California State Test (CST) grade level data, utilizing Compass Learning (a district purchased software program for measuring student academic progress), exploring the Educational Records Bureau (ERB) Writing Assessment Program, reviewing the math adoption process, Developing Capable People, creating spreadsheets of student 
assessment data, and exploring state standards through vertically aligned teams comprised of K-8 teachers.

Beginning with the first full week of school in late August of 2007, every Monday morning students had late start and $\mathrm{K}-8$ classroom teachers attended professional development in the Large Group Instruction room from 7:50 am until 9:10 am. The two principals aided the assistant superintendent and engaged in collaboration with the teaching staff, while the assistant superintendent remained responsible for organizing, planning, and leading the weekly sessions.

The researcher qualifies the case, in its entirety, as an intensity sampling (Miles \& Huberman, 1994). Intensity sampling is a kind of purposeful sampling that provides an information-rich case but not to the point of extremity (1994). This case provides a wealth of information regarding the perceptions of participants experiencing a new way of doing something, professional development, and the school's capacity to support them through this change process.

\section{ParTicipants}

The participants are described in terms of the district, teachers, and administrators. The selected instrumental case (Creswell, 1998) of the participating district provided the context for teachers as participants and administrators as participants.

\section{District}

The principal investigator was searching for a school that met the following criteria:

- Experienced a system wide change in professional development during the 20072008 academic school year 
- Employed a professional development planner working on site.

- Considered a small K-8 school with less than 800 students.

- Contained a flat organizational structure often associated with smaller districts.

Although the researcher closely examined a number of smaller flat structured schools within southern California, the school that was selected best met the established criteria. By selecting this school, the researcher intended to meaningfully contribute to the existing body of literature that explores system wide changes in the area of professional development. In other words the school was "worthy of study" (Creswell, 1998, p. 63).

One could argue that this school was chosen out of convenience since the researcher was an employee of the district and the school is located relatively close to the researcher's graduate school. However, it was very difficult to find a school which met the initial criteria set by the researcher.

Specifically, the researcher's professional area of interest truly centered around a system-wide change in professional development in a small hometown school setting where staff experienced a shift from traditional to nontraditional methods under the direction of an on site professional developer. Since the passing of the No Child Left Behind Act of 2002, many potential cases had already made systemic changes years prior to the time frame which bound this study, and potential study participants had already received inter district transfers, moved on to other districts, were reassigned to other positions, or left the teaching profession to pursue other career avenues. As mentioned by Creswell, a challenging part of quality case study is deciding from "possible candidates" a case "worthy of study" (1998, p. 63).

Researchers have long been gathering evidence of the advantages small, flatly structured school settings provide for students, teachers, administrators, parents, and 
community. In a sense, smaller schools can be likened to a self-governing community. A flat organizational structure common to smaller schools allows for a varying degree of independence over things like curriculum, budget, personnel, and organization. Administratively, programs can be designed to maximize the benefits of smaller faculty.

Rather than change the criteria for school selection, the researcher chose this school as a case "worthy of study" (Creswell, 1998, p. 63) for the study with the awareness that she would need to clearly define her role as researcher, employ extra measures to ensure objectivity, and bracket researcher bias.

\section{Teachers}

This purposeful sample $(N=24))$ was derived in the following manner. Attendance at professional development meetings was mandatory for all full time and part time K-8 teachers including specialists such as art, music, and literacy teachers. Therefore, all 20082009 returning full time and part time teachers including specialists were invited to participate in the study. This included probationary teachers who were in their first or second year as well as permanent teachers. In-service teachers on full time leave during the 20072008 were excluded from the study. Also excluded from the study were teachers who resigned or were relieved from their positions.

\section{Administrators}

A stratified purposeful sample of the Superintendent, Assistant Superintendent, and the two principals (K-4, and 5-8) represented the administrative subgroup, which served as another unit of analysis in the study. 


\section{INSTRUMENTS}

The instruments for data collection were as follows: teacher surveys, focus group interviews, and administrator interviews. The instruments are described and organized according to the phases in the overall research design.

\section{Teacher Survey}

Each survey contained a number in the upper right hand corner beginning with 1 and ending with 24. A trained research assistant later used these numbers during post coding and analysis of the data to form homogenous focus groups, track responses in the content survey portion, and alert individuals of their respective focus groups. The 2-page teacher survey was divided into two sections. The first section contained the participant profile. The second section contained the Questionnaire to Assess Organization Support (Guskey, 2000). The first section, the participant profile, was designed to gather a range of demographic information, which the researcher analyzed to form the homogenous focus groups. Isaac and Michael (1997) reported that when designing a survey, "necessary and sufficient characteristics of the respondent must be collected at the time the survey is administered and on which the data analysis will be based" (p. 137). These characteristics may include occupation, related background, life history, and demographic factors. In a programmatic evaluative study conducted by Marriott (2003) teacher profile criteria included total years of teaching experience, grade level, school's Academic Performance Index (API), and credentials.

Fessler and Christensen (1992) provided a data driven Teacher Career Cycle Model that provides a "foundation to understand the stages that teachers experience in their careers and to assess and guide their professional growth and development" (p. xi). The Teacher 
Career Cycle Model shows how components of an individual's personal environment, organizational environment, and career cycle all influence the career cycle of teachers. Because of the nature of the research questions, the participant profile included a combined criteria adapted from Isaac and Michael (1997), Marriott (2003), and Fessler and Christensen (1992). Specifically, the participant profile demographics included the following: total years teaching (within and outside the district) at the start of the 2007-2008 school year, level of education, teacher career stage (Fessler \& Christensen, 1992) and consumer type (Joyce et al., 2002; see Appendix A).

The second section of the survey design employed Guskey's (2000) proposed Questionnaire to Assess Organization Support which included 12 statements that assessed the five dimensions of organizational capacity: vision and leadership, collective commitment and cultural norms, knowledge and access to knowledge, organization structures and management, and resources (0’Day et al., 1995). For example, a statement assessing resources was as follows: The resources required to implement new practices are considered during planning and built into our school budget. Participants responded to the 12 survey items using a Likert-type scale in which: Strongly disagree $=1$, Moderately disagree $=2$, Slightly disagree $=3$, Slightly agree $=4$, Moderately agree $=5$, and Strongly agree $=6($ see Appendix B). The higher the rating given to a statement, the greater level of organizational support. In the event of a low participant ratio, the 6-point Likert type scale may be collapsed into two over all categories: agree or disagree. Responses to these two overall categories then will guide the focus group interviews. 


\section{Focus Group Interviews}

Focus groups (Krueger, 1988) emerged from the quantitative analysis of the participant profile. The focus groups included grade level teachers along with any specialists who completed the inital survey. The focus groups excluded any teacher who did not participate during phase one (survey) of the procedures. Each focus group was considered a unit of anlysis. Once the homogenous focus groups were formed, based on response patterns in participant profiles, a descriptive item-by-item analysis of the Questionnaire to Assess Organization Support (Guskey, 2000) guided the content for the focus group interviews. The purpose of the focus group interviews (Patton, 1990) was to add context to the quantitative analysis findings through gaining an understanding of different subgroups' conceptions and perspectives on the support at the organization level of the professional development program. Guskey (2000) reported, “An increasingly popular means of gathering information on organization support and change is in the use of focus groups" (p. 170). Focus groups can reflect subgroup behavior; reveal patterns in group interactions, and can stimulate productivity of others (Isaac \& Michael, 1997). Frechtling and Sharp-Westat (1997) concurred that, "The hallmark of focus groups is the explicit use of the group interaction to generate data and insights that would be unlikely to emerge without the interaction of the group" (p. 8). However, conducting focus group interviews also has drawbacks such as the possibility that one participant will control the conversation and shut out more hesitant speakers. Also, participants in any given focus group may not actually attend their group session, reducing the number of voices and anticipated interaction within a focus group. This could defeat the purpose of group interaction. 
Krueger (1988) recommended that focus group sessions should last approximately 40 minutes and contain four to six participants. Researchers Salant and Dillman (1994) recommended focus groups with 8 to 10 participants. Krueger (1988) also suggested that for every demographic variable, two focus groups should be formed. Since the participant profile initially contained five demographic variables, the researcher anticipated the formation of ten focus groups through homogeneous sampling.

\section{Administrator Interviews}

All four site administrators, the K-4 principal, 5-8 principal, assistant superintendent, and superintendent were invited to participate in individual, semi structured face-to-face interviews. Although all four administrators initially volunteered to participate in the study, only three completed the interviews. The sessions were scheduled to last approximately 1 hour each and included the option of concluding early or continuing forward, based on participant responses and unexpected circumstances (Weiss, 1994). Each administrator was asked 10 open-ended mirrored questions, as recommended by Creswell (1998). Each session concluded with the interviewer posing, "What didn't I ask about that I should have?" (Mertens, 2005).

\section{ETHICAL STANDARDS}

The researcher received approval on April 1, 2009, from the Internal Review Board (IRB) at both affiliated universities. All participants in the study were volunteers and signed consent forms. 
The teacher surveys were designed to assure teachers' anonymity. The surveys were placed in a sealed envelope and directly mailed to the researcher's outsource team for data analysis.

Participants in focus groups and one-on-one interviews were guaranteed their confidentiality verbally and in writing beforehand. They were also told that the interviews would be audio recorded for transcription purposes only. An outside interviewer not familiar with the school or its personnel conducted the interviews and forwarded the files to transcription, where names were changed. For the administrator one-on-one interviews, participants could still participate if they did not feel comfortable being audio recorded. The interviewer's notes would then be forwarded to the outsource team.

\section{VALIDITY AND RELIABILITY}

The responsibility of the researcher is to lessen the chance of error. All data collection procedures are vulnerable to mistakes in methods and measurement (Patton, 1997). A researcher cannot eliminate the possibility of flaws in the methodology. Regarding validity and reliability, the principal investigator included the following processes in the design of the research:

1. Member checks were performed twice during the project to increase credibility and validity. During interviews, the interviewer restated information for accuracy. After the completion of the study, participants reviewed a summary of key findings.

2. Triangulation of the surveys, focus groups, field notes, transcriptions, and administrator interviews.

3. The researcher planned inquiry strategies that would best bring out the information desired for the study. 
4. The teacher survey was field tested on teachers who closely matched the sample. The individuals doing the field testing were those teachers who took part in the system wide change during 2007-2008 but were not eligible for the study. The field testers shared responses offering insightful modifications.

5. Part two of the survey, the Questionnaire to Assess Organization Support (Guskey, 2000) was an instrument specifically designed to measure support at the organizational level by Guskey, a well-known researcher and leader in the field.

6. The 10 administrator questions were reviewed by an assistant principal and principal who formerly worked at the site but moved on to another district. The reviewers shared responses offering suggestions for modifications.

7. An outside source along with Dr. Percy reviewed the focus group interview questions and suggested changes to produce more group interaction and thoughtful responses during the focus group interviews.

8. For the qualitative data from the focus group interviews and administrator interviews, the data was analyzed by a second researcher. A second reader was also employed to review the data for inter-rater reliability.

\section{Procedures}

The data collection process was conducted in two phases. While phase one involved administering the teacher surveys, phase two involved conducting the focus groups, and phase three involved interviewing site administrators.

\section{Phase One}

A short 10-minute presentation was given to introduce the study to staff. Procedures and time commitments were made very clear to the potential volunteers. The returning teacher population $(N=55)$ from the 2007-2008 academic year who met the criteria were invited to complete the two-section survey. Consent forms were distributed at the end of the presentation. Because the researcher did not want the population to feel pressured into volunteering, and desired that participants sincerely follow through with the entire process, 
teachers and administrators were asked to think about it. Teachers were then informed of a follow up meeting in which they could return the signed consent forms and participate in the survey. Administrators were asked to forward their signed consent forms to Dr. Percy, the objective, outside source employed to lead the interviews.

One week after the initial presentation, the follow up meeting for those teachers interested was held after school, in the Large Group Instruction room. Participants signed the written consent forms. The numbered surveys were distributed and administered by another researcher, Dr. Percy, a professor of teaching and learning. Prior to this, the principal investigator (main researcher) met with Dr. Percy to review directions, coordinate a schedule, and prepare a script. The script, which Dr. Percy read aloud to the group, provided the rationale, context, and directions (Marriott, 2003) for administering the survey (see Appendix C).

To help participants better identify their teaching career phase and consumer prototype, they received a hard copy, yellow one-page simple reference guide adapted from Fessler and Christensen (1992) and Joyce et al. (2002; see Appendix D). Participants were reminded that all responses would remain anonymous, and the participant profile data would only be used to form the focus groups. Participants were also reminded to record the number located at the top right hand corner of their survey. Dr. Percy reminded participants that this number would be used to identify their particular focus groups. Although the principal investigator was not physically present at this session, she was available by telephone in case questions arose during the proceedings. Upon completion of the surveys, participants placed them in a preaddressed manila envelope. Dr. Percy sealed the envelope and mailed it to an outside source for post coding analysis. 


\section{Phase Two}

After completion of the quantitative analysis of the surveys from phase one, focus groups were formed based on the participants' responses to the participant profile. The data analyst assigned numbers one through seven to each homogenous focus group. These numbers were only used to distinguish the focus groups and held no ordinal value. A blanket email was sent to all staff which listed the formation of focus groups according to participants' individual survey numbers. Focus group meeting dates and times were also announced in this same email. The day before a scheduled focus group meeting, the researcher sent another blanket email to staff asking participants to confirm attendance to Dr. Percy, the interviewer, via email. The researcher also reminded focus group members to bring any artifacts from the 2007-2008 professional development program to the interviews. The researcher intended for the artifacts to enhance participants' responses to questions and encourage them to bracket the context of the interviews to the 2007-2008 school year.

Semi structured open-ended questions were used as the interview format for all focus groups. The content for each focus group was based on the quantitative analysis of participant responses to the second portion of the survey, Questionnaire to Assess Organization Support (Guskey, 2000). Therefore, some interview questions were the same and a number of questions were different. By reviewing the results of the descriptive statistical analysis from the second portion of the survey, the researcher developed an Interview protocol (Creswell, 1998) for each of the initial seven focus groups (see Appendix E). Focus group one contained four participants, focus group two contained five participants, focus group three contained four participants, focus group four contained four members, and originally focus groups five, 
six, and seven contained two participants each. The focus group interviews were audio recorded and field notes were taken as needed by the interviewer, Dr. Percy.

According to Patton (1990), focus groups provide an efficient method for the researcher to record multiple voices that hold a collective or shared meaning. However, the nature of a focus group can also encourage one voice to dominant and exclude other shyer people in the group. To protect against this, the interviewer encouraged all to participate and made each member feel they had something worthwhile to contribute. A phrase he used to begin each interview was "Everyone's thinking matters." The interviewer also arranged tables and chairs to foster group participation.

Dr. Percy, in the role of interviewer and researcher, traveled to the school on three separate occasions in the spring of 2009. One participant whose demographic profile did not match any of the focus groups was interviewed separately on May 13th. This interview took place during the participant's lunch break and lasted approximately 20 minutes. Back-to-back focus group interviews were conducted starting at $3: 20 \mathrm{pm}$ and 4:20 pm. Two focus groups, subgroups one and two, were interviewed on May $13^{\text {th }}$. In the first group, only one participant of the confirmed four attended the interview session. The interview proceeded as planned and the interviewer was able to capture the teacher's voice in response to the system wide change in professional development. The second focus group contained four participants. On May $20^{\text {th }}$ two more back-to-back focus group sessions were conducted as planned. In subgroup three, two out of the four confirmed participants attended. In subgroup four, three participants out of four were in attendance. The remaining three focus groups labeled five, six, and seven scheduled for June 3rd, initially contained only two participants each. 
Because the design of the research called for focus groups and the principal investigator was interested in the group interaction, a decision was made to collapse the remaining three focus groups into one group of possibly six participants. Combining the pairs would also decrease the likelihood of having one of the original pairs or neither of the pairs show for the interviews. On June $3^{\text {rd }}$, the final focus group (a combination of the pairings that emerged which originally were labeled subgroups five, six, and seven) was held and all six confirmed participants attended.

Because the principal investigator was interested in generating thoughtful, honest responses and wished to make the participants feel at ease, all participants were emailed the set of questions in advance. All focus group sessions were held in classroom 124, a stand alone relocatable situated away from the flow of school pedestrian traffic. As volunteers gathered, Dr. Percy in the role of interviewer explained the procedure. He also provided each participant with a copy of the interview questions. Dr. Percy reminded the participants that the sessions would be audio recorded, and they had the option of listening to the recording. Participants were informed that their responses would only be presented in summary form and therefore would remain confidential. To ensure credibility, the interviewer reviewed any field notes with the focus groups and made sure the notes accurately reflected each focus group's position (Mertens, 2005). Dr. Percy's field notes were housed on his password protected computer until they could be prepared and coded for analysis.

\section{Phase Three}

Phase three of the data collection process involved semi-structured individual face-toface interviews with three out of the four site administrators: the K-4 principal, the 5-8 
principal, and the Assistant Superintendent. Each administrator signed consent forms that were returned to Dr. Percy prior to the interviews. Although the Superintendent signed a consent form and wanted to participate in the study, a family emergency along with data collection time constraints prevented this from happening.

The principal investigator developed an interview protocol (Creswell, 1998). The questions were adapted from a protocol designed by Guskey (2000) and centered on the five dimensions of organizational capacity: vision and leadership, collective commitment and cultural norms, knowledge or access to knowledge, organizational structures and management, and resources (see Appendix F). The interviewer, Dr. Percy, used an identical list of questions to guide each session. Because the principal investigator was interested in generating thoughtful, honest responses and wished to make the participants feel at ease, the three administrators were emailed the set of questions in advance.

Dr. Percy, as interviewer, contacted via email and telephoned each administrator to establish a convenient interview time and location. Dr. Percy conducted back-to-back interviews with the three administrators on May 20, 2009. The interviews were held in the respective administrator's office and lasted approximately 1 hour each. Administrators were reminded that they could opt not to answer any question that made them feel uncomfortable. Initially the principal investigator had planned to audio record the interviews; however, all three administrators declined to have their sessions audio recorded. Although the administrators declined to be audio recorded, the interviewees still provided thick, descriptive data from this stratified purposeful sample related to organizational support through the lens of the administrative subgroup ( $n=3$ ), which directly affects an education system's ability to support organizational change at the school and district level. 
The interviewer took extensive field notes in order to accurately capture the administrators' voices. To ensure credibility, the interviewer, Dr. Percy, read back his notes from the interview protocol and asked participants if the notes accurately reflected the conversation (Mertens, 2005). Upon the completion of the interviews, Dr. Percy met with the principal investigator to review the field notes. These documents were then reformatted in preparation for data analysis and stored as Microsoft documents on the principal investigator's password protected personal computer.

\section{LIMITATIONS OF THE STUDY}

All evaluative studies are contextual in nature and therefore may not be generalizable to other evaluative studies. However, because teachers working in public schools experience benefits and constraints of the educational system in similar ways, similar subcultures may be formed within any school's overall culture. In other words, employees working in the same type of system will most likely act and react in similar fashion (Senge, 2006).

Although it is atypical to have four administrators working on site at such a small school, after reviewing the body of literature, the researcher asserts with confidence that lessons can still be learned from these administrators' perspectives. For school leaders everywhere, it is a unique opportunity, one rich in potential knowledge, to observe and study the experiences of working closely with staff during a system's level change.

At any given time, public institutions may experience high turnover rates of its employees. During the past 5 years, from 2004 to 2009, the district employed on average about 55 full and part time teachers. This number also includes specialists. Since 2004, four 
administrators have also been employed by the district. At the end of the 2007-2008 school year, several teachers applied and were granted a year's leave of absence for the 2008-2009 school year. Others retired, resigned, or were asked to leave the district. These previous examples of staff fluctuation, from one school year to the next, could also be considered a limitation of the study as it directly affects the number of potential participants.

The researcher, in the role of teacher, experienced the initial 2007-2008 implementation of the professional development program and consequently could be subject to certain biases during the project. In an attempt to limit researcher bias, the principal investigator and author of this study, as strongly recommended by the dissertation committee, employed a research team of objective sources to administer surveys, conduct all interviews, postcode and enter data into SPSS, reread qualitative data, and review qualitative analysis. The researcher also bracketed potential biases by remaining professional and separating her current independent researcher role from that of a teacher who experienced the initial implementation of a new professional development program.

During the data collection phase of this study, the state of California was experiencing a severe economic budget crisis, undoubtedly one of the worst in history, which may have affected participation numbers and the responses of those individuals who volunteered for the study. The public school system suffered severe budget cuts and many tenured teachers employed by the state of California lost their jobs. Although this particular district was considered an excess tax district at the time of the study, it still experienced a reallocation of funds and some budget cuts.

The timing of the data collection, May $13^{\text {th }}$ through June 3 rd, in relation to the traditional school year may also have limited the study. Participants involved in the study 
may have responded more positively or negatively depending on their individual feelings toward the end of the school year. This school site was also in the process of preparing its campus for a major renovation. Consequently, teachers and administrators had the additional responsibilities of preparing for demolition and construction to begin the day after school ended. Exhaustive efforts of school teachers and administrators toward the end of any school year may decrease the number of volunteers for a study.

The purpose of this study was not to unmask the truth. After all an underlying condition of any truth is that it is only the partial truth. Human responses, interactions, and behaviors often are greatly affected by many conditions and circumstances. As Marriott (2003) noted, school personnel responses can be affected by educational philosophy, exhaustion, economic hardship, satisfaction or dissatisfaction on the job, relationships with colleagues, or other personal and professional challenges.

The purpose of this study was not to reveal errors or lay blame on any one subculture of the population. On the other hand, the main researcher did not seek to position any one subgroup on a pedestal. Additionally, the researcher did not design the study to evaluate different subcultures based on the perceptions and responses of other subcultures; this study was designed to investigate how teachers and administrators perceived and evaluated the capacity of a small institution to support individual change during a system wide implementation of a newly designed professional development program.

\section{Data Analysis}

The data analysis was approached and conducted through quantitative and qualitative methods. The quantitative approach was applied to the two-part teacher survey data and the 
qualitative approach was applied to the data collected through the one-on-one teacher interview, focus group interviews, and administrator interviews.

\section{Quantitative}

An assistant analyst, unfamiliar with the participants or school district, was employed by the main researcher to first sort and code the quantitative data from the participant profile section of the participant survey. All surveys were identified by a number, so that the assistant analyst could place them in the appropriate focus group after the initial analysis. Post coding was used to assign codes to the participant profile categories after the data were collected (see Appendix G for post coding). After the teacher profile data were sorted and coded, then the assistant analyst tabulated the data by running frequency counts, percentages, proportions, the mode, and creating bar graphs using the software SPSS. Erickson (1998) stressed the importance of descriptive statistics to define what is different and what is the same between various groups. From the tabulation of the teacher profile data, the original seven homogenous focus groups were formed.

The assistant analyst organized the numbered surveys into each respective homogenous focus group. A second analysis was then conducted on the precoded data from the Questionnaire to Assess Organizational Support (Guskey, 2000). Because each item of the questionnaire addressed a different element of an organization's support, responses were analyzed and reported separately (Guskey, 2000). The assistant analyst performed a descriptive line-by-line item analysis using measures of central tendency (median), interquartile range, overall range, and variation. The results of this quantitative analysis drove the qualitative data collected through each of the respective homogenous focus groups. 


\section{Qualitative}

Upon data collection from the focus groups and administrator interviews, the researcher followed the Data Analysis Spiral proposed by Creswell (1998) for the qualitative analysis: data management, reading and memoing, and describe, classify and interpret. However, throughout several steps, the researcher moved back and forth between the different spirals.

\section{Data Management}

All aspects of data managing were done immediately following each data collection procedure. In an effort to take an organized and systematic approach to the analysis, every piece of data was numbered. This allowed the researcher to keep better track of the text. From the five focus group interviews, the one-on-one teacher interview, and three administrator interviews, Dr. Percy's notes were emailed in nine separate word documents to the principal investigator. All files were saved onto the principal investigator's password protected computer. As a precaution, the files were also saved on a memory stick. Additionally, all documents were printed out in hard copy.

Focus group documents were labeled with the respective focus group number along with the date and time of the session. The one-on-one teacher interview was labeled as such and stored along with the focus group documents in a desktop file folder labeled FGINT (focus group interviews). Documents from the administrator interviews were placed in a desktop file labeled ADMINT (administrator interviews). Because the principal investigator wanted to further ensure the anonymity of the digitally recorded teacher participant voices, she instructed Dr. Percy to directly email the focus group digital recordings along with the 
one-on-one teacher interviews as MP3 files for transcription to an outside source. The transcriber changed all names used in transcription before emailing the documents back to the principal investigator. The transcripts were printed in hard copy and also remained on the principal investigator's password protected computer until the next step in the qualitative analysis, reading and memoing.

\section{REAdiNG AND MEMOING}

For all three methods of data collection, the researcher viewed all data collected to get a sense of the whole picture (Creswell, 1998). First, the researcher skimmed over the data and jotted first impressions of the data on the documents. She then carefully read the inquiry data set (focus group transcriptions, Dr. Percy's field notes, and administrator data) quick writing more responses and questions on the hard copies. The researcher also highlighted important quotes for future use. As the researcher carefully read the data set again paying attention to her previous jottings, she recorded more analytic responses into a separate journal.

\section{DESCRIBE, Classify, AND INTERPRET}

The researcher began by using case analysis to describe and classify the data from each focus group, one-on-one teacher interview, and administrative subgroup separately. All text concerning each group was kept together. The researcher first described the data in detail. Data collected from each source was segmented and labeled by creating descriptive names for the subject matter. The researcher then grouped together any of the labels similar in nature to form categories. Within each focus group, the one-on-one teacher interview, and administrative subgroup, the data was reduced to themes that varied in number around the overarching research questions as recommended by Creswell (1998). In many cases, these 
themes then evoked further questions which are listed at the end of each within case analysis. The data was also analyzed by an assistant researcher for objectivity and consistency. The researcher employed another reader to review the data for interrater reliability.

The researcher then used cross-case analysis to compare and contrast the themes, as they related to the two overarching research questions, across the five focus groups, the oneon-one teacher interview, and the administrative interviews asking, "How are the themes the same, how are they different?" The cross-case analysis also generated further inquiry posed at the end of each across case theme. The data generated by the cross-case analysis was also analyzed by an assistant researcher for objectivity and consistency. The researcher employed another reader to review the cross-case data for interrater reliability.

In summary, the findings produced from the analysis were organized thematically around the two overarching research questions of this study. The interpretation was composed as a rich, descriptive and detailed narrative which collectively captured and blended together the participants' voices to further support each theme. The findings within each case are preceded by a participant profile composed in narrative form. Additionally, three tables were included to represent and potentially enhance the reader's understanding of the participant demographic variables 1 , years spent teaching, 2, teacher career stage, and 3, career description. The final project includes key findings from the analysis. These key findings were arranged thematically around the two over arching research questions and the contextual sub questions. Key findings were composed in narrative form and include participants' voices to support the findings. The final project also included recommendations for practice and research written in narrative form. 


\section{CHAPTER 4}

\section{FINDINGS}

The following chapter explores teachers' and administrators' perceptions of a K-8 school's organizational capacity to support a system wide change in professional development. The findings presented in this chapter will add to the evidentiary base (Steinaker \& Bustillos, 2007) begun in Chapter 2: review of the literature. The data analysis addresses the two overarching research questions, raises additional questions, and provides an expanded understanding of an organization's capacity to support teachers and administrators during a system wide change in professional development.

The chapter is organized into the following sections: background, participant teacher surveys, summary of descriptive analysis, overview of focus groups, subgroup participant profiles, each followed by a qualitative analysis identifying themes within each subgroup, cross case analysis, and an overall chapter summary.

\section{BACKGROUND}

Teachers participated in homogenous focus groups formed by the results of the participant profile survey. The questions for each focus group were formulated by the result of a line by line item analysis of the Questionnaire to Assess Organizational Change (Guskey, 2000). Because of this, some questions were the same and some were different in each focus group interview session. Each focus group interview lasted from approximately 30 minutes to 60 minutes. 
All interviews were conducted by an outside researcher who was a professor of teaching and learning. The interviewer used a protocol developed by the main researcher but because the interviews were semi-structured, he also had the opportunity to ask questions not on the protocol in an effort to gain a better insight into the participants' perceptions.

The purpose of the survey was twofold: first, to provide quantitative data that would describe the population and identify homogenous groups in terms of teaching experience and career stage; second, to provide a content analysis on organizational capacity in which the researcher developed an interview protocol based on the results of the survey. These interview questions were designed to explore more deeply the aspects of organizational capacity.

Because of the small sample $(N=24)$ which produced only a few cases (five focus groups), the researcher did not intend to utilize the results in the traditional quantitative approach. Rather these cases are being presented to show how certain subgroups of the population perceived critical aspects of organizational capacity during a system wide change in professional development.

\section{Participant Teacher Surveys}

The survey data was collected anonymously. The first section, the participant profile originally consisted of five demographic variables: (a) years teaching, (b) education level, (c) consumer type, (d) teacher career stage, and (e) career description. The second part, the Questionnaire to Assess Organizational Support (Guskey, 2000) consisted of 12 closed ended questions that participants responded to using a Likert type scale. The responses were post- 
coded, tabulated, and analyzed to create the homogenous focus groups and provide a baseline for the focus group open ended interview questions.

Response frequencies were based on the participation of 24 teachers from a K-8 school district. Following an initial analysis of the surveys, the original five variables listed in the participant profile section of the survey, (a) years spent teaching, (b) education level, (c) consumer type, (d) teacher career stage, and (e) career description, were narrowed to three demographic variables based on their potential significance to the study: (a) years spent teaching, (b) teacher career stage, and (c) career description. The remaining two variables, consumer type and years of education, were excluded when forming the homogenous subgroups. Because this study only involves participants working in the public education system, the researcher selected the three demographic variables, which represented attributes unique to individuals working in such systems.

The system wide change in professional development under study was designed to meet the needs of beginning and veteran teachers. Exploring the data in relation to teachers' total number of years in the profession was relevant to distinguish the potential differences in the perceptions of experienced and inexperienced teachers. Rather than assign categories such as (a) 1-3 years, (b) 4-7 years, the researcher intended for the categories to be defined through the analysis.

The participant data for the total number of years spent teaching were as follows: 3 teachers at $0-5$ years, 12 teachers at $5-10$ years, 3 teachers at $10-15$ years, 5 teachers at $15-$ 20 years, and 1 teacher at 20-25 years. As represented in Table 3, 50\% of this sample was comprised of teachers with 5-10 years of experience. 
Table 3. Years of Teaching

\begin{tabular}{lccccc}
\hline Years of teaching experience & $0-5$ & $5-10$ & $10-15$ & $15-20$ & $20-25$ \\
Frequency count & 3 & 12 & 3 & 5 & 1 \\
\hline
\end{tabular}

The teacher career stage A was predetermined by the researcher as induction, stability, and career wind down. As shown in Table 4, 11 participants described their career stage as induction, 10 participants identified stability as their career stage, and 2 participants described their stage as career wind down. One participant did not respond to the question.

Table 4. Teacher Career Stage $A$

\begin{tabular}{|c|c|c|c|c|c|}
\hline & & Frequency & Percent & $\begin{array}{c}\text { Valid } \\
\text { Percent }\end{array}$ & $\begin{array}{c}\text { Cumulative } \\
\text { Percent }\end{array}$ \\
\hline \multirow[t]{4}{*}{ Valid } & Induction & 11 & 45.8 & 47.8 & 47.8 \\
\hline & Stability & 10 & 41.7 & 43.5 & 91.3 \\
\hline & Career Wind Down & 2 & 8.3 & 8.7 & 100.0 \\
\hline & Total & 23 & 95.8 & 100.0 & \\
\hline Missing & 9 & 1 & 4.2 & & \\
\hline Total & & 24 & 100.0 & & \\
\hline
\end{tabular}

Converted to percentages, $91.33 \%$ of the sample was not planning on ending their careers during the year of the system wide change, 2007-2008.

The description of how participants classified themselves within their career stages was also predetermined by the researcher as competency building, enthusiastic and growing, and career frustration. As shown in Table 5, 3 participants selected competency building; 18 categorized themselves as enthusiastic and growing, while 3 selected career frustration. Percentage wise, only $12.5 \%$ of the sample selected career frustration to describe their career 
stage. These two variables are significant to the study as the model for the system wide change in professional development was created for all teachers at various career stages.

Table 5. Description Within Career Stage

\begin{tabular}{lccrc}
\hline & Frequency & Percent & $\begin{array}{c}\text { Valid } \\
\text { Percent }\end{array}$ & $\begin{array}{c}\text { Cumulative } \\
\text { Percent }\end{array}$ \\
\hline Valid Competency Building & 3 & 12.5 & 12.5 & 12.5 \\
Enthusiastic and Growing & 18 & 75.0 & 75.0 & 87.5 \\
Career Frustration & 3 & 12.5 & 12.5 & 100.0 \\
Total & 24 & 100.0 & 100.0 & \\
\hline
\end{tabular}

In forming the homogenous subgroups, the researcher reviewed again the three demographic variables most significant to the study: (a) years of teaching, (b) career stage, and (c) description within career stage. After the initial analysis, seven focus groups were originally formed. Focus group 1 contained four participants, focus group 2 contained five participants, focus group 3 contained four participants, and the remaining focus groups labeled 5, 6, and 7 all contained two participants each.

Once the homogenous subgroups were formed, the researcher analyzed the results of the survey content portion, Questionnaire to Assess Organizational Support (Guskey, 2000), using the following criteria in developing open ended follow up questions for each focus group interview. The researcher divided the responses into two categories: agree or disagree. The collapsing of categories on the response continuum was a result of the small sample $(N=$ 24). Responses indicating strongly, moderately, or slightly agreeing with a statement were placed in the agree category. Responses indicating slightly disagree, moderately disagree, and strongly disagree were placed in the disagree category. Within each subgroup, if over 50\% 
agreed or disagreed, the researcher created a follow-up question for interviews. For example, in the first homogenous subgroup containing four participants, three out of four participants had to either agree or disagree with a statement in order for a follow-up question to be drafted.

\section{SUMMARY}

The results of this descriptive statistical analysis are limited to the perceptions of teacher participants with various levels of experience and various teacher career stages. The results described the sample population and provided only a baseline for how these teachers perceived the first year of a system wide change in professional development. The intent of the participant survey was not to produce findings that could be generalized to any other group other than the one involved in the study. Opposed to acting alone such as in a quantitative study, the survey served as one of several instruments in a mixed methodology

providing a baseline and direction for the second part of the methodology, the qualitative data collection and analysis toward finding answers to the research questions.

\section{OVERVIEW OF FoCUS Groups}

The homogenous focus groups were designed to bring different subcultures of the teaching profession together and explore in depth their perceptions of the school's organizational capacity to support a system wide change in professional development. An outside interviewer was enlisted to conduct the focus groups and facilitate the discussion. He used an interview protocol and varied from the protocol when appropriate to gain significant data for the study. 
Five focus groups met during the months of May and June of 2009. All focus groups were audio recorded and transcribed verbatim. These focus groups were in response to the criteria described in Chapter 3 and the analysis of the participant portion of the teacher survey described earlier in this chapter, Chapter 4.

Participants in these five focus groups responded without fear and candidly about their experiences during the system wide change in professional development. To protect their identities, individual respondent voices were blended together and captured collectively to produce the narrative. Also, to protect participants' identities, only generalized profiles of each focus group member are given based on how each individual answered questions one, four, and five of the participant profile survey.

In some cases, participant responses better answered other interview protocol questions than the one specifically asked by the interviewer. These responses were moved within the narrative to where they would best contribute to the overall discussion. As with all discourse, discussions can at times move way from a selected topic. The researcher edited participants' dialogue that did not pertain to the study. Finally, to clarify vague pronouns or unclear words and phrases, the researcher added text enclosed in [ ] to produce a more compelling and easier to understand narrative.

The questions for each focus group were developed from the content analysis portion of the survey and overall corresponded to the research questions. The interviewer informed participants of how they, as a group, responded to each of the 12 statements on the Questionnaire to Assess Organizational Support (Guskey, 2000). For example, the interviewer would say, "Three out of four in your group slightly, moderately, or strongly agreed with the following statement." This was done for each question in order to make 
known to participants how each subgroup felt as a whole. Refer to Appendix E for the questions used in each focus group and the one-on-one teacher interview.

\section{Focus Group ONE}

Participants in this focus group perceived their careers as enthusiastic and growing. According to the Fessler and Christensen's Teacher Career Cycle Model (1992), teachers in this focus group identified their career stage as one of Induction. All members of the focus group were upper grade teachers at the K-8 school. Within the group, one participant was a resource teacher.

One participant out of the four slated for this homogenous focus group attended the session. The interview proceeded as planned, and the researcher was able to gather data significant to the study.

Theme One: A well planned program designed only by administrators may not impact all members of the target population.

The participant felt that the "administration team" planned the professional development program during the initial year of implementation. When asked to define the administration team, the focus group member initially identified the superintendent and the assistant superintendent as the "team." However, throughout the interview it is important to observe that the participant did not mention the superintendent again but frequently perceived the assistant superintendent as "in charge of activities."

According to this focus group member, teachers were "never consulted" to select, plan, or prepare weekly "study topics" for Monday mornings. All weekly topics were "predetermined by the assistant [superintendent]." The topics were aligned to the district 
school calendar. For example, the week parent conferences began, the "topic related to conferencing." In May of that year the participant recalled, "focusing on testing" as the state testing started the following week. The participant noted the accuracy of his/her recollection by confirming, "It's relevant to the school calendar that's for sure."

When prompted to elaborate on the outcome of participating in a weekly professional development program in which the learner is "never consulted" and all topics are "predetermined" by someone else, the participant identified the following consequences.

You take what you can out of it.

If it pertained more to me, I would get more out of it.

I feel that there is some wasted time.

I am not engaged.

I feel isolated and really not a part of it.

I would grow instead of just sitting for the length of time I have to sit.

Overall the respondent viewed the weekly professional development meetings as "thought out and planned." S/he observed that "clearly our assistant superintendent sits down and does some planning." The participant also noted that teachers usually received an agenda relating to Monday's topic toward the end of the week. The agenda was often an "email page" long and included a "list of materials" teacher would need to bring to the session.

Although the respondent perceived the events of professional development as "thoughtfully planned," and credited the assistant superintendent for "planning them [professional development sessions] well" the topics did not pertain to his/her field of expertise. For example, the participant could not provide an example of an activity 
throughout the year that was not thoughtfully planned. However s/he could not recall an example of an activity, which directly pertained to his/her classroom responsibilities.

The participant believed that the professional development program and activities were aligned to and supported school level efforts. For example, "test scores" seemed to be a "reoccurring topic" in the Monday morning sessions. The participant stated, "maintaining our already high test scores is definitely a school wide effort and district goal but has little to do with my students' learning." The respondent also noted that the one time s/he could have benefitted from a professional development "pull out" session, his/her team of teachers was excluded. When asked to expand upon the experience, the participant shared the following:

Once during that year we had a staff developer from Columbia pull out several teachers from a Monday morning session to work on our new school wide writing program through the Teachers' College in New York. My team of teachers and I were not offered that opportunity. We were never pulled out and trained, even though it was a school wide mandatory program. From what the classroom teachers have shared with me, our population of students could have really benefitted from us learning the program. So, I think it's a shame. You know the one time I could have used what they were offering.

The following questions arise from this first part of the discussion:

1. How might this participant's experiences have been different if $s /$ he was included in the planning process?

2. What other members of the target population may have been excluded? What are their perceptions?

3. How could professional development planners provide instruction more aligned with the members of a target population?

4. How might future professional development be changed to ensure that learners are actively engaged?

Theme Two: Teachers may define a norm of continuous improvement as always doing something new. 
It is interesting to observe that when asked to comment upon the norm of continuous improvement within the district, the participant confidently remarked, "Oh, yes, we are constantly doing something new." S/he further elaborated by saying that each month brought a different focus to the "classroom teachers' plates." Although the respondent admitted that most of the change "again did not pertain to me," s/he observed colleagues "running around doing a little of everything" and "never getting the time to perfect anything." Addressing colleagues' frustrations, the participant empathized with them by acknowledging the emotional struggles which accompany "feeling like we don't know how to do anything well anymore."

The participant noted that from the district's point view, she understood why it encouraged teachers to keep changing in hopes of improvement and maintaining higher test scores; however, the change just does not seem to be "implemented in the best way" to "sincerely bring everybody on board." The respondent credited administration as best supporting and presenting a district norm of continuous improvement if "it means continually improving in different areas." S/he also commented that teachers as individuals "worked hard to improve student achievement and wanted students to meet their benchmarks." The participant concluded that a norm of continuous improvement may be defined as an attempt to improve by trying new things, but s/he did not "really know if this resulted in positive or negative outcomes for the district."

Theme Three: Trying new instructional approaches without fear of criticism or failure depends upon the teacher's level of autonomy.

Although the participant acknowledged "a certain fear associated with trying new things" s/he "took risks all of the time" in terms of implementing new or different 
instructional strategies based on students' needs. However, the respondent also observed, "For me it is different because we have no predetermined instructional approach with the students." The participant suggested that because his/her field was so specialized, administration probably "doesn't even know what we do." The participant also speculated that they (administration) probably "set foot in our room twice this year." S/he considered this freedom to experiment without fear of failure under someone's "watchful eye" a luxury that the majority of teachers within the district did not experience. "Autonomy works nicely most of the time. I am in my own classroom doing whatever I want and no one really cares."

The respondent suggested her colleagues worried about failing because "they might be punished" as a result. When prompted to share these forms of "punishment" the participant asserted, "You could be placed somewhere else for example a grade level that you don't want." The respondent again remarked that because s/he is specialized, administration would have a difficult time carrying out "that type of punishment." The participant hypothesized that this (not fearing a grade level switch) might be another reason why s/he feels more comfortable taking risks. It is important to note that the participant also explored other consequences of trying and failing such as "Teachers might talk about you and not want you on their team and the teacher may lose some self esteem which could affect students."

The respondent concluded by suggesting that the school held very high expectations of its teachers and expected a "sense of perfection the first time through." S/he perceived this emphasis on "success the first time around" as actually prohibiting teachers from trying new instructional approaches in the classroom. The participant again noted, "For me it is again different because if I do try and fail, well I can keep at it, build confidence, until I see my 
learners improving. It's like who is going to know? I love these kids and I am just going to give them what I feel they need because I can shut my classroom door and do that." Theme Four: Follow up support is available from other teachers.

The participant suggested that follow up support could best be found among the teaching staff. For example, the respondent discussed a need for reading assessment booklets. The books were never ordered for "her department" because "they forgot about us." This prompted the participant to "seek out the literacy support teacher." S/he perceived all teachers, on an individual basis as "definitely very helpful" in terms of answering questions and working with students.

Although the respondent provided several short examples related to technology, s/he chose to relay the following experience in detail. "Every year our computer system changes from how to post our homework to our report card program. We also have a fairly new program called Compass Learning." The participant recalled "doing something in professional development" with Compass Learning. S/he then expressed that the program was complicated but "seemed like it might make a difference in her ability to provide differentiated instruction." Not "tech savvy" the respondent asked and received support from many of his/her colleagues. "It's only because the teachers were willing to take the time and help that I actually learned how to build some differentiated assignments for my students." Reflecting back on professional development, the respondent could only remember "maybe part of a Monday" devoted to the computer program, Compass Learning.

On another occasion, the participant sought follow up support from another teacher regarding the adoption process of a new math program. During the year of the system wide change in professional development, several teachers were pulled out to "work on adopting a 
new math program." The respondent was interested in how the new curriculum would affect some of his/her students. "I remember a presentation or something about the math adoption process [made] by our assistant [superintendent]. A group of teachers were then chosen to work on this. I remember I wanted to know a little more about the process and if my students would be affected."

The respondent asked one of the math teachers, serving on the adoption team, to explain how or if his/her students would be considered throughout the selection of materials. "Like I said earlier, the teachers here at this school are so willing to help and great one-onone."

When prompted to provide an example of follow up support from someone other than a teacher, the participant inquired, "Do you mean is follow up support part of the professional development plan? Like administrator driven? Well, actually no. Not at all. "

The following inquiries can be posed, based on the discussion in its entirety:

1. How might this participant's perceptions have been different in the presence of the three absent focus group members?

2. How can professional development opportunities better reach the target population?

3. How can a program be perceived as thoughtfully planned, supportive of school wide efforts, follow a district's calendar and yet not be perceived as relevant to members of a target population?

4. If a professional development program aligns to a district's master calendar, why does a certain percentage of the target population regard the program as "not pertaining to us"?

5. If weekly program topics are aligned to the district calendar, how much of what is scheduled and valued as important by a school district impacts specialized teachers and student achievement? 


\section{Focus Group Two}

Participants in this focus group perceived their careers as enthusiastic and growing. According to Fessler and Christensen's Teacher Career Cycle Model (1992), teachers in this focus group identified their career stage as one of Stability. All members of the focus group were upper grade teachers at the K-8 school.

Theme One: Consequences arise when teachers perceive themselves as excluded from planning professional development.

Participants in this focus group disagreed that the administration, faculty, and others worked together to plan the professional development activities during the initial implementation in 2007-2008. They all agreed that the teachers had not been included in any of the planning for professional development and that the district "plans it [professional development] for us." All participants in the group specifically identified the assistant superintendent as in charge of planning.

One respondent voiced that "teachers are told what to do and where to do it but not how to do anything." Another group member stated that "the entire year was just the administration dictating to us." When asked if they could recall any activity during that year not planned or executed by the assistant superintendent, the group concurred that on one occasion, the K-4 and 5-8 principals appeared to "run the show." Teachers were divided into upper and lower grade level groups. None of the focus group participants could explain or remember the content of those principal lead sessions.

As the group explored more deeply the results or consequences of not being involved in the planning of their own professional development, they identified three major consequences: 
1. No differentiated instruction

2. No authentic learning

3. No buy in

Group members discussed the connections among differentiated instruction, authentic learning, and teacher buy in. They expressed that without differentiated instruction, authentic learning is "a long shot at best." The group suggested that when people do not feel like they are learning anything beneficial to their own needs and priorities, then they are not going to "buy in." Respondents remarked "Presenting the same content to all teachers in grades K-8 including specialists was just ineffective."

Theme Two: If we had been included in the planning, our experiences would have been very different.

Focus group members were asked to consider how their professional development experience might have been different if they had been more involved and worked together with administrators to plan the sessions. The group suggested that being included in the planning process would have resulted in differentiated instruction and having their needs met as adult learners. "If I would have been asked to even help design one session, I would have begun with offering differentiated instruction to the various grade levels." This comment prompted a lively conversation in which group members candidly spoke about the consequences of "all in the same place, learning the same thing, at the same time."

I have a lot of compassion for the specialists who had to sit through all of that. Yeah and what about teachers like the music teacher and coach?

I couldn't help but tune out on so many Mondays, myself. 
Well--the result of K-8 instruction all together is people goofing off, playing on their computers, texting.

I think that is rude.

Well so do I but how do you make people active learners?

We could have at least split from lower to upper grade.

The dialogue closed with participants acknowledging that only through differentiated instruction, would teachers be inspired to "actively engage and get work done in the Monday morning sessions."

One participant expressed frustration with so many topics being introduced throughout the year. S/he commented that just when the (grade level) team would really "get going and want to delve a little deeper on an issue, the staff was forced to move on to something new." Members of the focus group agreed and felt that if teachers had been involved in "at least some" of the planning from session to session, the staff would have moved beyond just a glimpse of "what that [a new program, teaching method] looks like" to "at the least the possibility of implementation." As one participant candidly acknowledged, I think I would have engaged more .... I mean for real.

Another focus group member contributed,

Maybe we could have moved beyond talking about doings things instead of just doing things. It seemed like we just sat around and did a lot of talking about doing things instead of doing them.

A third participant responded,

Yeah, it could have been more beneficial because we could have identified as learners what each team or group needed to work on and laid down a plan that involved more than just one Monday. 
Teachers as adult learners want and need to guide their own learning for a more concrete, authentic learning experience. To maximize the benefits of professional development, a program should be developed with teachers not for them.

Theme Three: Thoughtful planning does not always equate to meaningful learning.

Participants were asked to expand upon their views of the program in terms of thoughtfulness and complementing school wide efforts. While the focus group concurred that the alignment of the program with the school's mission statement and school wide objectives demonstrated thoughtfulness, there "was no follow through and it [the professional development program] felt like a year-long checklist." One participant shared, "I really think that the overall intentions were good-I mean clearly thinking was involved to try and connect or maybe develop our planning [professional development] around the school's vision and values." Another agreed but remarked that the line of thinking was often, "hard to follow and lacked clarity in terms of exactly where the whole thing was headed." Participants offered an explanation as to why the line of thinking and activities seemed difficult to follow. "There is just little modeling . . . and I think that modeling is a sign of thoughtful planning." The grouped agreed and reflected back to their classrooms acknowledging, "good teaching entails lots of modeling, clear expectations, and goal setting."

When encouraged to provide an example of a program or activity thoughtfully planned and one that also complemented school wide efforts, all agreed that the ELA (English Language Arts) project was such an activity. Group members thought it was "interesting to look at the ELA standards throughout different grade levels." The group concurred that it was beneficial to see what concepts students should have mastered at the previous grade levels. Participants perceived looking at essential standards, meeting with 
different grade levels and exploring different strands of the English Language Arts Framework a valuable experience, one, which "matched school wide efforts and involved thoughtful planning."

Discussion around the ELA project quickly came to a halt when one participant interjected, "It's [the word thoughtful] a subjective word and what is thoughtful may not necessarily be useful or effective." S/he further explained, "As teachers, we might put a lot of thought behind something but I am sure we have all watched those thoughtful lessons bomb, too." Group members reflected upon some of their own thoughtfully planned lessons which "somehow in the middle of it all became a wash and went nowhere." Participants then collectively recalled a professional development activity introduced in the fall of 2007 that seemed thoughtfully planned because there was "some modeling, guidelines, and expectations." It is interesting to note that when prodded, no one in the group could name the activity or provide specifics about its content.

Hoping to learn more about why teachers better remembered the ELA project than other projects, the interviewer guided the discussion back to that activity and probed the group for more detail.

Participants described how teachers formed vertically aligned teams and concentrated on a strand from the Language Arts Standards. Teachers discussed how the essential or power standards fit together from one grade level to the next. Focus group participants used the terms "jigsaw" and "share out" to describe the culmination of the project, which lasted approximately 6 weeks. Focus group members remarked that the school is "always worried about high test scores" and the ELA project complemented the school's efforts toward maintaining advanced test scores. It is interesting to observe that the group could expand 
upon only one project throughout the year, which they perceived as meaningful. This observation evokes one overarching question and several sub questions. "What made the ELA project a journey worth remembering? Collaboration among different grade levels? A 6week time period? Knowledge that could have been used to guide classroom instruction? Theme Four: A norm of continuous improvement is supported by many but ultimately may be best supported through intrinsic motivation.

Focus group members agreed that a norm of continuous improvement exists at the school, which recognizes that learning about best practices is never finished. When prompted to identify observations a visiting educator might make to support the group's perceptions, one participant commented, "Just the idea of Monday morning professional development meetings shows that there is always something to learn." Another member confirmed that "just by meeting weekly for a scheduled length of time clearly follows the thinking that best practices are constantly refined and learned."

The focus group agreed that the school's newly implemented Columbia Writing Program would represent a norm of continuous improvement. One teacher felt that just the talk among teachers about how "absolutely frustrating it is to always be doing something new and not practicing the depth" would demonstrate to an observer that teachers are under constant pressure to keep up with this norm of continuous improvement.

When asked who best supports this norm of continuous improvement, participants named individuals or groups who exemplified the idea of continuous improvement. The dialogue then turned toward the concept of intrinsic versus extrinsic motivation to continually improve best practices. The following exchange demonstrates how the group began with different perceptions and ended with a more shared view. 
My first thought is it comes from several people in different areas ... like our administration, teacher leaders, and teachers, of course.

Well, I think the admin likes to think that it [desire to keep improving] comes from the literacy coaches...

True but there are plenty of dynamic classroom teachers on our staff . . people who express and set the example for what continuous improvement looks like toward best practices. For example, I think of Sally . . . who is constantly improving practices and always is so giving of her time. She motivates me to keep up.

For me, personally I think it comes from within [myself] or the person. You know extrinsic versus intrinsic? I have to be motivated that whatever [new teaching practice] is going to work. I just feel it's up to me.

I guess when I think about it that way-I agree-I may feel the pressures of outside forces pushing me to keep going with a new method but unless I am motivated to make something work for my students and not just because administration says so-I may do a good job of faking it but am I really adopting that attitude whatever new thing exists?

Through further exploration, participants came to a consensus that the desire to improve must come from within the individual and that "outside motivation or pressure might lead to improvement or change but then it might not."

Theme Five: Follow up support means different things to different people.

As participants explored their expectations of follow up support during a system wide change in professional development, one respondent remarked, "Well, what I would like to see or what I would professionally expect, I guess, is that, there's not a new topic each Monday. That the follow-up is that next Monday we continue to refine what we started the week before."

The other participants confirmed that starting something new every Monday and jumping around from topic to topic does not promote follow up. They would prefer a few new ideas that could then be followed up and supported. One teacher expressed that $\mathrm{s} / \mathrm{he}$ 
would like "time to try out the new idea, have the freedom to discuss it with team members and figure out what would be necessary in terms of more support." The group also concurred that "if the Monday morning sessions were more aligned to what we needed," teachers would be able to provide their own follow up and support by collaborating throughout the week.

One participant suggested that s/he would like to try things out without a "micromanager material eye." S/he continued to say "it would even be nice to discuss a new concept-one given to me five minutes ago-without someone from admin sitting at the table." The participant's words initiated the following exchange:

I would like a chance to go back and try whatever it is without admin coming in to check up on me. They might call it support or coming around to see how things are going but I just feel it is more of a check up. Like Are you doing this? Not how are you doing with this?

Me too. I have to totally agree. Follow up and support feel very different than the checking in with you.

I am thinking of this all in terms of my students. Checking in is definitely different than, "Hey, how can I help?"

Yes, and in the past when I have specifically asked for follow up support, that individual doesn't seem interested in doing what I need. And after a while I just say oh well.

Members concluded that the greatest consequence to not offering "genuine following up and support" is that people are not invested. Teachers attend professional development because it is mandatory. "Even if a teacher does try the new thing, without support and follow-up eventually s/he will go back to what they know and feel comfortable doing." Theme Six: Trying new practices without fear depends on several variables.

The focus group identified several factors which they felt strongly influenced teachers' perceptions of trying new instructional practices without fear of criticism or failure. 
They are as follows: tenure, administrators, literacy coaches, feedback, and end of year evaluations. Throughout the discussion, the group concluded that "while on the surface, a norm of trying things without fear exists at this school, teachers constantly carry with them the unspoken fear."

One focus group member initiated the dialogue by saying, "As a tenured teacher, I don't worry so much if my initial efforts fail. I am not worried about them holding a contract over my head." Another member agreed but commented that many newer untenured or probationary teachers are "absolutely terrified of trying new things and failing." The group all concurred that while the district is very clear about wanting teachers to try new things, especially in literacy, "these new things such as instructional practices and bottom lines are often expected to be mastered within an unrealistic time frame, like here it is on Monday and you are being observed Tuesday, the very next day."

The discussion moved toward a possible relationship among untenured teachers, feedback from observations, and year-end evaluations. Participants in this focus group concurred that they received little or no feedback after observations. One member remarked that s/he had to "flag them [the observer] down before they left the room and ask, 'How did you think that went?'" Although all members of this focus group were tenured teachers, they discussed how untenured teachers might feel when they do not receive feedback after an observation involving a new instructional practice. The following remarks highlight the emotions a newer teacher may experience.

Two members of my teaching team aren't tenured and they worry constantly. It's like an administrator or somebody else comes in sits down and takes notes for 2030 minutes then gets up and leaves. 
Shawn worries too. S/he says that she wonders if it's [observation when trying a new lesson] going in the evaluation ... and if $\mathrm{s} / \mathrm{he}$ will be hired back.

It's almost like a mind game. I mean here you are a new teacher, trying this new thing with a live audience in front of your boss . . . and they just get up and leave after it's over.

After taking a bunch of notes. And the teacher is left wondering if it went well did it meet district expectations ... so, although teachers are trying new ideas out in the classroom ... a new teacher probably always worries.

Although tenured and untenured teachers appear to be following the district's expectation of implementing new instructional practices, it appears unlikely that untenured teachers can do so without a fear of failing or fearing for their jobs. The group also noted that while a tenured teacher may ask an observer for feedback, a new teacher will remain silent. One group member noted that when s/he made the effort to ask for feedback, s/he received it. S/he also tried to encourage newer teachers to ask for feedback but the newer, untenured teachers seemed "too scared to force the issue."

The group also commented that trying out something new without fear of failing may also depend on your administrator's tone and leadership style. For example, one participant explained that s/he was with a different set of administrators and didn't quite have the feeling that "failing was forbidden." The respondent also shared that s/he did receive feedback after most observations lasting more than a few minutes. However, at times when s/he worked under a different administrator within the district, trying and failing took on an entirely different meaning. "We were encouraged to try. 'It's okay, you can try new things.' We were told that but then there was a total flipside to that, the unspoken fear." Mentioning the unspoken fear prompted a rapid verbal exchange:

Oh yeah! 
There's an unspoken fear.

It is everywhere and affects just about everyone.

I feel like there is a lot of criticism here and I don't think it's a place where people work without that fear of being criticized.

Or moved to kindergarten!

I'd say a lot of folks walk around here feeling like failures or paranoid, all of the time because of this unspoken fear.

People are just afraid here, period.

When the interviewer further explored where this criticism originated, the group acknowledged that they just couldn't really "define or explain it." They expressed that the unspoken fear could materialize in a "look from an administrator" or a "comment in an evaluation." One teacher circled back to the idea of little or no feedback and that someone just "pops into your classroom and then there is no feedback. You have a person coming in, sitting, watching carefully, writing things down and then that's it." Although the majority of this group previously concluded that trying new things without the fear of criticism or failing seemed easier as tenured teachers, they clearly demonstrated during this part of the discussion that they were still afraid of something, perhaps the unspoken fear. Receiving little or no feedback after an observation could logically contribute to this unspoken fear. These group members debated whether the idea of not providing feedback was purposely done to create and "feed" the unspoken fear and that "letting them live in fear that administration might not approve of what they are doing in the classroom" was not beneficial to them as professionals, and "absolutely was not encouraging to keep trying new things, and did not benefit the people who mattered most, the students."

Theme Seven: Teachers' pets, blanket praise, and nice job define recognition of success. 
It is important to note that the focus group became very quiet when prompted to discuss how teachers were recognized for their successes in the district. The dialogue was slow to start. One participant began by offering "I don't even know." Another added, "I am just really trying to rack my brain." "For something honest," finished another participant.

As members began to verbalize their thoughts, it became clear that the glory often was bestowed on the same teachers, consisted of general praise, and seemed insincere. As one participant remarked, "It's kind of like how kids say there are teachers' pets, well there are administrator pets too." The group agreed and another member contributed that, "It's not like we have a search party out there looking for people doing good things." The following discussion exemplifies the feelings these participants shared about their colleagues and recognition:

It's all over the place. Teachers doing amazing things here.

I know. Our staff is just such a tremendously talented staff-one that works so hard and is so fabulous.

I agree we really do have great, dynamic teachers.

If leaders could actually see not just look but really see. We could have such a positive energy here and people might say, "Claire is doing this in science - I need to get in there and see her!"

Instead, it's Monday upon Monday of clapping for the same people or team and I don't even really know what they did because the recognition often is so general.

The group moved ahead and discussed the fact that because recognition is so general, teachers do not have a good sense of the successful idea or lesson and consequently cannot replicate it. For example, if the third grade teachers are recognized for a "nice job with digital story telling," colleagues are left wondering what did the third grade teachers actually do that was so "nice" that I could try in the classroom? 
The participants' dialogue regarding recognition of success may lead to several questions: "What really is the motivation behind recognizing, in the form of public appraisal, professionals for their successes?" "What do those who are being recognized, those who are applauding, and those who are delivering the praise expect and want?"

Theme Eight: Change is hard and its outcomes are different than what we might expect.

As focus group members reflected back to the system wide change in their professional development during the previous year, a consensus was reached that "it was just too much too fast." They agreed that in order for something to really stick, it must happen slowly. One participant related the change to dieting. "It's like a diet. If you try to change it all too fast, you might lose a bunch of weight and meet your goal—but in the end people who have success in keeping the weight off did so slowly and steadily."

Other group members agreed with this analogy and commented that change had to occur in steps taking one step at a time. The group felt as if they were trying to jump "an entire ravine" throughout the year. They concurred that during the system wide change, some things were just not "as thought out as they could have been." The conversation expanded to include what was most difficult during the transition from very little professional development to weekly meetings. Respondents presented a range of answers.

For my team — we lost a prep period.

Starting off Monday morning with a meeting and then teaching all day.

This seems silly, but it matters - we lost our 15-minute recess on Mondays. Less instruction time which is a big deal when the pressure is on for high test scores.

It's not what I expected. 
Giving up that hour every Monday was heartbreaking.

It was a waste of what used to be a very productive hour-working with the kids.

Agreed - not an effective use of my time as an educator.

A few participants reflected back to the previous summer and school year of 2006-

2007 before the system wide change occurred. During the 2006-2007 school year, a

Revolutionary Education Team was formed in the district. This team was comprised of

school leaders, administrators, and teachers. The participants recalled that the idea of a

weekly professional development program emerged from the Revolutionary Education Team.

I was on that team, and we were really excited about having this time to collaborate. I had visions that it would be so much better and not so haphazard.

But, when it was all rolled out and we were experiencing it, well it just seemed so ineffective and different than what members of the Revolutionary Education Team had designed. We wanted it [professional development] to be team time, collaboration, a place for new ideas and a place to refine our practices.

Similarities can be drawn between implementing professional development and implementing a new classroom instructional approach. The implementation of a new instructional classroom practice often looks very different and at times unrecognizable when compared to the original blueprint. From the group's dialogue and reflection, it could be that teachers envisioned a system wide professional development program operating differently than what they experienced during the first year implementation. Participants also may hold different perspectives on what professional development really is and how it can prove valuable to them and affect student achievement.

Theme Nine: Expectations differ toward how leaders may encourage and support professional development through incentives and resources. 
The focus group concurred that although their district was "very rich and generous "in term of ordering classroom library books and classroom supplies, teachers were often left to create, write, and copy their own curriculum. "I just feel overwhelmed because every time I get excited about this new idea coming our way, it always ends with, 'Okay you guys now you come up with the materials to do this." Another respondent added, "And where is the time to do this? We never got the time in our professional development and quite frankly I don't even know where to begin half of the time. I need an example or modeling." One participant theorized that the administration wanted teachers to "learn through making the resources, and in some cases maybe that worked but not every time with every new program."

As the discussion came to a close, one group member shared a short narrative addressing the concept of school leaders providing incentives and resources to encourage teachers. The participant recalled an attempt to receive approval from the district to take an upper graduate technology course, which was aligned with the goals of professional development. The teacher shared that $\mathrm{s}$ /he was given a "very difficult time" in trying to get the coursework approved. "It just seemed so arbitrary in how and what classes were approved, so I don't really think real growth is encouraged at all here."

From this conversation among focus group members, several conclusions could be drawn regarding teachers' perceptions of leaders advocating, encouraging, and supporting professional development through resources and incentives. First, individuals may hold different ideas about what it means to "provide resources and incentives." While some may view resources as "a unit of study in a binder" another may view resources as upper graduate level classes. Yet others may define a resource as simply having the time to create a product. 
In terms of support or encouragement, again, teachers may hold different perceptions of how best to support and encourage individuals on a pathway to new learning experiences. While some individuals may view support as being "granted time to plan" others may define support and encouragement as "approving a class for professional growth."

\section{Focus Group Three}

Participants in this focus group perceived their careers as enthusiastic and growing. Teachers in this focus group recently shifted grade levels, came from another district, or experienced a career change within the educational system. Consequently, these participants still considered themselves in the induction stage of Fessler and Christensen's teacher Career Cycle Model (1992) although they each had over 3 years of classroom teaching experience. Theme One: Follow up support may be as simple as working on an idea for more than just one session.

Participants in this focus group did not feel they were offered adequate follow up support to many of the new topics introduced during their professional development program. When asked how this affected their learning experiences in professional development, one participant simply replied, "I might remember something." This participant elaborated by saying that the focus of professional development seemed to "change almost weekly". and that follow up on anything from one week to the next proved almost nonexistent. Another participant agreed and remarked that, "This is almost embarrassing, but I can honestly say nothing vividly sticks out that we even talked about last year." Participants attempted to prompt one another's memory by naming topics each could recall from their experience. Throughout this naming exchange, only one topic, "ELA Project," elicited more than a one- 
or two-word response. The group expanded upon the "ELA Project" sharing that it lasted for about 6 or 7 weeks. They defined the project as a "vertical alignment study of English Language Arts Standards that involved about eight groups of teachers working at different grade levels." Focus group members concurred that the ELA Project was the one piece throughout the year, which continued for a series of Monday professional development sessions.

They concurred that because teachers were given several successive Mondays to focus on one topic, the project was viewed as "something that mattered." Teachers could plan and work toward goals from one week to the next. Participants recalled that "administrators gave us graphic organizers, a copy of the language arts framework, and some guiding questions." Although the group did not discuss much more than the logistic of the ELA Project, they clearly remembered more about this professional development topic than any others they initially named as "the rest of it [professional development] just blended together."

The group acknowledged that covering too many topics and seldom taking more than 1 week to explore any issue in depth negatively impacted not only what they could remember but more importantly what they learned and utilized in the classroom. Teachers then may define follow up support in terms of how much scheduled professional development time is spent on any given issue.

Not only did this focus group comment on follow up support of topics during the regularly scheduled professional development time, they also discussed follow up support outside of Monday mornings. For example, participants shared a professional development experience about being "handed a binder" and listening to a "speech about Developing 
Capable People." One teacher voiced that her team requested some "sub time to plan out how this [Developing Capable People Program] might be woven into the academic curriculum." Despite the denial of release time, this participant attempted to implement some of the program's ideas into the teaching day but admitted to "shelving the binder" after about 1 week.

Focus group participants explored the consequences of not receiving follow up support. The following exchange demonstrates what these teachers felt was the greatest consequence to no follow up.

I think you said it best by referring to that Capable People binder.

What ... the shelf thing?

Yeah, just like with that. If we don't get any help in implementing all of these new programs, eventually we give up and don't do it. I mean we definitely give it a go but well just like the Compass Learning [a software program purchased by the district to aid in individualized instruction] thing. I know several folks have really tried with that but I don't know of anyone who went as far as trying to design lessons based on the kids' needs. In fact, that whole thing is another binder on the shelf so to speak.

Theme Two: Asking for follow up and support might be a shared responsibility, one that proves risky.

Participants suggested that as learners they were somewhat responsible for follow up support and that the instructor should not necessarily always initiate it. For example, one focus group member remarked that it was a teacher's responsibility to speak up and ask for support when new programs were not going well. Another group member commented that "a teacher would be waiting a long time for someone to show up in the classroom and offer follow up support." Although participants perceived the idea of follow up support as part of their responsibility, they had mixed feelings on asking for and receiving support. One 
participant expressed, “I don't think I have ever really asked for follow up support." While another focus group member shared this view:

I think I have access to follow up support because of my literacy coach, Kerri.But I know other teachers don't have her as their coach. But with Kerri, I can go to her and ask questions plus she is readily available to come in and model whatever needs to be modeled. She digs right in and gives me support. Also, I think that sometimes people just get so busy and overwhelmed that they feel like they don't even have time to ask for follow up support. With all of these new things, they are busy just getting by.

Yeah I agree or asking for help might be taken as a sign of weakness. Unspoken of course.

I know what you mean ... for example, "Oh guess who doesn't really know how to teach fractions?"

Exactly. Then it gets back to them and maybe so and so shouldn't be tenured or needs to move grade levels.

Well, I guess that is why I would think twice about asking for help, period. I mean nine times out of ten, there is a big risk of being jabbed in the back. I would say going to your team is safer than asking for help from the office or my literacy coach.

Theme Three: The incentive is the resource in supporting professional development.

This focus group agreed that the lack of incentives and resources to support professional development negatively impacted their learning. The group discussed the differences and similarities between incentives and resources concluding that if "teachers had the materials or resources instead of being asked to create them, it would act as an incentive for teachers to learn." When asked to provide an example, the group identified a data assessment project they described as "busy work, laborious and archaic." According to participants, the goal of the data assessment project was that teachers become more familiar with their classroom learners through manually creating a hardcopy spreadsheet containing all existing data for each student. Teachers were instructed to compile and record student data 
such as previous and current CST test scores, MAPS test scores, and independent reading levels. Administrators would then schedule conferences with teachers after the completion of the pencil and paper spreadsheets. Following the conference, the handwritten data would then be entered into a computer based program and accessible school wide.

Focus group participants concurred that "teachers were somehow now creating this resource of information for the district, disguised as a way for us to learn more about our students by having all student data in one place." Participants suggested that if the goal of this data assessment project was "really to help teachers know their students" then an incentive would have been to "already have the data compiled on a computer spreadsheet available at our fingertips." When inquiries were made about the follow conferences with administrators, although these participants did not have a follow up conference, they each knew at least one teacher that did present the data to administration. "The teacher next door actually did go down and turn in the spreadsheets. But it wasn't like admin scheduled a follow up conference, she just went in on her own to turn the project in."

"That's probably because she was a new teacher to the district," another member responded.

Theme Four: To encourage professional development among teachers, planners should call upon best practices.

Focus group participants explored how professional development planners could best encourage learning during new professional development programs. One teacher expressed the desire to have "some input" into the topics. When asked to clarify the idea of "some input," the group as a whole responded with ideas such as "surveys, feedback, and team discussions." The interviewer asked the group to expand upon its responses in terms of how 
the ideas of surveys, feedback, and team discussions might encourage new learning in a professional development setting. The following exchange demonstrates the desire of teachers to provide input for professional development.

I think it would have been really helpful if they would have at least given us a survey and asked, "Hey what do you and your team want to learn about this year?"

Or if they already had set topics because I think that maybe they might not be able to choose sometimes either, the survey could have asked us to identify our knowledge of that particular topic. Like, Compass Learning, for example. A survey could have determined who needed all of that training and who did not.

Exactly - and I remember we all had to sit through that training. Because I was newer to the district, it was fine with me. But the other teachers at my table . .

I agree but do you think if we were given a survey about what we wanted to learn and our knowledge on upcoming topics, would the feedback matter?

I actually do think it would. For example, if we took a survey with a question like, what would be an effective use of you time to help improve your craft or what would you all as a five through eight staff want to learn about this trimester ... or maybe what would you like to see on the agenda that promotes our school's vision and values. I think they might read it and maybe let it guide some of our meetings.

The interviewer interjected and asked the group to speak more about the idea of feedback on previously planned sessions and how it might encourage new learning in professional development. The group concluded that providing feedback on something already planned and delivered would only work if teachers reacted honestly and professional development planners listened and used feedback to guide and support future professional development. As the dialogue continued participants made a connection about how surveys and feedback lead to best practices and that the idea of best practices should be followed in adult learning. One participant felt that "it doesn't matter the age of the learner it should 
always come back to models of teaching that we know are best practices . . . and I feel like somehow these models get left by the wayside with our professional development."

The interviewer asked if the participant or anyone else in the focus group could provide an example of best practices being left behind during professional development.

Well for me, looking back on the year in its entirety, it seems that so many of the new things were just described ... like this is what we want all of you TO DO now go do it. Learn about it, read about ... and we'll be coming around Thursday to make sure you are doing it. I guess a better way to encourage me as a learner would be to provide the resources, provide the time, and provide the modeling.

The concept of providing modeling as a best practice for adult learners prompted the following detailed exchange among group members.

Exactly, modeling is the piece I think we forget about when teaching adults.

Yeah and we all know what happens when we don't model for kids!

We forget to model and we just tell them to go from point A which is not knowing it at all to doing a finished product and figure it all out along the way.

Without seeing the contextual pieces.

Or not showing them how to do whatever it is ... first you know you explain what you want them to do and then you show them how it's done and then you engage them in starting to do it correctly ...

Yeah ... while guiding them and providing feedback. You release them and watch them do it . . coaching as needed. That's what I want for myself as a student.

The group recommended modeling as an effective approach for teaching adults and proposed the idea that adult learners can become frustrated perhaps more than children when they are only told and not shown what to do in a new learning experience. Participants remarked that only in one strand of professional development, Columbia, separate and apart 
from the Monday weekly professional development program, did they receive modeling as a component of a new learning experience. As one participant voiced,

Our Mondays really centered around the traditional teaching model of here is this thing we are going to talk to you about and this is why it's useful. Now you learn about, write about it on this graphic organizer, and talk to one another. Without showing us how and the idea we are supposed to be implementing a week from Thursday just ends. It never happens.

Theme Five: A norm of continuous improvement must go beyond those in charge.

Focus group members believed that school administrators best supported the school's norm of continuous improvement recognizing best practices. The group remarked that the administrators set agendas and hold high expectations of the staff. One participant commented that in terms of best practices,

There has been a shift in reading during the last few years as to what best practices really are ... and this has been coming from the administration. We are now using models that are recognized as best practices like student collaboration, small group guided reading, flexible grouping .... Doing away with whole group.

When prompted to think about if and how this example of a shift in reading toward best practices lead by administration was appreciated and supported by the faculty, the group responded unanimously with, "It depends." The group chose not to make any further comments but suggested the idea of a professional development committee of teachers. This committee would be comprised of actual classroom teachers interested in implementing and developing best practices among colleagues. The focus group felt faculty might be more receptive if best practices were not always coming from "soldiers not on the front line." By not asking teachers to collaborate and actually be involved in running some of the Monday morning sessions, the group felt that a norm of sincere continuous improvement would fail to reach beyond "those with offices." 
Theme Six: All new programs have learning curves.

Participants did not perceive the Monday morning professional development program as complementing school wide efforts. When participants were asked to better define their perceptions, the discussion centered upon the difficulty of a first year program implementation. For example, one teacher expressed high regard for everyone involved in the process. "Well the admin team was really just putting its toes in the water and trying it all out. The person in charge of the whole thing had never done this before." Another agreed by adding,

Since last year was new for everybody, it was a learning curve . . it's just like a new teacher has a lot to learn with a new program. We might be thoughtful in our planning but thoughtful doesn't always mean that new thing is going to be a success.

The group surmised that perhaps the learning curve could explain why "things last year just seemed so fragmented, although you could tell sincere thought was involved. At least we seemed to get more agendas and emails about upcoming events more so than this year." Participants viewed sessions completed during Mondays as important but the activities did not necessarily complement school level efforts. When asked to provide an example, the conversation expanded to include the Columbia Model.

Well all of this emphases has been placed on training teachers in the Columbia Workshop Model. The school has paid for teachers to go to New York, for developers to come here and work with us, and they have bought a lot of leveled books. Yet our Monday morning professional development of last year seldom, if at all, tied into this school wide shift.

Agreed. It's like we have different kinds of professional development happening but it's all separated and not heading toward the same station. Like maybe a good time to tie Columbia into our Monday morning session would have been during our ELA project. The two naturally complement each other, I would think. 
Participants in this focus group were able to move beyond the idea of self and recognize challenges others involved may face during "a dramatic change from virtually no professional development to Mondays upon Mondays of new things."

\section{Focus Group Four}

Participants in this focus group perceived their careers as enthusiastic and growing. Teachers in this focus group identified their career stage as one of Stability according to the Fessler and Christensen's teacher Career Cycle Model (1992). Members of this focus group were tenured teachers and collectively possessed over 45 years of teaching experience. Theme One: Alignment to a district's mission statement, goals, and objectives does not necessarily always generate meaningful professional development.

Participants agreed that while the majority of sessions were aligned to the school's mission statement, it did not necessarily make for a "meaningful Monday morning experience." While group members viewed the alignment of topics in their professional development as noble and the ideas worth exploring, the professional development calendar was not "sensitive to the school calendar." Members considered the planned events as often “artificial and disconnected." For example, participants discussed that if parent conferences were coming up that week, or report cards were due, it was difficult to focus on the math adoption process.

One participant initiated an exploration of professional study groups developed around the district's mission statement, visions, values, goals and objectives. "I was in the technology one and it was so big that we were split into three groups. The one I was in just fell apart." 
Another focus group member added, "Yeah, I remember that. I was in the technology study group as well. There wasn't any clear direction and it seemed a misunderstanding of expectations. We had no cohesion and didn't know exactly what we were supposed to be doing with our time."

As participants continued to dialog about the technology study group, they noted it was "ironic" that there seemed to be no technological support when teachers had questions. "We would try and chase someone down to ask questions but got no answers." Focus group members discussed that although the school's mission statement declares "Revolutionary education through twenty-first century thinking skills," there wasn't much happening which would be considered revolutionary in the technology study group.

One participant shared, "I expected that I would have a chance to actually explore some of the various software programs and learn how to increase my students' learning," Another responded by saying that when their technology group asked to explore some software programs, they were told "that is not what this time [professional development] is for and they [the technology group] could do that [explore software programs] after school." The group also shared that finally toward the end of the project, the goal for the technology group was presented as "Not a time to become familiar with programs, but a time for learning how to use the programs in the classroom through reading and discussing articles about technology." Participants experienced frustrations with this goal as one focus group member asserted, "Really, if I don't have a chance to get to know a program through physically exploring it, you know hands on--how can I implement in the classroom?"

The focus group acknowledged that the theory of choice and professional study groups "were great" and many topics of the study groups aligned with the district's mission, 
values, objectives, and goals. However, unclear expectations, teacher assumptions, and micromanagement lead to an overall ineffective learning experience.

This ineffective learning experience was also "troublesome" in the sense that the time spent in professional development did not reflect a caring community, one of the school's values. As one participant shared, "I just don't feel like our Monday morning meetings reflect a sincere picture of a caring community." Other members agreed and perceived the tone of Monday morning as "cold and hard." The group expressed a desire to be treated and shown some compassion just as they practiced in their individual classrooms. The following exchange illustrates the members' perceptions:

One thing is we never have enough chairs for people to sit in on Monday. Yes, and I don't understand that-it's not like they don't know how many of us there are on staff. So, what happens is if you come in a few minutes late, you sit on the floor. It's almost like it's your punishment or what you deserve for coming late to the meeting. I mean why we can't have enough chairs?

The dialog elicits the following questions:

1. What does a caring community look like among adult learners?

2. Could practicing the value of a caring community be as simple as providing enough chairs for staff members?

3. How is a caring community defined by teachers, administrators, and others working in the system?

One respondent observed that the "whole thing [professional development planning] looks good on paper" but so many ideas were just "not followed through or a waste of time." Other participants agreed and one noted, "One Monday we spent the whole time talking about MARE and by the end of the week the whole thing had changed and our administrator said 'the planning we spent time on that previous Monday wouldn't go along with our 
schedule." The group reflected on other Mondays, which seemed to promote the school's vision and values, but more often than not the plans foiled and ideas just "faded away." One focus group member concluded the discussion by saying, "After a while it's like why bother." Theme Two: If we had been involved in the planning process, maybe it would have been different and then again maybe not.

The focus group felt that teachers were not involved in the planning process during the first year of implementation. One participant reflected upon how the idea of a weekly, job embedded professional development program began:

I think we had this survey a few years back, which reflected a high interest in improving our staff development. Prior to this, we had a few days here and there at the start of school, around holidays breaks ... before that we literally had no staff development, unless you took a class or something.

Another member added, "And wasn't the survey completed after we had that day of Unpacking the Backpack [a professional development seminar hosted by an outside source] right before Christmas break?"

Another member finished the dialogue of how it (professional development) began by saying, "The following August every Monday we were sitting in these meetings referred to as our professional development."

The group alleged that excluding the teacher feedback from the initial survey, the district did not attempt to include teachers in the planning process. The group asserted that "It's [professional development] dictated to us."

From the very first professional development session teachers were told, "This is when it will be and how it will be done." According to the group, the structure was given to the teachers and any attempts to offer feedback or input were "simply ignored." For example, 
the group shared how the district's teachers stressed repeatedly that Monday morning was not a "good time" to conduct professional development. Also, several teachers suggested implementing the model of an early afternoon dismissal for students and professional development for teachers. However, despite the feedback, the professional development program, now in its third year, has remained on Monday morning because "It's a smooth transition for the children and their parents and the parents are vocal and donate a lot of money. They absolutely will not support changing it [professional development]."

Despite attempts from the interviewer to move forward in the discussion, the group remained focused on the district's decision to continue holding professional development on Monday mornings. The following dialogue attempts to capture the emotional response of the group and how the component of timing may very well affect teachers' attitudes toward professional development and could potentially directly affect student achievement.

You have to be ready to go Friday or come in early on Monday.

Or say forget it - what gets done gets done.

That's right. And you know studies have been done about worker productivity on Mondays.

Absolutely nobody wants this on Monday morning.

Our feelings have been expressed loud and clear and it's just not going to change. Admin won't do it.

Well, I don't blame the admin as much as I fault the parents. In this community families are always taking long trips ... so if you get in from Vail late Sunday evening, no worries because we can sleep in on late start Monday.

For me, it's like we show up after the weekend and it feels like a two by four to the head.

Exactly, that's right. Then we are expected to recover in 10 minutes from the meeting-because our students are waiting outside the door. 
It just really sets a bad tone for the week.

I mean when is it ever a good thing? You walk into your classroom after the meeting just feeling so depressed and just so heavy-burdened by all of the new things. I really think our stress has to affect our students.

Well, not to mention when admin announces in our meetings that someone is sick or dying. That really makes you feel like getting out there and doing it!

As the discussion came to a close, one respondent added that the Monday late start also took away Monday break for the students and teachers. "We have asked for the past two years to have a normal break again, despite the early start." Prior to late start Mondays, students were given a 15-minute break in the morning before lunch. Since late start Mondays, teachers now are responsible for ensuring that students receive just a little "stretch your legs" break and are often covering for one another in an attempt to make a "mad bathroom dash."

The following conclusions can be drawn from the group's persistent desire to elaborate upon and discuss the day and time of their professional development program:

1. The timing of professional development may contribute to teachers' attitudes toward professional development.

2. While a late start Monday may benefit parents and students, difficulties arise for teachers which may impact classroom instruction.

3. Teachers' perceptions of what time works best for them may make the topics covered during professional development irrelevant.

It is interesting to observe that while the group agreed that the planning of

professional development came from "the top down," they also commented that not too many teachers would want to be involved in the process anyway. When asked to expand upon their perceptions, one responded declared, "The last thing I want to do is get together and have a big hubbub on what we should do, when nothing is actually really going to happen." Another respondent contributed, "I know I wouldn't want to be a part of it, that's for sure." The group 
further elaborated by acknowledging that most teachers would not want to be a part of it (planning for professional development) because it's just not a "receptive environment" and after awhile it becomes "very unmotivating to be involved when no one listens, anyway." From this exchange, a conclusion can be drawn that although teachers may be asked to plan their professional development program, they may choose not to participate based on past experiences or preconceived notions. Additionally, it is interesting to observe that although focus group members voiced dissatisfaction with the planning of the program, none of the members expressed an interest in participating in the process if given the opportunity. Because this focus group consisted of tenured teachers with over 10 years of teaching experience, the question arises: How do teachers' perceptions and years of service affect their motivation toward participating in planning professional development?

Theme Three: The criteria for incentives and resources is perceived as unclear and often biased.

Although the district has an "abundance of resources" and often does offer incentives to encourage professional development among teachers, respondents felt that the "wealth was seldom distributed equally." They also remarked that it was difficult to identify the criteria for "who got what" in terms of materials and support. The group explained "there are a certain some [teachers] that receive everything and also have multiple opportunities [outside training opportunities] and then some that are at the bottom of that list." For example, a reference was made about the science teachers "inventing water, walking on it, and having anything they want." Participants explained that some of the decisions stemmed from the foundation's (Rancho Santa Fe Educational Foundation) contributions toward certain content 
areas. For example, if the foundation expressed an interest in improving the school's science program, then incentives and resources may be offered to science teachers.

The group remarked that on certain occasions an email would "descend upon the staff" asking for volunteers to attend a particular training. If enough teachers responded, then teachers' names were "put in a hat" and drawn. An inquiry was made as to whether names were even drawn from the hat at all. Although the group expressed that they weren't bothered by the "names in a hat" approach, participants questioned, "Why send the email in the first place, why not make a decision based upon who would benefit most from the training?" Although members acknowledged that they did not expect the district to provide resources and incentives for every teacher, they suggested the district adopt a more unbiased approach toward the distribution of those incentives and resources.

The group also mentioned that they weren't particularly interested in the materialistic aspect of incentives and resources. Members identified differentiated instruction as an incentive toward encouraging professional development. As one respondent commented, "A fundamental flaw in the program is the fact that we are considered a $\mathrm{K}-8$ school and our professional development is geared toward housing all of the teachers in one room." Another member contributed, "I sit through a lot of Mondays where what is being said just doesn't pertain to my job. It seems that the presentations are so often focused on just a small segment of our school's teaching population yet we are all expected to be present."

Participants concluded this part of the interview by speculating that the best incentive or resource the district could offer might not come in the form of materials and training. The group agreed, "Lots of planning but not a lot of action" resulted from their professional 
development and certainly a "huge incentive" would be to put "plans into action and follow through, every time."

Theme Four: How prosperity complicates the change process.

The group expressed irony over the district's attempt to implement a system wide change in its professional development program. They explained that just the logistics of a one-schooled district should make a system wide change at least manageable if not successful. The following exchange emphasizes the group's perceptions:

Our greatest asset should be our ability to change and it's our ...

Biggest problem.

We have the money ... the supplies ... the resources ...

Don't forget we also have four administrators.

Yes, and they have these cabinet meetings of furious brainstorming sessions which lead to new things and surface change.

Throw this out because this new thing is coming.

And, we have the money to actually go with the ideas.

Well, maybe that is just it—we have too much. We have too much money, too many administrators.

Well it appears that they [administrators] have taken this idea of change and used it to justify their positions.

The group continued to explore their perceptions of change and how change leads to something "new being developed" which requires someone to "administer the something new." They discussed that "something new often meant teachers creating new curriculum." Members expressed dissatisfaction with always starting over working on the next new thing. Participants also expressed confusion as to why the district didn't follow other high scoring 
districts leads as opposed to always inventing something new. Throughout the dialog the group concluded that maybe the change is all about "looking good in front of the board." Theme Five: Experimenting without fear may depend on several variables.

The group discussed its perceptions toward trying new instructional methods or activities in the absence of fear or criticism. During the exchange, the word retaliation was explored in relation to having an idea fail. Participants felt that if they "went out on a limb" and "strayed from the path" too much, certainly retaliation would follow. When prompted to identify some retaliation methods, the group unanimously replied, "Changing grade levels." One respondent emphasized that people "can't fail here." Another added, "Well, that depends, you can be set up for failure really easily in this district."

One group member remarked that s/he felt relatively at ease with trying new things because there "isn't a whole lot that they can do to me." The respondent moved on to say that s/he would not "go overboard although there are things s/he would push." Another participant remarked that most teachers try things without really advertising it to administration.

Participants further elaborated by saying that even when new things were a success, "It's not like we would announce it, anyway."

The group suggested that trying things without fear of failure or criticism might depend upon your years of experience and concentrated subject area. As one participant speculated,

New teachers are afraid because they are new and a teacher near retirement probably doesn't want any trouble and wants to be left alone. I guess that leaves the teachers in the middle of their careers-- they may be apt to try new ideas without worrying about repercussions. 
The group also referred to a new math curriculum implementation. "If you taught math last year, you were probably always afraid, but if not you were mostly left alone." Members investigated the idea that science and social studies were two areas in the curriculum that invited a lot more freedom and encouragement to try new things without fear. As one member observed,

Because of the state tests, teachers are fearful of doing out of the box type things because of the potential impact of the testing and if the administration sees that they are doing those types of things--they'll get yanked. Right there and then.

The respondents considered having "parents on your side" a good thing if you were going to try something new. For example, they discussed the idea of trying a new method for teaching fractions. "If the kid in your classroom goes home happy about math, then you are a success."

From the discussion, teachers perceive certain risks associated with trying new instructional approaches. It may be that teachers are not necessarily afraid of failure or criticism but would rather take the path of least resistance including the following:

1. Practicing in isolation

2. Keeping successes quiet

3. Experimenting only in those content areas not so regimented.

\section{Focus Group Five}

Members of this focus group were tenured teachers, represented the upper (5-8) and lower (k-4) grades, and collectively possessed teaching experience outside of the district. Four out of the six participants in this focus group perceived their careers as in the competency building stage and the remaining two perceived their careers as enthusiastic and 
growing. Four out of the six teachers in this focus group identified their over arching career stage as one of Induction according to the Fessler and Christensen's teacher Career Cycle Model (1992). Teachers in the Induction stage may have recently shifted grade levels, came from another district, or experienced a career change within the educational system. The remaining two participants identified their career stage as one of Stability.

Theme One: How leaders could encourage learning in professional development.

This focus group did not perceive school leaders as supporting or encouraging professional development through incentives, yet they did have a "vast supply" of resources. In terms of tangible monetary resources, the group agreed that they were extremely "fortunate and blessed" to have a school budget which supplied materials to support new programs. They also commented that other schools would be "jealous of their technology and supplies." Participants recognized that the district provided for "more than enough classroom supplies, textbooks, classroom library books, and technology related equipment such as document cameras, smart boards, clickers (classroom response system), and student computers." Members also remarked that, in most cases, "If they could demonstrate a need for something, the request usually came through either from the district or from the parents." It is interesting to observe that respondents felt "having it all" is "definitely helpful" but does not necessarily "make it happen in a classroom."

When asked what types of incentives they would expect school leaders to use to support new programs, the participants discussed the following incentives:

1. Trusting and respecting the teachers

2. Focusing on a select few concepts

3. Raising the bar to meet learners' needs 
4. Providing differentiated instruction

5. Asking for feedback and listening

Focus group members declared trust and respect as their number one incentive for actively participating in the professional development program. The group discussed several aspects of the program, which they perceived as demonstrating a lack of trust and respect toward the teaching staff. Participants felt that too many "parameters" were placed on weekly planned activities. The group considered these parameters "restrictive and detrimental" to the adult learning process. One respondent commented, "It was just so regimented as to what you could do or couldn't do." Another member contributed, "I think we, as professionals, should be able to select an avenue of study and pursue it from Monday to Monday." One participant recalled a series of Mondays in which teachers could go study with the literacy coach, explore Compass Learning, and investigate MAPS data. Another member shared in the recollection but stated that "those topics were predetermined on a list and we never made it past the first rotation." The focus group then concurred that "seldom were they given any choice" regarding the topics of Monday morning. They perceived not being given opportunities of more choice in their professional development program as a lack of trust and respect. As one participant remarked, "Your learning was just in this kind of box, you were boxed in with little opportunity for exploration." Another member added, "Our leaders should trust us to identify what we as professionals need to work on in order to improve our teaching and increase student achievement, minus the task sheets." At the mention of "task sheets" the group explained that, during a number of the sessions, teachers were given "graphic organizers or task sheets" to complete during the professional development time. They 
viewed the task sheets as a form of distrust and micromanagement. For example, one respondent asserted that it was a "check in to ensure we were using our time wisely." Members also expressed dissatisfaction with the "restriction of work space." Participants considered "making us all stay in the LGI (large instructional room) as a way to "micromanage" the teachers should they "god forbid talk about math when they were supposed to be discussing spelling." One participant voiced, "Not only could we not choose what we wanted to do; we all had to sit in one room to try and work." Another added, "It's like when we broke off into teams or groups, we couldn't be trusted to just go work in our team leader's room." Additionally, members noted that "pulling together and lugging our materials and resources" to the common meeting area was "cumbersome" and led to a "decrease in productivity." They expressed that their classrooms were similar to that of an office and "it was difficult not to have all of your materials, let alone your computer at your fingertips." Participants concluded that trusting and respecting teachers to act as professionals in their own physical work space, such as their classrooms would act as a "major incentive" to continue developing best practices.

Participants identified "concentrating on a few select topics throughout the year" as a third incentive toward supporting professional development. The group expressed a high level of frustration toward the number of topics covered during the initial system wide implementation. One member declared, "I can't even begin to count how many things we were focusing on last year. Every meeting we were focusing on something different, ELA standards, accountable talk with students, read alouds, twenty-first century learning." Other respondents agreed and noted, "There wasn't a lot of learning happening - all of these new things just discouraged you from actively participating." They also suggested that the 
majority of these new ideas just ended up "getting pushed under the rug." When asked to provide an example, members discussed the ELA Project. They agreed that a number of consecutive Mondays were devoted to the ELA Project allowing teachers to meet in vertically aligned teams to discuss high priority standards. However, the project "just sort of dropped off." As one participant recalled, "I think the end product was each vertically aligned team filled out these graphic organizers and turned them in to administration." One group member added that his/her team leader had requested copies of the ELA project data from administration and "It was never received."

The group hypothesized that if the year's focus had consisted of "three areas of best practices," teachers would have been more vested, gained an increased knowledge of the selected topics, and been able to confidently implement new strategies in their teaching practice, which may have resulted in an increase in student achievement. Respondents suggested dedicating each trimester toward core curricula areas such as math, reading, and writing. From these broad areas, teachers would then choose an area of focus such as "best practices in vocabulary, learning how to use data to inform instruction, or using technology to enhance learning across the curriculum."

The discussion turned toward the desire for challenge in a professional development program. The focus group asserted that, just as in pedagogy, adult learners need to be challenged. Participants noted that to be challenged is an incentive to actively participate in training or professional development programs. Members expressed a need for more thought behind what the teachers were doing as opposed to, "Oh, here's a photocopy [of an article]. Read it, discuss it, and fill out this sheet." The group agreed that the staff was highly educated and the bar for learning needed to be raised. Participants discussed that as teachers when they 
have a highly intelligent group of students, they must "raise their own level of instruction or risk losing them" The following exchange illustrates teachers' reactions toward a program that they view as unchallenging.

We are very talented teachers here. You can't just give us an article to read.

Exactly, I don't think having us read articles is true training.

Agreed. Also, you can't just photo copy some chapter out of a book that we've all had on our bookshelf for five years.

Do you remember that video? That 20 -year-old video?

That 20-year-old video? Awful-you couldn't hear it . . it was fuzzy. Then we get reprimanded like children for talking and not paying attention. I mean as a teacher when I see that the majority of my students are disengaged, I think about how my instruction might be causing the kids to goof off.

Yes, or maybe your class needs some differentiation.

The theory of differentiated instruction became the fourth incentive the group perceived as lacking in their professional development program. Members discussed how staff members, all varying in length of service, subject area, and grade level could "possibly benefit from the same level of instruction." For example, the group discussed how they didn't perceive the entire staff benefiting from a session focused on "student goal setting." Rather this group identified training in student goal setting as something "probably very beneficial for a new teacher or a teacher changing grade levels." The group suggested that even a division between "new and experienced teachers" would provide some level of differentiated instruction. Participants also considered a "division among upper and lower elementary grades" as a means for differentiated instruction. Members regarded some of their own "behavior such as texting to my friends in the room" and that of others as a direct result of being "bored out of my mind" and listening to "so much stuff that just doesn't pertain to 
anything I do in the classroom." One participant, rather than feeling "bored out of my mind," felt that s/he was often viewed as highly knowledgeable by leaders, offered this view:

Let's say administration sees me as knowing a lot about Compass Learning. Well, I get utilized to train other teachers because it's assumed I know it all. I then miss out on the opportunity to learn what others are learning during that time period. I don't benefit from that time, personally or professionally.

The group acknowledged and agreed with the participant's commentary and felt that his/her viewpoint further identified a clear need for differentiated instruction. The respondents concurred that when an incentive such as differentiated instruction is lacking in a classroom "filled with at least 50 highly talented educators, nothing much meaningful happens." As one participant asserted, "It's [content of professional development] about 10\% applicable to just about anyone in the room." Another concluded, "I would love to have that time to learn something or do something with my position."

The focus group members explored a final incentive toward supporting their professional development: feedback. When participants discussed feedback as an incentive toward actively participating in professional development they expressed the need for leaders to not only ask for feedback but to listen and hear the opinions of the staff. As one respondent commented, "Take what teachers are saying and actually use that feedback rather than just moving forward and planning the next thing before finding out if whatever you implemented worked for your teachers."

The group shared how "not once during that first year" were they given any type of written survey. One participant recalled a few times during the course of the year the professional development planner announcing, "Come talk to us, we want to see how it's all going." The group vocalized that this type of blanket announcement was insincere and a 
"weak attempt at best." Participants also felt that if they had tried to express their opinions to administrators, they would have been viewed as "complainers and not as someone wanting to get in there and roll up their sleeves."

The group noted that at the start of the following school year, teachers were given a written survey "about how they wanted professional development to look." The group felt that the survey was flawed as it "merely asked teachers to prioritize a list of predetermined topics for the year." One respondent also recalled that the survey did not contain any openended responses. Participants recalled receiving the results on a graph and then "nothing was done about it." One respondent recalled that the survey results identified technology as a high priority. However, it was shortly thereafter that the focus of professional development shifted toward PLCs (Professional Learning Communities), which was identified as a "low priority" by the teachers. The group commented that the results of the survey were distributed "months and months afterward" making their feedback meaningless and "not what they [school leaders] wanted."

Theme Two: Experimentation without fear depends on parents' perceptions.

The focus group did not consider its district as a place where a norm of experimentation exists which lets educators try new practices without fear of criticism should initial efforts fail. One participant acknowledged that when new instructional practices are implemented, "You are really left alone to struggle though the challenges." Another respondent agreed noting, "No one ever even comes in to observe me and it's not the administrators you need to fear here anyway." When prompted to further explore the meaning behind the previous statement, "It's not the administrators you need to fear here anyway," group members identified criticism from the parents as "the one thing to watch out for." 
Participants discussed that new instructional approaches "go along fine" until a parent becomes upset over "some aspect of the program." They admitted that although parents are not educators, it felt "a little scary to be trying something new and know that I failed in the eyes of a parent." Participants perceived parent feedback as the determining factor between failing and succeeding. One respondent espoused, "It was an absolute shock coming to this district and feeling like parents didn't support you." It is interesting to note the course of events participants discussed which lead to a teacher being "summoned to the office." A participant led the interviewer through the process.

A parent gets wind of something new we are doing and they might ask their child, "Are you being challenged?" If the answer is no, then the parent will just call or email the superintendent. Next thing you know, you are backing yourself up about a new practice that the school mandated.

Another participant interjected by saying,

I think that when the parents are unhappy with the child's initial frustration with starting a new program, they don't want their child upset and wish for it all to be smooth sailing - and if it's not, then the teacher hears about it not from the parent, but from an administrator-usually the superintendent.

The group further hypothesized that struggles in starting new programs were often perceived as a "lack in teaching skills from parents and the office." Participants agreed that more than anything, failure results due to "a lack of time to prepare and get those new programs started." The group agreed that it was "expected and required" to try new instructional practices, but when parents didn't support them and the administration did not genuinely support and trust its teachers, failing was frightening. One member remarked, "It's just crazy that they can't tell the parents 'Hey we trust our teachers.' Instead they say, 'Hey if you have a concern about the teacher, come see us.' It just seems so unbelievably unprofessional to know that parents can just go see the superintendent." 
Theme Three: Grade level teams best support a norm of continuous improvement toward best practices.

The focus group recognized the "collaboration efforts of grade level teachers" as best supporting a norm of continuous improvement toward best practices. Participants reflected upon the significance of grade level teams "working together through lunch, before school, and during the summer months to plan and improve their teaching strategies." When prompted to describe the focus of their collaboration efforts, group members explored the following: establishing pacing guides, creating curriculum for the Columbia Writing program, planning across the curriculum, analyzing student work, studying state released test questions, and providing feedback about their own classroom instruction.

One respondent declared, "I don't know what I would do without my team and even other teachers working at different grade levels." Another member contributed, "We have to support each other, teachers, because we aren't going to get it anywhere else around here."

When probed to expand upon their perceptions of school leaders supporting the norm of continuous improvement toward best practices, the group identified the Columbia Writing program as "maybe the one thing." Participants regarded school leaders as dedicating time, training, and resources toward the Columbia Writing program.

Members felt that the administration supported a norm of continuous improvement by hiring Columbia professional development trainers to visit the school and train teachers through a laboratory classroom design. The district also budgeted for a "select few" to attend Columbia University and receive the training in New York. The group concurred that the Columbia training not only "looked good on the surface but actually was a move toward continuing best practices." 
The dialog expanded to include school leaders supporting a norm of continuous improvement only at the "surface level." For example, one participant began the dialog by saying, "All of the wealth a person would see when they come into our classrooms might indicate that we are always improving and just the amount of resources would show our school leaders as vested in continuous improvement." The group observed that so many of the resources are about looking good and "checking off boxes." The following discussion further defines the group's perceptions.

They [the district] have the need to make sure our board members or whoever knows we covered all of these topics for the year.

Yeah, like the smart boards. The district bought them, they are in our classrooms, but do most of us know how to use them?

Let's add to our list the CRS. The board saw one demonstration by a technology teacher. But do we know how to use these things toward improving our teaching?

I never even took mine [CRS] out of the box.

Theme Four: Our professional development programs are aligned to a "thinking curriculum" but only on paper.

The participants perceived their professional development program as "more of a show and looking good on paper." They discussed how if an observer examined their weekly Monday agendas, followed the "email trail," viewed the board agendas and minutes, the program would demonstrate alignment to the district's mission statement, goals, and objectives. Group members believed that true alignment followed "goals set by our school board." For example, one member noted that the school is to improve its AYP by $2 \%$ annually. Another participant contributed that increasing the AYP is not part of the district's vision and values. 
The group observed that much of professional development is spent on testing which is aligned not with the district's vision but with the school board's goal. As one contributor acknowledged, "Yeah, the maintaining or increasing of test scores - that is really our bottom line." Participants concurred that the "majority of professional development is data driven and doesn't help teachers develop or refine skills." Members perceived the focus on MAPS data and other assessments as not a strategy to guide instruction but a way to "just get scores up to meet that $2 \%$ increase every year."

The group viewed many of its "Monday mornings" as simply "sitting around" discussing ideas for improving test scores. One respondent added "there isn't a whole lot going on in professional development to develop us as teachers." Participants remarked that although teachers discussed the concept of academic rigor, teachers seldom "walked away with anything like a teaching strategy they could implement in the classroom to improve student achievement." In order for the program to be truly aligned with the school's mission statement, objectives, and goals, participants suggested hiring "someone to come in" and teach them strategies for improving student achievement. As one respondent commented, "I want someone for example from Columbia to come in on Monday and demonstrate some strategies that I could use with my struggling students." The group also claimed that focusing professional development on analyzing MAPS data and CST scores leaves little or no time for "using the data to inform instruction" which ultimately could lead to a "Thinking Curriculum," the school's vision.

Theme Five: A limited knowledge of the change process could potentially impact student achievement. 
Participants remarked that "just the mere fact of making such a huge change to a Monday morning" implied that the leaders possessed a "limited knowledge" of the change process. Members identified Monday morning as the "absolute worst time" to hold professional development. They speculated that parents pushed for Monday mornings so students could have late start and "sleep off" the weekend. The focus group voiced that all of these "weekly curriculum changes" coupled with "hearing bad news over personnel matters" made the transition from Monday morning to classroom teacher especially difficult. As one participant acknowledged, "It just doesn't set the right tone for the week and hearing that, say a former teacher you worked with is sick is upsetting. Then you know it's off to greet the kids with 'Good morning." Another member commented "trying to teach anything after some of those sessions was useless."

The focus group concluded that "not much time had been devoted to studying the process of change" before the system wide initial implementation of the professional development program. They supported their beliefs with the following statements:

We tried to change too many things at once.

We weren't given time to actually work through an idea or concept before it changed again.

There is no one big objective, no big thinking.

The year was full of change because everything we studied was a reaction to a board member or a parent or a personal motivation of a leader.

I've been here a long time, yet every year I feel like a new employee.

Members considered how the perceived lack of leaders' knowledge toward the change process impacted their experiences. Participants agreed that not only is it " frustrating," the majority of the staff "isn't buying what you are selling." The group also acknowledged that it 
affected their self-efficacy, and they felt "stressed" and did not believe "they were doing anything well." Respondents suggested that a "trickledown effect" impacted their own students. The focus group concurred that students can and do feel a teacher's stress. Additionally, because teachers were always being mandated to change, the students "suffered along with us" through these changes. For example, as one respondent remarked, "One week we are teaching vocabulary this way and then it changes again in two weeks." Members also identified a sense of "calmness and confidence" which comes with perfecting the same instructional strategy. Another participant added, "When we are constantly changing, our kids are a little unsettled."

Theme Six: Follow up support equates to time and conversations.

One word began the discussion: "anything." The focus group declared that "anything" would have been helpful. Members narrowed their commentary to what they felt could have been the best type of follow up offered during the system wide implementation: time and dialogue. The focus group agreed that follow up was "impossible" based on the number of new programs and the amount of overall changes. "We don't have the time," contributed one participant. They recommended "drastically reducing" the number of new programs and "giving the teachers back some of their prep time" to develop, implement, and refine "just a few things." As one participant voiced, "It's like if a new program is even mentioned one time on Monday, then Tuesday they [school leaders] want it up and perfectly running." The group believed it was ironic that a program, which was "initially sold to them as unpacking the backpack and making time for the important things" did just the opposite.

When prompted to explore these provisions more deeply, one participant expanded upon the concept of dialogue. "I would like some follow up discussion. I would love it if 
someone would just ask me, 'Did you get that?' And then actually listen to my answer." Another member contributed, “Or how about, someone saying, 'How can I help you with that?"”

The group then discussed the risks associated with "admitting you needed help with a new teaching approach." For example, a school leader might say, "We're here if you need anything." However, the group felt that "seeking out help is kind of frowned upon." Participants thought administrators perceived asking for support as a sign of weakness. They agreed that if a teacher needed follow up support, it was better to just ask another teacher, "somebody you trust who isn't a mole." Members also reflected upon former colleagues who were no longer employed by the district because "they asked too many questions." The focus group questioned the "genuineness and intelligence" of a person who doesn't have questions and challenges when learning a new concept. As one member expressed,

It's so opposite of how they are teaching us . . and the model they want us to use with our students. We are to encourage organic thinkers and do exploratory and inquiry. These are all ways of learning that require follow up through questioning and dialoging.

The group felt that the lack of time and dialogue as a means of follow up caused teachers not to "get too serious about much of anything." They identified lack of follow up as a "major reason" why teachers have "given up trying."

\section{ONE ON ONE TEACHER INTERVIEW}

The participant perceived his/her career stage as Winding Down according to the Fessler and Christensen's teacher Career Cycle Model (1992). The participant may have been preparing to leave the profession with positive and/or negative recollections. This self- 
identified stage may have lasted throughout the year, or occurred only during a matter of weeks or months.

The participant also experienced a sense of career frustration at the start of the 20072008 school year. According to Fessler and Christensen (1992), teachers who identify themselves as frustrated, experience job dissatisfaction and question why they remain in the profession. The participant was entering year six of teaching when the system wide change occurred in the district.

Theme One: The impact of not planning with but planning for a targeted population.

The participant did not perceive the administration, faculty, and other staff members as working together to plan professional development activities. S/he stated, "It just seems like something that is put upon us. We show up on a Monday morning and this is what we're doing." Upon further clarification, the participant remarked that the staff was not "surprised by the content" as agendas were "usually emailed out the previous Thursday or Friday" containing information such as what materials teachers would need to bring to the training. The participant noted that from week to week, "We were always bumping this to finish that — so the agenda didn't necessarily hold true." Not following the agenda created a problem with teachers not having access to the materials needed or "dragging it all down and not using it."

The respondent reiterated that teachers were not unaware of the topics from week to week, rather 'it's that we didn't have a say in what we would've liked to do during those weekly trainings." When prompted to explore the consequences of teachers not being involved in the professional development planning, the respondent replied, "I don't feel like I 
truly come out of our professional development meetings having learned or gained anything of use."

Upon further elaboration of the Monday morning structure, the participant identified "administration as usually running it." Additionally, the respondent also stated that the sessions are designed for the "entire faculty" and much of the material covered does not apply to his/her department. The participant commented that subgroups, such as his/her department, existed within the faculty and identified the "specialist teachers" as another such subgroup. "Definitely, a few groups exist to whom the professional development doesn't always apply but it does seem that the trainings might apply to the majority of self contained classroom teachers." The participant acknowledged that his/her department was a "very small part of the larger picture" and "it must be difficult as an administrator to try and meet the needs of such a wide range of professionals." The respondent thought that some sessions were "useful" and it was "just nice" to hold one meeting a week set aside for "some kind of development."

The respondent suggested that dividing the staff into two groups between upper and lower grades would be "a huge improvement" over the current meeting structure. Upon further reflection, the respondent admitted "there is no way you could meet my department's needs and the remainder of the school [teaching staff's needs] under one roof." When asked to recall a specific example of a session that did not apply to the participant's needs, s/he offered the following:

If we are talking about curriculum planning in grade level formations, for example planning reading units, I may be told to join the fifth grade team as some of my students are in the fifth grade. However my students may not actually be working at that level or even with that curriculum. 
After reflecting upon the experience, the respondent voiced, "I walk away from a grade level meeting like that and from many of our professional development sessions not feeling like I really gained anything that I can use with my students." The participant concluded by saying, "I still think the fact that we have it [professional development] is good. The time can just be used a little more wisely."

When asked to recall a professional development session that did meet the needs of the target population, the interviewee identified the topic of character education. S/he shared that the school could be a "hard environment for kids if you don't meet the mold." Also, the school in past years experienced several "bullying incidents" and the fact that the school did not have a "consistent discipline plan and expectations for students" created difficulties for students and teachers.

Prompted to share more about the attributes and differences between the character education topic and other topics studied during the Monday professional development sessions, the participant stated that character education affects all people working in a school, "so it did apply to everyone in the room." However, the respondent acknowledged that only "one session" was "spent going over the binder." S/he stated, "We were all left kind of wondering, 'Okay so it sounded good-but what do we do now?'”

Two conclusions can be drawn from this part of the discussion:

1. What topics would be considered important to all faculty in a whole group setting?

2. In what ways could professional development be improved to meet the needs of subgroups existing within the population?

Theme Two: The impact of change without consideration of those expected to change. 
During the year of the initial implementation of the weekly professional development program, change was omnipresent. The participant identified "going from basically having no professional development to regular Monday morning meetings" as the largest change impacting the staff. S/he expressed that a change of this magnitude might have been more effective if "we had been a part of it." When asked to elaborate, the interviewee shared the following recollections:

I don't remember being asked if we thought that this would be valuable or if such a huge change was necessary.

... or what we would be doing during the time.

... or when the best time would be to have it.

I would probably prefer to do it after school.

It was a decision that was just made and there we were sitting in chairs every Monday.

We were left out-it was just put on us.

From these reflections, the participant concluded that such a school wide change should involve the members that the change will impact. "At least take into consideration the opinions and desires of those who the change is mostly going to affect, and at this school it most directly affects teachers." $\mathrm{S} /$ he felt that organizational change is more effective when people, who will be greatly affected, are involved in different ways or at least, "feel like they have the opportunity to do so." The respondent further noted a "sense of impending doom" surrounded the program from the start. S/he attributed these feelings to "teachers not having an awareness as to why we needed to change, how that change would happen, and a long term goal associated with the change." The participant suggested, "If teachers had been in on 
the change from the start, we might have been more aware of the challenges made imminent by change, and strategic measures might have been put in place to help us sort it all out." Upon further reflection, the participant suggested that planners of change ask "people on the front lines" for feedback along the journey. S/he added that feedback after every Monday session during the first year, might have guided administration in planning the following year of training. The respondent perceived "even a simple useful or not useful check sheet after each session" as making a difference in planning future professional development.

Three questions emanate from this part of the discussion:

1. In what ways can organizations prepare their members for system wide change?

2. How can teachers be supported through a system wide change?

3. If teachers feel included in the initial change process, how might their perceptions differ during the initial implementation of a program?

Theme Three: Norms are simultaneously supported and thwarted by administration.

When asked to address the concept of teachers trying new instructional practices without fear of criticism if they failed, the participant acknowledged that s/he "thinks more about my colleagues more than myself." The respondent further commented that his/her department is based on meeting every child's individual needs. Consequently, the department experiences "much more freedom with instructional strategies."

The interviewee believed colleagues were held to a "very rigid standard." For example, classroom teachers must all teach reading at the same time, use the same program, and follow the same pacing guide. Additionally, any new instructional approach is "frowned upon" if it did not "come from the top down." The respondent also commented that a history 
or "twisted tradition" exists within the school culture. Further discussion identified this "twisted tradition" as parents in the role of "informants" coming to "check up" on the teacher. If that particular teacher is trying something new or different, and the parent "doesn't go for it" then a "big negative response from the administration is felt all over campus." The participant, speaking for colleagues, identified "parent response" as the number one factor detrimental to the norm of experimentation which permits teachers to try new approaches without fear of criticism.

Additionally, the respondent elaborated on the concept of success. "Here such an emphasis is placed on success and perfection, that teachers are afraid to try anything new or different." When asked to provide an example, the interviewee hypothesized the following scenario:

Say you are teaching math and you know that the students might understand a concept better with a hands on type lab activity. However this lab is not in the curriculum or pacing guide. Probably most teachers would not give the lab a try because they will not be successful in meeting the team's pacing schedule. Not to mention if someone else sees the lesson and it somehow turns into a flop.

The participant suggested that "a sense of insecurity" exists among the staff, even "if you have been here 10 years." S/he contributed this "sense of insecurity" to an inconsistency throughout the years from administration toward teachers' evaluations. For example, two teachers may "pair up" and try a new instructional approach. One teacher will receive a "meets the district's standard" and another will receive a "needs improvement." The participant stated, “It's inconsistent as to who gets reprimanded for doing one thing while another teacher can get away with doing other things." The interviewee concluded by suggesting that teachers want to try new things but are scared because of "parent backlash and administration's response which leads to an overwhelming sense of insecurity." 
When asked to expand upon the norm of continuous improvement, the participant commented that "nothing is very static around here" and that the constant state of change was generated by administration. The respondent noted that the word improvement does not necessarily equate to change. "We do a lot of changing but I think a lot of teachers would argue whether this constant state of change really supports a norm of continuous improvement." S/he also suggested that administration's point of view differs. "From the top, the changes that we are constantly experiencing are considered improvements.”

When asked to provide an example, which would support the different perceptions of teachers and administrators, the respondent discussed a partnership the school formed with the Columbia Teachers College.

In the last couple of years, teachers have been trained at the Institute, and professional staff developers have come here to provide the onsite lab experience. Some teachers are having a hard time and don't necessarily view the program as an improvement but it has made teachers completely change their writing instruction. From the start, administration has viewed this program as an improvement.

Based on the discussion in its entirety, several overarching questions remain:

1. How might a participant's self perceptions of career wind down and career frustration impact the responses?

2. How does self identification in the teacher career cycle affect teachers' attitudes and beliefs toward a system wide change in professional development?

3. In what ways would the responses be different if more than one participant in the sample had formed this subgroup? 


\section{Administrative Subgroup}

The three participants in this subgroup were interviewed separately. The data was then combined for the qualitative analysis. Respondents were all administrators with varying degrees of experience.

One subgroup member was hired into the district as a principal and currently served the district as the assistant superintendent. Another subgroup member began his/her career in the district as a literacy coach. S/he earned an administrative credential and was internally hired in the role of a K-4 principal. The third member of the subgroup possessed a doctorate degree and had administrative experience outside of the K-8 school district. S/he was finishing year two in the administrative role of an upper grade principal during the time of data collection.

Theme One: Leaders use various methods when preparing for a system wide change.

Subgroup members prepared for the system wide change in a variety of ways. For example, one participant "networked with assistant superintendents to explore their successes and challenges." S/he also explored the district's culture and studied "Fullan" to acquire more knowledge in the area of combining "school culture with change theories." Additionally the participant "networked" with the "National Staff Development Council."

In preparing for the system wide change, another respondent gathered "input from the leadership team and colleagues by asking, "What are our priorities?" S/he held "conversations with parents and the [school] board." Additionally the respondent explored the relationship between "student achievement and teacher knowledge," linked "student achievement with coherent professional development," and "focused on adding coherence among professional development [sessions]." Also, the respondent collected student "data" 
from programs such as "DRA (Developmental Reading Assessment) and MAP (Measures of Academic Progress.)."

One subgroup member used his/her knowledge of professional literature such as Power of Protocols (McDonald, 2007) to establish "protocols" such as "an instructional routine for adult learning in professional development." Additionally, s/he called upon previous experiences working with Professional Learning Communities. As the participant noted, "[I have] lots of experience with PLCs."

The following two questions can be drawn from participants' responses.

1. How do these methods of preparation compare to methods utilized by school leaders in other districts?

2. What other methods did school leaders use to prepare for the system wide change? Theme Two: Professional development activities that complement school wide efforts share the ultimate goal of improving instruction.

One subgroup member described a professional development activity designed to increase a teacher's knowledge of assessing student data. In the district students take a MAPS (Measure of Academic Performance) computer test three times a year, which "generates data in the areas of reading, writing, and mathematics." The overall goal of the professional development activity was to "Help teachers to learn how and why we use MAPS." For example, outcomes of the activity included "zeroing in on the data and learning how to use data to inform instruction." The concept of building teachers" "assessment literacy" complemented school wide efforts to use student data to inform classroom instruction.

Two participants reflected upon the design of an ELA (English Language Arts) standards project. One participant described the planning stages in detail. S/he began by 
recalling the project goals as "Helping teachers understand the role of professional study, building stamina around one project, and promoting collaboration through study and reflection."

In the preliminary planning stage of the ELA project, discussions revolved around "[a] cursory understanding of what state standards were ... after three years [we] knew but didn't know the importance of power standards." Curricular coherence was lacking and the "need for alignment based on standards" was identified. Before the actual implementation of the ELA project, "teachers had not been asked to study something ... [we] wanted it to be a collaborative culture instead of competitive."

The project was implemented by "the two principals, the literacy coaches, and I in the spring of 07-08." Teachers worked in K-8 vertically aligned teams for "about seven weeks . . . most of spring and studied high priority standards." The culmination of the project required "experts on ELA strands" to report findings back to their grade level teams.

Another participant, who identified the ELA project as a professional development activity complementing school level efforts, stated that teachers worked with the high priority standards and posed questions to team members such as, "What does it [a standard] mean?" And "Who [which grade level] teaches it?"

Three overarching questions emanate from this section of the discussion.

1. What attributes did the professional development activities have in common with research based best practices in professional development?

2. What other professional development activities during the first year of the system wide change complemented school level efforts?

3. Why did two out of three participants focus on the ELA project? What made the project memorable? What attributes defined the project as complementing school level efforts? 
Theme Three: Leaders differ in their approaches toward supporting and encouraging professional development.

One participant supported and encouraged professional development through modeling. For example, s/he stated, "[I] model professional development as who we are as educators. We know a lot, [and/but] can know more." The participant also believed that teachers are lifelong learners and stated, "We as teachers must also be learners . . . and [I] hope to do [show] that through modeling."

Another respondent supported professional development through monthly staff meetings. For example, s/he coordinated the literacy coach to demonstrate "an interactive read-aloud." The respondent also provided support and encouragement for professional development through correspondence such as "emails and newsletters." S/he also recognized "goal setting" and "introduced alternative evaluations" as a means for support and encouragement. When asked to elaborate on alternative evaluations the respondent shared the following:

[I] introduced alternative evaluations and then teachers brought their proposals to me. Teachers can tackle a subject of interest with one to two others and [I] then meet with the teachers. For example, two teachers pursued integrating technology into the curriculum. Another group focused on learning how to confer with writers.

All participants in this subgroup stated that they offered follow up support to professional development programs. Methods utilized for follow up support varied from participant to participant. One respondent shared that he/she "tapped into teacher expertise." When prompted to provide an example, the participant remarked, "Sally, a classroom teacher, knew how to use the Compass Learning computer software program. Folks signed up to work with Sally on topics of their choice." 
More than one participant voiced that follow up provisions were offered in Monday morning seminars. For example, one respondent said, "Sometimes it [follow up] occurred in the next Monday morning meeting." Another respondent agreed and stated, “. . . always followed up with faculty ... maybe during Monday morning professional development or in faculty meetings." Participants generated the following examples of follow up support:

[Teachers] were given opportunities to learn more about CRA [Columbia Reading Assessments].

Literacy coaches would follow up with grade level teams on Dibels and CRA.

Analyzed STAR data.

Analyzed MAP data.

Training on Compass.

At the end of the ELA project, results were shared in team meetings.

Three questions can be posed from this section of the discussion.

1. How would teachers perceive these forms of support and encouragement?

2. What kinds of support and encouragement do adults learners desire?

3. How do these forms of support and encouragement compare to what adult learners desire?

Theme Four: Evidence of the norm is exemplified throughout the school and modeled by leaders.

Participants concurred that a norm of continuous improvement exists within the district, which recognizes that learning about best practices is never finished. The degree to which the norm was followed varied. For example, one member stated that the district was "getting there." While another participant believed that, "way over the majority have 
developed this [norm of continuous improvement] mentality." S/he felt it was important to create a "safe place" where people would "want to improve in their area."

One respondent commented that "change is essential." S/he also noted, "Our practice was antiquated and there has been lots of change - a paradigm shift toward the norm of continuous improvement." The respondent acknowledged that "Implementation [of best practices] is hard. [I] work with thoughtful, reflective teachers. We have processed the change process-but need to do better and refocus."

Members of this subgroup believed that newcomers to the district would observe several examples that would support a norm of continuous improvement across the district. One participant remarked, "[Newcomers would observe] ... wiki, blogs, digital storytelling, smart boards." S/he also thought newcomers would view "leaders" throughout the school "helping people to understand and learn how all is connected through PLC's (Professional Learning Communities)."

Another respondent noted that a "newcomer would observe collaborative efforts around district goals and objectives that would come to fruition in the classroom." Additionally, another member of this subgroup commented, "They [newcomers] would definitely know our focus is around the Columbia work."

When asked what a new teacher or administrator might notice which would reflect a norm of teachers trying new instructional practices without fear of criticism, one participant perceived "modeling" as supporting the norm. For example, "Principals will teach minilessons at least one per grade level. The principal is learning as she presents with kids, with teachers, and with literacy coaches." The participant continued by detailing a 10-day classroom experience in the area of mathematics. 
[I] prepped and taught 10 days side by side with the teacher. I wrote a reflective piece on each lesson and emailed it to the teacher and team. [You] can't believe how much thinking you do after you teach. [I] modeled reflective behavior.

Another participant also perceived modeling as a way to support a norm of trying new strategies without fear of criticism. The participant recounted an experience of trying something new in the classroom. "I got into classes [classrooms] and the teacher explained the pre/post work. Then [I] taught [the lesson] and the teacher saw me flounder and also succeed. [Then] we debriefed after each [lesson]." Additionally, s/he remarked that a "slogan, 'Mistakes are expected and welcome'" generated by the district's "vision and values campaign," reflects a philosophy of trying new ideas without fear of criticism.

This section of the discussion evokes the following questions:

1. What were the teachers' perceptions of leaders modeling the norms?

2. How did the system wide change in professional development establish, affect or contribute to the norms?

Theme Five: School culture is perceived as evolving despite a difficult contextualized nature.

One member of the subgroup described the culture as "interesting and evolving." However, s/he mentioned that there was a "small group who don't perceive the evolving nature of the profession. Some people are interested in the status quo and resist change." Another respondent agreed and remarked, "There is a small group living in the past." One participant estimated that " $75 \%$ to $80 \%$ " of the teaching staff was hired within the last 5 years, while another respondent approximated that over " $50 \%$ " of the teaching staff had been hired since s/he came to the district. 
Two participants used the word "fear" when discussing the "historical component" of the district's culture. For example, one participant remarked, "Teachers did as [they were] told for fear of their jobs." While another subgroup member commented that a previous longterm administrator was "autocratic" and "ruled by fear." Consequently, this subgroup perceived a small percentage of the population with personal histories as "storytellers" who continued to pass down "myths and legends."

Additionally, members of this subgroup perceived an "us against them" mentality encouraged by "a few on campus" and "a small group" of the population. One respondent stated that the "administrator versus teacher" resulted from "something deep in the culture."

When prompted to provide an example of the "us against them" culture, two participants replied that the principals, assistant superintendent, and superintendent were referred to as 'the administration and not by name. Instead of 'What does Mary think?' it's 'What does administration think?"' Another respondent commented on the consequences of an "us against them" mentality by hypothesizing that "teachers versus administrator may undermine the collaborative spirit of the many and some were frustrated with the vocal few."

Veteran members of this subgroup described how the collaborative nature of the culture has significantly changed throughout the years since their arrival to the district. Upon reflection, one member stated, "Five years ago it was the least collaborative district s/he had experienced but now teachers do work together and it's the norm not the anomaly." Another member concurred by expressing, "[It's] much more collaborative here now and less divisive." S/he further explained that the collaboration was "not just collegial as we now are pushing each other's thinking." Additionally, the subgroup member described collaboration 
time as "Now looking at student work which stems from our Professional Development Monday morning meetings."

The subgroup perceived recognition of success as steadily improving and becoming part of the district's culture. According to participants, in previous years, "[There was] a history of not wanting recognition" and "some teachers commented 'Don't recognize as it shows favoritism." One respondent remarked, "[It] wasn't part of the culture when I got here." Another subgroup member perceived recognizing successes as "putting people in uncomfortable places."

When asked to provide examples of honoring school personnel for their success in the profession, participants shared the following:

Years of Service award at board meetings.

Asking someone to take the lead.

Offering a smile—a compliment read aloud during professional development. Thank yous.

Kudos to colleagues.

Teachers share and model.

Examples provided by the participants indicate that personnel are recognized privately and publicly, informally "through conversation" and formally "at board meetings."

Three questions can be posed based on the discussion of school culture.

1. In what ways do school leaders contribute to the school culture?

2. How do leaders in other districts perceive their school culture?

3. How might the school culture be perceived in future years by these same administrators or future administrators? 
4. How would school personnel prefer to be recognized for success in their careers? Theme Six: Leaders choose different focal points upon final reflections.

When asked to comment on final reflections related to the system wide change in professional development, responses varied from administrator to administrator.

One participant reflected upon the importance of professional development. S/he stated that "the purpose" and "why it's important" rests in the theory "student achievement is based on teacher knowledge." The participant perceived teacher knowledge as "always growing" and that "time was needed" to do so. Additionally, she/he expressed that professional development was "about building community through vertical teams."

Another respondent thought it was "important to know the goals and purposes of the system wide change in order to explain previous responses." S/he defined the purpose of the system wide change in professional development as "teacher collaboration" and "working with colleagues in a variety of structures." The respondent also connected the district's "vision and values" to "best practices."

During the first year of the program, s/he believed it was important to define the parameters of professional development. For example, the respondent stated that in the initial year, "[we] classified what professional development is and is not." The respondent wanted school personnel to realize that professional development is "not an extension of planning time" such as "grade level logistical planning like when a fieldtrip will happen" but rather a time for "learning and growing together." Consequently, the first year was "tight in keeping a focus on goals and purposes." The respondent envisioned the program as "evolutionary" and "looking different this year than last and different next year than this year." 
In reference to the interview questions, one subgroup member stated, "It was difficult to remember a year ago." S/he referenced the district as "unique" implying that what occurs in this district doesn't happen "anywhere else." The member also shared his/her philosophy relating to the system wide change in professional development. "You have to believe that Monday mornings are not just an add on and the time for professional development has to be provided." S/he also declared that "clear expectations are needed" for all those professionals involved in a system wide change.

Several questions can be posed from the discussion in its entirety.

1. How might responses have been different if participants were interviewed together?

2. If participants would have been audio recorded, would they have responded differently?

3. Did participants confer with one another before the interviews? If so, how might it have affected their responses?

4. How might leaders in other school districts, experiencing a system wide change in professional development, respond to the same set of interview questions?

\section{Cross Case Analysis}

The data across the one-on-one interview, the five teacher focus groups, and the administrative subgroup were explored and organized into five themes which address critical aspects of an organization's capacity to support individuals through a system wide change.

\section{Theme One: Strategies for Engaging Adult Learners: An Opportunity for Growth}

Participants identified and expanded upon several components they described as "essential and conducive to adult learning." These components discussed by participants are 
disaggregated into the following five constituent parts: (a) feedback and follow up support, (b) active and interactive learning, (c) differentiated instruction, (d) time for construction of new knowledge, and (e) participatory planning.

\section{FEEDBACK AND FOLLOW UP SUPPORT}

Several focus group participants suggested a desire to give feedback throughout the first year of implementation. For example, in the one-on-one interview, the participant commented that feedback might help guide the planners and create a more valuable program. S/he envisioned "a simple useful or not useful check sheet after each Monday session" as making a difference toward future professional development.

Participants in focus group three remarked on the absence of "surveys, feedback, and team discussions," components they believed essential to any new program. For example, the group discussed distributing teacher surveys in order to identify learning needs on any given topic. As one member expressed, “. . the survey could have asked us to identify our knowledge of Compass Learning and who needed all of that training and who did not." Participants also suggested that surveys administered throughout the year might have provided planners with valuable feedback that would ". . . hopefully guide future sessions."

Members of focus group five listed feedback as an incentive toward actively participating in a professional development program. The groups shared how, "not once during that first year," were teachers given a survey. They believed that leaders should ask for and listen to teachers' opinions. For example, the group remarked, "Take what teachers are saying and actually use that feedback rather than just moving forward and planning the next thing before finding out if whatever you implemented worked for your teachers." Although 
teachers did not complete surveys, group members did recall a few Mondays when the professional development planner would invite staff to "Come talk to us, we want to see how it's all going."

Definitions, expectations, and perceptions of follow up support varied from group to group. However, the majority of groups did not feel enough support and follow through was offered during the first year of the new professional development program.

Focus group one participants viewed follow up support as an essential element that was "somehow missing" from the professional development program. Although the group felt that follow up support was not "administrator driven," it could be found within the teaching staff. Several examples of support from colleagues were provided such as assistance with technology for Compass Learning, help in the comprehension of a new math program, and assistance locating reading assessment resources.

Members of focus group two expected more follow up support during a system wide implementation. They did not believe that the structure of the program encouraged follow up. For example, the participants concluded that starting something new every Monday did not allow sufficient time for learners to identify areas where "they might need help."

Participants in this group voiced a desire to have some of the Monday mornings designated as support and follow through sessions. As one participant stated, "The follow up is that next Monday we continue to refine what we started the week before." The group also discussed how administrators probably thought they were offering support by coming into classrooms for a "check in." Focus group members strongly perceived this type of checking in as checking up on teachers rather than supporting them in new learning. Because they did 
not feel supported, participants noted a lack of investment and "a return to what they know and are comfortable with" in terms of instructional approaches and classroom procedures.

Focus group three participants expected follow up support from their administrative team but they also felt it was a teacher's responsibility to ask for additional support. One group member remarked that a teacher would be "waiting a long time for someone to show up in the classroom and offer support." The group did admit that asking for help may be viewed as a weakness through administrators' perceptions and could lead to grade level changes or the end of an untenured teacher's assignment. Additionally, participants in the group suggested that as a means of support, they would like to have resources available instead of having to "create everything" for newly adopted programs.

Members of focus group four defined support for the program in terms of resources. They commented that support for professional development was biased and it was very difficult to determine the criteria used for "who got what." As one participant observed, "There are a certain some [teachers] that receive everything and also have multiple opportunities and then some that are at the bottom of that list." They believed that the district's educational foundation decided much of where "the money goes in our program."

Focus group five participants viewed the program as having a "vast supply" of monetary resources available to support teachers. They commented that they were "fortunate and blessed" and other schools would be "jealous of their technology and supplies." Consequently, this group discussed the concept of support in terms of how teachers were treated and what teachers needed to improve their learning experiences. For example, they wanted to be supported through "a sense of professionalism" that encouraged "trust and respect toward teachers." Participants also viewed changing specific elements of the program 
as a means of support. For example, focus group members believed focusing on a few concepts, asking for feedback, providing differentiated instruction, and raising the bar to meet teachers' learning needs could all be seen as supportive measures lacking in their program.

The administrative subgroup members collectively voiced that they always offered support and followed up with participants. For example, one respondent stated, "Sometimes it [follow up] occurred in the next Monday morning meeting." Another agreed by saying, “. . always followed up with faculty ... maybe during Monday morning professional development or in faculty meetings." Additionally, the subgroup believed that they offered support and follow through using a variety of methods indicative of their leadership styles. For example, one subgroup member modeled what professional learners do and think. S/he explained, "I model professional development as who we are as educators. We know a lot, [and/but] could know more." The participant felt that teachers were lifelong learners and $s /$ he "hoped to show that through modeling." Another administrative subgroup member opted to support teachers through monthly staff meetings and "tapping into teacher expertise." For example, s/he coordinated the literacy coach to model "an interactive read-aloud." S/he also supported and followed up through correspondence such as "emails and newsletters." Goal setting and alternative evaluations were also methods identified in supporting and encouraging professional development.

\section{ACTIVE AND INTERACTIVE LEARNING}

Focus group participants felt that they were mostly passive learners during the Monday morning sessions. They did not view the process of learning during professional development as active or interactive. Members in focus group two remarked that Monday 
mornings did not move much beyond "sitting around and talking about doing things." Focus group three recalled most of the year as "listening to descriptions and definitions of programs." Focus group four participants viewed their learning time during professional development as "Lots of planning but not a lot of action." They viewed the process of "actually doing something" as an incentive toward learning.

Participants in focus group five recalled "filling out graphic organizers and task sheets" during several Monday mornings. Group members did not view this as helpful in their learning but as a method for planners to "check in and ensure we were using our time wisely." Participants described many Monday mornings as "sitting around" discussing strategies for improving test scores. They also commented that "reading articles" and "watching old videos" was a "waste of time." Additionally, focus group five members summarized, "There isn't a whole lot going on in professional development to develop us as teachers."

In the one-on-one interview, the participant recalled a Monday devoted to learning about a character development program where teachers sitting in grade level teams "went over the binder" preceding a presentation by the 5-8 principal.

Although all of the focus group participants mentioned collaboration with grade level and vertically aligned teams during the interview process, they were adamant in expressing even collaborative efforts as not moving beyond "envisioning, discussing, and planning." As one participant noted, "[teachers] seldom walked away with anything like a teaching strategy they could implement in the classroom to improve student achievement." 


\section{DIFFERENTIATED INSTRUCTION}

Teacher participants in every interview addressed various aspects related to differentiated instruction in a professional development program. Collectively, they expressed dissatisfaction in what they believed to be a lack of differentiated instruction throughout the year. Specifically, focus groups discussed the consequences of not offering differentiated instruction, proposed several methods of how professional development planners could structure future meetings to encourage differentiated instruction, and identified differentiated instruction as an incentive to learn.

Focus group one participants and the one-on-one interviewee commented that much of what "went on in the Monday mornings just did not pertain to us." When prompted, focus group one participants could not recall a single activity from the entire year that directly pertained to their classroom responsibilities. This group also mentioned that an outcome of no differentiated instruction leaves people "feeling disengaged and just sitting for the length of time they have to sit." Focus group two members agreed and stated, "All in the same place, learning the same thing, at the same time," only encouraged adults to "tune out," and participate in disengaged behaviors such as "texting," and "playing on computers." Participants in focus group two perceived differentiated instruction as an "incentive" toward learning. Focus group four believed that a lack of differentiated instruction was a "fundamental flaw" in the program and considered the content of many Mondays geared toward "just a small segment of our school's teaching population, yet we are all expected to be present."

Participants suggested a variety of structures that would allow for "at least some differentiated instruction." For example, during the one-on-one interview, the participant 
commented, "dividing the staff into two groups, upper and lower grades" would be a "huge improvement." Focus group two participants said that if they had been involved in the planning process, offering differentiated instruction based on "various grade levels" would have been a component of every session. Focus group three members believed a survey to measure teachers' knowledge on the selected topics would have been beneficial in designing "some kind of differentiated instruction." Focus group five proposed a division of "new and experienced teachers" along with separating teachers into "upper and lower elementary groups."

Although the administrative subgroup responses did not directly address the concept of differentiated instruction, members of the subgroup did remark that part of the first year plan was to "create a common language" and "get people on the same page" in terms of professional development. They also commented that research "often warned against creating a program with features that contribute to the tradition of practicing in isolation." Since program developers mentioned that each year would look different than the previous year, a conclusion could be drawn that differentiated instruction might become a component in future years.

\section{TiME FOR CONSTRUCTION OF NEW KNOWLEDGE}

Several members across and within focus groups agreed that teachers were expected to learn something new just about every Monday and "have it up and running later that same week" without the necessary "resources and time." For example, participants in focus group two perceived new teaching approaches to be perfected "within an unrealistic time frame, like here it is Monday and you are being observed Tuesday, the very next day." Additionally, this 
group also expressed the desire for "time to try out things, team-teach, and observe and collaborative with other colleagues" before formal or informal observations.

Focus group three members felt that new material presented on Monday should be implemented on Thursday, as school leaders would hint, "We'll [school leaders and professional development planners] be coming around Thursday to make sure you are doing it." Teachers expressed disappointment in not being given adequate time to "make sense of it all" and desired the "gradual release of responsibility" approach, a strategy they practiced with their own students.

Participants of focus group five thought that "a lack of time to prepare and get those new programs started" resulted often in failure. They remarked that teachers were "expected and required" to try new instructional practices. However, teachers in focus group five expressed a need for more time before "unveiling" the programs to parents.

\section{Participatory Planning}

The one-on-one interview along with four out of the five teacher focus group interviews generated data that indicated that teachers perceived themselves as excluded from the planning process of professional development activities. Teacher participants explored this viewpoint through a discussion of attitudes, benefits, and consequences related to nonparticipatory planning. As one participant shared, "It just seems like something that is put upon us. We didn't have a say on what we would've liked to do during those weekly trainings." The respondent continued to voice that without any involvement in the planning of professional development activities, s/he "came out of meetings not having learned or gained anything of use." Teachers in focus group one also considered themselves not 
involved in the planning process. They expressed that teachers were "never consulted" in the preparation of weekly topics and that all study topics were "predetermined by the assistant superintendent." Adult learners in this focus group described the consequences of not being involved in the planning of their own learning as follows:

I feel that there is wasted time.

I am not engaged.

I would grow instead of just sitting for the length of time I have to sit.

Focus group two participants believed that "the district" planned professional development for the faculty. Respondents espoused that the first year of implementation was nothing more than "administration dictating to us." Members listed the top three consequences of not being involved in the planning process as follows: no differentiated instruction, no authentic learning, and no teacher buy in. This group also described how the experience might have been different if teachers were included as participatory planners. Participants thought that if teachers had been involved in "at least some" of the planning from session to session, fewer topics would have been studied throughout the year allowing for a deeper understanding of concepts and a better chance of classroom implementation.

Focus group three participants discussed how to best encourage adult learners. Members explored the concept of self directed learning and believed that if teachers would have had an opportunity for "some input" into the topics selected for study, the staff might have shown more of an interest in learning.

Members of focus group four did not feel teachers were included in the planning process. The group concurred that the planning of professional development came from "the top down." They believed that the content of the Monday mornings was "dictated" to the 
teachers as in, "This is when it will be and how it will be done." Interestingly, this group speculated that even if teachers were invited to plan a few professional development sessions, most teachers would "not want to be involved." Participants felt that teachers tired of planning events and activities that rarely come to fruition. As one member emphasized, "The last thing I want to do is get together and have a big hubbub on what we should do, when nothing is actually going to happen." This group also viewed the district as an unreceptive environment if the idea did "not come from a certain someone."

Participants of focus group five believed they were "seldom given any choice" or "opportunities to plan topics of study" from Monday to Monday. They viewed not being part of the planning and decision making process as a negative aspect in their learning during the system wide change.

\section{Theme Two: Structure and Management: Two Organizational Policies That Present Challenges}

Participants perceived several challenges stemming from the aspect of organizational policies. Since aspects of organizational policy are interrelated and blend together in terms of cause and effect, the data is not further broken down into specific categories.

Several focus groups expressed frustration toward the amount of topics introduced in the first year. For example, focus group two members remarked, "It was just too much too fast." They felt as if teachers were expected to jump "an entire ravine" in one year. Focus group three participants also appeared disheartened by the number of topics covered during the year of initial implementation. For example, one participant shared, "[we] would just get going and want to delve a little deeper on an issue then the staff was forced to move on to 
something new." Focus group three participants exemplified what may happen to learners when they feel overwhelmed with "too many topics." Participants in this group felt embarrassed when they experienced difficulty in recalling topics of study. For example, one participant admitted, "This is almost embarrassing, but I can honestly say nothing vividly sticks out that we even talked about last year." Others in the groups agreed by saying, "the focus changed almost weekly.” Focus group four stated, “. . . can't even begin to count how many things we were focusing on last year. Every meeting we were focusing on something different." This group proposed choosing a few topics to cover in depth during the school year. They provided an example of dedicating each of the three trimesters toward core curricula areas such as reading, writing, and mathematics.

Focus group four also elaborated on additional aspects, which tainted their learning experiences. They believed that the sessions were micromanaged to the extent of "absurdity and silliness." For example, the group said teachers could not leave the K-8 meeting area to work in another location unless they "asked for permission." The group viewed leaders as "extremely resistant to giving us time without being monitored or managed." Participants also commented that school leaders would "hover over them" when teachers were in teams collaborating. The focus group viewed administrators and their comments as an "interruption" to collaborative work.

Aside from feeling micromanaged, focus group four also found "troublesome" what they considered a "lack of caring" during professional development sessions. "Promoting a caring community is one of the school's values," contributed one group member. Participants believed that Monday mornings were of a "cold and hard" nature. They also discussed the lack of chairs "almost every Monday." Participants explained that many times teachers were 
forced to sit on the floor, as not enough chairs had been set up for the meeting. As one interviewer shared," I don't understand that - it's not like they don't know how many of us there on staff." Another member asked, "I mean, why can't we have enough chairs?"

Additionally, participants in focus group four clearly disagreed with the district's decision to hold professional development on Monday mornings. They were disappointed that although teachers had repeatedly stressed the downfall of scheduling professional development on Monday mornings, their voices were ignored and “. . . every Monday we were sitting in these meetings referred to as our professional development." Participants felt that "it just really set a bad tone for the week," "... it feels like a two by four to the head after the weekend," and ". . our stress has to affect our students."

Members in focus group five agreed with focus group four, commenting that too many "parameters" were placed on the weekly professional development sessions. One member remarked, "It was just so regimented as to what you could do or couldn't do." The group identified "work space" as an example of a micromanaged aspect which proved "restrictive and detrimental" to the learning environment. They resented not being "allowed" to leave the common meeting area and found it frustrating to try and work with the entire K-8 teaching staff under one roof. As one participant elaborated, "It's like when we broke off into teams or groups, we couldn't be trusted to just go work in our team leader's room."

The administrative subgroup viewed the structure of professional development as evolving. They believed it was important during the year of initial implementation to define the parameters of professional development by classifying “... what professional development is and is not." Members of this subgroup also commented that the first year was "tight in keeping a focus on goals and purposes." Due to the evolving structure, participants 
stressed that the program in the second year looked much different than in the initial year and that the third year would bring even more structural changes.

The administrative subgroup members acknowledged that they were "well aware" of the staff's frustration with the decision to reserve Monday mornings for professional development. They further commented that early release on any given school day was not an option for the district and research "showed late start Monday as a viable option in adjusting the school day."

\section{Theme Three: Identifiers of a Culture as Defined by Those Who Live It}

The feedback related to culture obtained from participants is described in terms of the following three abstract concepts: fear, norms, and perfectionism.

\section{FEAR: A FOUR-LETTER WORD FOUND IN CULTURE}

The administrative subgroup along with the teacher participants all used the word fear when directly or indirectly addressing characteristics and norms of their school culture. For example, two participants in the administrative subgroup viewed fear as a "historical component" of the district's culture. According to this subgroup, a previous long-term superintendent "ruled by fear." Consequently, teachers were afraid of losing their jobs if they did not follow the rules. This type of fear continues to be a part of the school culture. Long term employees referred to as "storytellers" seem to pass down the fear in the form of "myths and legends" to new and untenured teachers.

Participants in teacher focus groups and the one-on-one interview remarked that fear was a major component of their school's culture. The groups mentioned that teachers were 
afraid of some sort of retaliation or "punishment" if they "stepped over the line about anything" or "did something to upset parents." Tenured teachers throughout the groups feared a "punishment" such as "moving grade levels" and untenured teachers feared losing their jobs.

In the one-on-one interview, the participant discussed a "twisted tradition" in the school that involved parents as "informants" going into teachers' classrooms. If parents saw something they didn't like, a "big negative response from the administration was felt all over campus." S/he also remarked that "a sense of insecurity" existed among staff, even "if you have been here for 10 years." The participant thought the inconsistency administrators showed in teacher evaluations heavily contributed to this sense of fear and insecurity. For example, one teacher may "get away" with something while another is "reprimanded." Members in focus group two explored the concept of an "unspoken fear" existing in the "hearts and minds" of fellow colleagues. Participants hypothesized if the "unspoken fear" was purposely created to "keep them in line." Members felt that on the surface level teachers appeared confident but untenured teachers were "absolutely terrified of trying new things and failing." The group felt that the degree of fear experienced by teachers depended on an administrator's tone and leadership style. They speculated that new teachers were receiving little or no feedback after observations or any other time and this lack of communication attributed to their sense of fear. "It seems that new teachers only heard from the principal when a parent was unhappy and even this feedback often came too late in year." When the group attempted to rationalize and identify the unspoken fear among tenured teachers, they attributed it also to a lack of feedback, comments in formal evaluations, or even a "look from an administrator." 
Focus group four participants felt that teachers responsible for state tested curriculum such as English and math often lived in fear of "doing out of the box type things because of the potential impact of the testing along with administrative repercussions." They viewed social studies and science teachers as having the least amount of fear. This group also mentioned that the way parents responded to teachers' performances could also lead to a sense of insecurity and fear.

Additionally, members of focus group five identified parents as creating and maintaining a "culture of fear." For example one participant remarked, "No one ever even comes to observe me and it's not the administrators you have to fear here anyway ... it's the parents." This group viewed their daily teaching lives as "going along fine" until a parent complains over "some aspect of the program." The group viewed their fears as very real and noted that parent feedback was the determining factor between failing and succeeding at the school.

\section{A NORM OF CONTINUOUS IMPROVEMENT EXISTS}

Although participants agreed that a norm of continuous improvement exists within their culture, focus groups expressed some confusion and indecision regarding whom best supports the norm and where the norm originates. They speculated on the meaning of continuous improvement and identified several different subcultures as supporting the norm. For example, focus group one thought that a norm of continuous improvement translated to "constantly doing something new." The group further expressed how teachers were "running around doing a little of everything" and "never getting the time to perfect anything." Emotionally, teachers were downtrodden "feeling like we [they] don't know how to do 
anything well anymore." Focus group one speculated and empathized with the district, as they were worried about maintaining the high test scores and needed teachers to keep changing in the hopes of improvement." They credited administration as best supporting the norm but also commented that teachers as individuals "worked hard to improve student achievement and wanted students to meet their benchmarks."

Focus group two identified several individuals and groups such as "administrators, teacher leaders, literacy coaches, and teachers" as supporting a norm of continuous improvement. Members of this group also discussed where the norm or continuous improvement first originates. For example, they believed that the desire to continue working toward best practices must come from within the individual teacher if it is to be genuinely sincere. This group commented that extrinsic motivational factors may or may not lead to improvement or change.

Members of focus group three perceived school administrators as best supporting the school's norm of continuous improvement recognizing best practices. They also acknowledged that these attitudes and beliefs toward continuous improvement must move beyond "those in charge" to affect student achievement. Members of the group suggested forming a committee comprised of classroom teachers interested in implementing and developing best practices among colleagues. They felt that teachers might be more receptive and willing to change or improve their teaching methods if the ideas originated from "others just like them, working daily in the classroom."

Focus group four participants discussed that teachers were only perceived as supporting a norm of continuous improvement in the district if they shared the same viewpoint as administration, as most ideas for continuous improvement came from "the top." 
Focus group five observed grade level teams as best supporting a norm of continuous improvement toward best practices. For example, they discussed the significance of grade level teams "working together through lunch, before school, and during the summer months to plan and improve their teaching strategies." Products of collaboration such as pacing guides, analysis of student work, and curriculum for the Columbia Writing program were identified as evidence in demonstrating a norm of continuous improvement.

Although participants in the administrative subgroup agreed with teachers' perceptions of the campus demonstrating a norm of continuous improvement toward best practices, the degree to which the district employees upheld the norm varied. One subgroup member said, "Implementation of best practices is hard. [I] work with thoughtful, reflective teachers." Others in the subgroup viewed the district as "getting there" and that "way over the majority have developed this mentality." The subgroup collectively sighted several examples campus wide that provided evidence of the norm such as "PLC's [professional learning communities] collaborative efforts around district goals and objectives, Columbia work, wikis, blogs, digital storytelling and smart boards."

Throughout the interviews, discussions around the concept of professional development further indicated a norm of continuous improvement. For example, several groups remarked that they saw a true need for professional development and the concept "was great." In the one-on-one interview, the participant remarked it was "useful" and it was "just nice" to hold one meeting a week set aside for "some kind of development." Focus group two confirmed that the very idea of weekly professional development meetings "shows that there is always something to learn," and "just by meeting weekly for a scheduled length of time clearly follows the thinking that best practices are constantly refined and learned." 


\section{The Push to Be Perfect?}

Several groups commented that teachers employed by the district were expected to be perfect and they often fear repercussions if efforts fail. The participant in the one-on-one interview thought colleagues were held to a "very rigid standard." S/he also remarked that teachers fear trying anything new or different as "such an emphasis is placed on success and perfection." Focus group one speculated that their colleagues worried about failing because "they might be punished." They listed forms of punishment such as changing grade levels or being placed on "special assignment like monitoring the respect room." Participants of focus group one also felt pressured by "an expectation of perfection the first time through." Focus group four commented, “... [people] can't fail here.” Focus groups concurred that there "wasn't a whole lot of room for error, even if you are tenured."

Feedback from the administrative subgroup indicated that teachers were encouraged to try new learning approaches without the expectation of "perfect the first time through." Two participants perceived modeling as a way to support the norm. For example, they created "labs" in teachers' classrooms and modeled new instructional strategies in front of classroom teachers. As one participant elaborated, "Principals will teach mini lessons at least one per grade level. The principal is learning as she presents with kids, with teachers, and with literacy coaches." In other words, classroom teachers would see their principals "floundering and succeeding."

One administrative subgroup member recalled a slogan from the district's previous vision and values campaign launch that s/he believed encouraged teachers to try new things without expecting success the first time through: "Mistakes are expected and welcome." 


\section{Theme Four: A Learning Experience Worth Mentioning: The ELA Project}

All groups were able to expand somewhat on the ELA project. The majority of focus groups identified the project as beneficial, meaningful, thoughtfully planned, and aligned to the school's objectives. Groups also remarked that the ELA project was the "one thing that we focused on for a series of Mondays." Focus group two found working in vertically aligned teams and studying the essential standards relevant to their classroom practices. As one participant noted, "[it was] interesting to look at the ELA standards throughout different grade levels. They recalled the project lasting 6 weeks using words such as "jigsaw" and "share out" to describe the culmination of the experience.

Focus group three recalled the project as lasting approximately 6 or 7 weeks. They described the project as a "vertical alignment study of English Language Arts Standards that involved about eight groups of teachers working at different grade levels." This group regarded the project as "something that mattered" as it was the one topic of study which continued for a series of Monday mornings. Because the project was designed to carry over from Monday to Monday, participants could plan and work toward goals.

Participants in focus group five recalled the ELA project in detail stating that it lasted for a series of Mondays with teachers studying the standards in vertically aligned teams. However, participants in this group perceived the project as "just sort of dropping off." They struggled to recall how the project ended. "I think the end product was each vertically aligned team filled out these graphic organizers and turned them in to administration."

Participants in the administrative subgroup also recalled in detail the ELA project. This group addressed the "thinking behind" the project along with its intended goals such as 
"helping teachers understand the role of professional study, building stamina around one project, and promoting collaboration through study and reflection." This subgroup believed that curricular coherence was lacking and a "need for alignment based on standards" was identified. The culmination of the ELA project was defined as "experts on ELA strands" reporting findings back to their grade level teams.

\section{Theme Five: Institutional Roles Affect Attitudes, Beliefs, and Perceptions of Change}

Prior to the year of implementation, the administrative subgroup expressed a need for a systemic change in professional development. One respondent defined the purpose of the new program as creating "teacher collaboration" and "working with colleagues in a variety of structures." Another participant felt that a change was needed as practices were "archaic" and prior to the systemic change, "... it was the least collaborative district $\mathrm{s} / \mathrm{he}$ had experienced ..." Participants also suggested that they needed a change, which incorporated the district's vision and values and best practices.

The administrative group spoke about a "vision and values" team representative of all school personnel such as administrative assistants, classroom teachers, specialists, and others. Together the group decided upon how the "change in professional development would look" and the "roll out" of the plan. The administrative group each prepared differently for the systemic change. Collectively methods included the following approaches: networking, data collecting, and professional study. The following school year marked the "beginning of a new way of thinking."

Overall the teacher focus groups viewed the systemic change very differently when compared to the administrative subgroup. Only focus group two indicated that teachers had 
been involved in the preliminary stage of the implementation. One participant commented, "I was on that team, and we were really excited about having time to collaborate ... we wanted it [professional development] to be team time, collaboration, a place for new ideas and a place to refine our practices." The group then recalled envisioning a new way of professional development and holding high expectations of the new program. One member commented, "It just seemed so ineffective and different than what we expected."

Several focus groups thought the change was ineffective because similar to the program sessions; it was "all too much." For example, in the one-on-one interview, the participant observed that the school went from "basically having no professional development to regular Monday morning meetings." S/he further elaborated that again similar to the program weekly sessions, teachers had not "been a part of it." S/he did not recall "being asked if a huge change was necessary ... when the best time would be to have it ... what we would like to do during the time."

Several teacher focus groups seemed to lack clarity in an awareness of "why we needed to change," and "the overall goals of the program." Focus group one remarked that the program was well thought out and planned but "confusion existed as to where this was all going . . big picture." Focus group two also acknowledged that the program was thoughtfully planned but they questioned if "thoughtful" always equated to meaningful learning in a school wide experience. One member espoused that the lines of thinking were often "hard to follow and lacked clarity in terms of exactly where the whole thing was headed." Focus group three perceived the change as very hard to follow "without seeing the contextual pieces." Additionally, members of focus group three acknowledged how difficult it would be to implement such a system wide change. For example, one member stated, 
"Well the admin team was really just putting its toes in the water and trying it all out. The person in charge of the whole thing had never done this before."

Focus group four participants remarked that during the systemic change, they felt teachers had "intelligent ideas" regarding how to make the change "less stressful" but "they [planners] just don't seem comfortable at dealing with individuals who have ideas and experiences." The group also speculated that the people responsible for implementing such a "massive change in program design" did not have much experience working with adults. For example participants perceived school leaders as trying to tell teachers "how to be or behave" throughout the change process rather than guide them through the challenges presented by the system wide change. The group also acknowledged that the system wide change did align professional development to the district's visions and values, but the process seemed "artificial and disconnected."

It is interesting to note that focus group four believed that their district's prosperity complicated the system's ability to change. They felt that their resources should make a system wide change easier not harder. As one participant shared, "We have the money ... the supplies ... the resources ... and four administrators." The group questioned the motive for the change and speculated that such a drastic change could justify [employee] positions.

Focus group five viewed the systemic change in professional development as a way to "show the board" that the district would meet its goal of a "thinking curriculum" They viewed the program as a vessel for providing evidence of "big changes." Participants in this focus group believed that the "real reason" why such a big change occurred in their professional development program could be traced back to improving state test scores, a goal 
of the school board. They believed that so many of the sessions were "data driven" and lacking in support to "develop and refine skills."

The cross case analysis in its entirety evokes the following questions:

1. How might strategies to engage adult learners be incorporated into a professional development program?

2. How does a lack of communication between participants and planners affect the overall goals of a professional development program?

3. Did the program change school culture? If so how?

4. What made the ELA project most remembered and discussed by participants and planners?

5. How could institutional roles be redefined to encompass and comprehend all aspects of organizational change?

\section{SUMMARY}

The cross case analysis concludes Chapter 4. Two inquiry approaches of teacher participant surveys (which generated the singular one-on-one teacher interview) and teacher focus groups were employed to collect and analyze the data. Additionally, administrators were interviewed to gain evidence and insight on their views of organizational capacity. The findings within and across the cases now move the researcher toward a discussion of key findings, which incorporate significant data from the review of literature found in Chapter 2. Throughout the discussion, implications will emerge and lead the researcher toward the finale of proposed recommendations for practice and future research. 


\section{CHAPTER 5}

\section{DISCUSSION, IMPLICATIONS, AND RECOMMENDATIONS}

The chapter begins with an introduction about the study overall which includes a review of the research problem, the purpose of the study, and the rationale for the study. A discussion of key findings and their implications then follows. Finally, the chapter ends with recommendations for practice and additional research.

\section{The Problem}

The Goals 2000: Educate America Act passed in 1993 introduced systemic reform into the public school system. Almost a decade later, the No Child Left Behind Act of 2002 reinforced systemic reform in public education by demanding the strengthening of in-service teachers through nontraditional professional development programs. Major educational reform efforts cause systemic changes in America's public schools' traditional professional development programs.

Without evaluating the critical aspects of organizational capacity, the ability of schools at the system level to support individuals experiencing such systemic change in professional development is unclear. Without evidence of an organization's capacity to support individual change, a system's culture remains the same (Sparks, 1996). If a school's capacity to support a new systemic professional development program remains unexplored, then it is not known how much knowledge individuals gain, retain, and sustain. Also, more 
important, it is unclear if or what knowledge in the program impacted instructional practices and student achievement.

\section{PURPOSE AND RATIONALE}

The purpose of this evaluative study was to explore teachers' and administrators' perceptions of organizational capacity during an initial implementation of a systemic wide change in professional development. Findings in the study may serve to inform future change initiatives, contribute to future studies and to the existing body of literature.

The evaluation approach to the study attempted to determine the worth (Scriven, 1983) of a system's organizational capacity to support and encourage learning and change at the individual participant level. Because organizational capacity and individual capacity are interdependent if individuals' perceptions of an organization's capacity to support new learning during a systemic change in professional development are not explored, it is unclear which of the five critical aspects of organizational capacity, vision and leadership, collective commitment and cultural norms, organizational policies, resources, knowledge and access to knowledge, are most relevant in supporting the individual capacity of those involved in the change.

\section{RESEARCH Questions}

Two overarching and five sub questions guided the study.

1. How do teachers and administrators perceive the organizational capacity of a school to support the initial implementation of a site-based weekly job embedded professional development program? In what ways do they differ? In what ways are they the same? 
2. What are the different teacher subcultures' perceptions of the organization's capacity to support new learning during the initial implementation of a site-based weekly job embedded professional development program?

Several subquestions, including the following, provided a context for the study:

1. How is the school's vision and leadership supported by administrators? Colleagues?

2. How are collective commitment and cultural norms supported during the implementation of the new program?

3. How is knowledge and access to knowledge supported by the organization?

4. How does the organizational structure and management of operations support individual teachers?

5. How are resources allocated and used to support teacher knowledge and skills?

Essentially these questions ask, did teachers and administrators view the capacity of their school as supporting new learning and change created by the implementation of a system wide change in professional development? More specifically, what were their perceptions of the five critical aspects, vision and leadership, collective commitment and cultural norms, knowledge and access to knowledge, structure and management and resources?

The participants or those involved in this study are collectively responsible for educating our nation's children Without exploring teachers' and administrators' perceptions of their school's organizational capacity to support individual capacity during a system wide change in professional development, it is unclear which critical aspects of organizational capacity matter most to individuals working in a profession dedicated to and responsible for educating America's youth. 


\section{KEY FINDINGS}

As the data was analyzed and synthesized in Chapter 4, emerging themes within and across the cases began to provide tentative answers to the research questions. Carefully considering a set of key findings threaded throughout the data and linking the findings back to the review of literature creates the possibility of more definitive responses.

\section{Perceptions of Organizational Structure and Management May Create Unhealthy Cultural Norms}

Data from this study suggested that teacher participants did not view the management and structure of the weekly professional development meetings as conducive to their individual learning experience. In fact, these two aspects of organizational policy, structure and management, prompted lengthy verbal exchanges throughout the focus groups. Teacher participants vividly described and elaborated upon many "troubling" aspects of the program's structure and management.

Through these detailed responses, it was clear that teachers perceived the structure as "too rigid" and the management as "too controlling." These perceptions of such a "tight and controlling" learning environment with "too many parameters" led teachers to believe that administration did not "respect or trust" them. These perceptions and beliefs are significant as findings from studies discussed in the literature review indicated, working relationships between teachers and leaders have the potential to strengthen or weaken the link between individual and organization capacity (Blasé \& Blasé, 2002; Corcoran \& Christman, 2002; Green \& Etheridge, 1999; Guskey, 2000; Lee, 2006; Pennell \& Firestone, 1998; Reeves, 2006). 
According to their responses, teachers also seemed unaware of the reasoning and could not see the purpose behind the program's "rigid" structure and management. The data also indicated that teacher participants did not foresee the structure and management of the program as changing. For example, not one participant across any of the focus groups conjectured as to how the structure and management might evolve.

Unlike the teacher participants, the administrative subgroup viewed the organizational policies of structure and management as "appropriate" for the year of initial implementation. They could and did explain the reasoning behind the structure and management of the program. Administrators felt that during the first year, it was important to set the parameters of "what professional development is and is not." They wanted to emphasize collaboration, professional learning communities, and create a common language among grade levels. In order to do this, the structure and management had to be tight. Administrators wanted to keep a focus on the program's "goals and purposes."

The data from this study then indicates that the organizational policy of structure and management to support individual learning and change is significant. Perceptions of this scope of organizational capacity have the potential to greatly affect individuals' beliefs and attitudes resulting in an unhealthy cultural norm-one of disrespect and mistrust. These attitudes and beliefs then have the potential to make content irrelevant in newly implemented systemic wide professional development programs. As one participant vocalized, "This is almost embarrassing but I can honestly say nothing vividly sticks out that we even talked about last year." 


\section{How the Adult Learning Strategy of Participatory Planning Impacts Collective Commitment and Cultural Norms}

Repeatedly within and across the teacher focus groups, data indicated that teacher participants did not see themselves as participatory planners in their own professional development. Rather they viewed the initial implementation of the systemic change as "something done to us." This perception has the potential to develop or reinforce a cultural norm of adult as passive learner.

Similar to findings from a study conducted by Hargreaves (2004), the data from this study indicated that this perception potentially impacted participants' learning experiences, affected their attitudes, and influenced their overall sense of collective commitment. Additionally, the belief of not being involved in the planning may have reinforced unhealthy existing cultural norms and created new potentially "toxic" (Peterson \& Deal, 1998, p. 28) cultural norms. For example, one teacher participant commented, "Our leaders should trust us to identify what we as professionals need to work on ...." It could then be said that not involving adult learners in the planning of professional development may even be perceived as a lack of trust resulting in cultural norms of mistrust among faculty.

The data further indicated many perceived consequences of adult learners not being included in planning their own professional development such as "no authentic learning," "no buy in," and a "lack of differentiated instruction." Like the findings by Spicer (2008), the data also suggested that this perception of a lack of differentiated instruction could lead to teacher participants feeling less committed and could potentially create a new, toxic (Peterson \& Deal, 1998, p. 28) cultural norm of not caring because "it doesn't pertain to me." This example of just how quickly a new subculture, which has the potential to weaken 
organizational capacity, can be formed corroborates findings by Barth (2002), Elmore (2004), Hargreaves (2004), Miller (2006), and Peterson and Deal (1998).

As in a study conducted by Marriott (2003), teacher participants in this study offered ways to differentiate instruction based on grade level, years of experience, and selfassessment of topic. This suggests that the participants have moved beyond the problem, seen into the future of their professional development, and have developed solutions.

In the end, inquiries must be made as to what organizational factors led teachers to believe they were not involved in the planning of their professional development. More important, have these perceptions been shared with the planners of professional development with the intent to strengthen collective commitment and cultural norms; a critical aspect of organizational capacity, systemic reform, and professional development.

\section{When New Knowledge Is Introduced, Expectations and Strategies of Support Differ}

The data indicated that the teacher participants and participants from the administrative subgroup held different expectations and employed different strategies of follow up and support.

During the initial systemic change in professional development, participants in the administrator subgroup felt that they offered follow up and support regularly. Some participants chose to follow up and support new knowledge informally and others opted for more formal approaches. Informal and formal methods varied from modeling "professional development as who we are as educators," to "following up on Monday morning with "How's it going? Come see us if you have questions," and "tapping into teacher expertise." 
Data from the teacher focus groups suggested that participants did not view support and follow up as coming from their principals or other school leaders. Rather they perceived follow up and support as coming from other teachers as did teacher participants in studies conducted by O'Day et al. (1995) and Riehl and Sipple (1996). Additionally, members of the teacher focus groups identified ways they as "knowledge workers" (Pava, 1986, p. 208) would like to receive follow up and support such as giving feedback after Monday morning sessions, engaging in dialogue with school leaders, focusing on one topic for a series of Mondays, not creating all of the materials, designating time for reflection, collaboration, and practice. These types of follow up confirm what findings from past studies reveal as making advances toward best practices and increasing student achievement (Reeves, 2006; Riehl \& Sipple, 1996).

In addressing this key finding, could it be that the theme created here has more to do with setting expectations and examining different perceptions through communication and less to do with the provisions of follow up and support during a systemic wide intervention of new knowledge? Consequently, what would the outcomes be if teachers as "knowledge workers" (Pava, 1986, p. 208) talked to school leaders about support and follow through? What would the outcomes be if school leaders shared their approaches and strategies toward supporting the new knowledge of their "knowledge workers" (Pava, 1986, p. 208)?

\section{There Was Something About the ELA Project}

What was referred to as the ELA (English Language Arts) project commanded center stage in the memory of participants. Members of the administrative subgroup detailed the history leading up to the project along with outcomes and goals. Data from the teacher focus 
groups suggested that they viewed this topic of study differently than other topics introduced during the system wide change in professional development. In fact, the data implies that the ELA project was the only content related topic teacher participants could recollect in detail.

Considering all the data related to this key finding along with findings documented by researchers such as Little (1993), Loucks-Horsley et al. (2003), Speck and Knipe (2005) and the standards formed by the NSDC, clues of why study participants could recollect in detail this one project began to emerge and now lead toward a possible conclusion: The ELA project, in its entirety, included strategies for engaging adult learners, characteristics of quality professional development, and the five critical aspects, organizational policies, knowledge and access to knowledge, vision and leadership, collective commitment and cultural norms, and resources of organizational capacity.

\section{Culture as We Perceive It}

Most teacher participants described their careers as enthusiastic and growing. The cross case analysis indicated that the teacher participants along with members of the administrative subgroup believed their school practiced the cultural norm of continuous improvement. Throughout the interview process, several teacher participants demonstrated this cultural norm by making statements such as "Just the idea of having professional development is great," and "It's nice to have time when all of the staff can be and work together." A member of the administrator subgroup commented, "I work with very thoughtful and reflective teachers." It would seem then that this present culture is for the most part an uplifting and healthy one. However the data across the teacher focus groups suggested that 
upholding a norm of continuous improvement could potentially lead to expectations of perfectionism.

While the teacher participants believed that they "could not fail here" and were "expected and required" to get it right the first time through, data from the administrative subgroup indicated quite the opposite. In fact the administrative subgroup participants described several occasions in which they "went into classrooms" and "tried new approaches" as teachers watched them "flounder and succeed."

As aforementioned in the literature review, Barth (2002), Guskey (2000), Joyce et al. (2002), and McCabe (2001) credited individuals within the culture of an organization as potentially having the most influence over the success or failure of any professional development program. Consequently, this differing of perceptions cannot go unnoticed and evokes the following inquiries: Where does a sense of perfectionism come from? Does the push to be perfect exist only in the hearts and minds of individuals? Or do the five critical aspects of organizational capacity somehow initiate and contribute, to this sense of perfectionism among individuals and their culture?

Last, how did the yearlong initial implementation of the system wide change in the school's professional development affect perceptions of "perfect the first time through"?

Unlike the findings from a longitudinal study conducted by Green and Etheridge (1999), data from the teacher focus groups and the administrative subgroup indicated that a notion of fear: spoken, unspoken, past, present, and future exists within the school culture. Interestingly, participants in the administrative subgroup referred to fear as something in the past. They also shared what they believed to be the cultural history behind individuals' fear and how that fear continues to be "passed down" by "storytellers" through "myths and 
legends." Teacher participants spoke of fear as a present day "worry" which had the potential to lead to future fears such as "untenured teachers feared for their jobs" and tenured staff experienced an "unspoken fear." Additionally, the members of the teacher focus groups feared the parents and retaliation from the administration based on parent feedback.

Similar to questioning the origins and contributors of perfectionism in a culture, inquiries must also be made about fear: past, present, future, spoken, unspoken, real or imaginary. As emphasized through the findings of researchers McGinnis et al. (2003), the intricacies and power of school culture present numerous implications. How can a culture of "school people" (Elmore, 2004, p. 215) come together and lay their fears to rest? Believing that the latter is possible how would a culture without fear move the capacity of an organization toward fulfilling its goals in a systemic wide intervention which potentially could strengthen teacher quality and impact student achievement?

\section{The Complexities of Systemic Change}

The combined data set from the teacher focus groups and the administrator subgroups indicated that systemic change is difficult and often confusing. What follows are excerpts of participants' perceptions, which illustrate and reinforce the key finding: the complexities of systemic change.

Confusion existed as to where this was all going.

... resist change

Since last year was new for everybody, it was a learning curve ... need to do better and refocus.

Don't forget we also have four administrators

[The] beginning of a new way of thinking. 
It just seemed so ineffective and different than we expected.

There is a small group living in the past

Practices were archaic.

We have the money ... the supplies ... the resources.

I don't remember being asked if we thought . . .

There has been lots of change.

Was a huge change so necessary?

... we have the money to go with the ideas

Thought behind something doesn't make it meaningful.

It was just too much too fast.

... some people are interested in the status quo

Our greatest asset should be our ability to change.

And it's our biggest problem.

We have processed the change process

You are really left alone to struggle through the challenges.

Us against them

... building a knowledge of school culture and change theories

We tried to change too many things at once.

Change is essential

What factors contribute most to the complexities of systemic change? From the review of the literature, Banathy (1992) theorized that all people involved in the systemic change must develop the ability to view a system from three different perspectives: a still picture lens, a motion picture lens, and a bird's eye view in order to understand how the new 
system connects with other systems. While Adelman and Taylor (2007) proposed that most change agents (Fullan, 1993) do not possess a concrete knowledge in systems theory nor do

they have the hands on experience. Joyce et al. (2002) advised that individuals in leadership roles, teachers and administrators, must exhibit a district wide synergy and be seen as genuinely vested in the change.

The data supporting this key finding coupled with the findings of Adelman and Taylor (2007), Bananthy (1992), Cohen (1995), and Senge (2006) as previously noted in the literature review suggest that the complexities of systemic change could be attributed to any one of, a combination of, or all of the following inquiries: Is it a lack of organizational capacity? Is it that systemic change affects all parts of the system and interacts with other systems? Is it the desire for all individuals involved to know and understand why a system needs changing? Is it an unawareness of systemic thinking? Is it decisions made by those individuals designated as the change agents? Is it an inability to perceive one's self as nothing beyond a helpless soul haphazardly reacting to circumstances brought about by change?

\section{RECOMMENDATIONS FOR FUTURE RESEARCH}

Based on the newly created definition of professional development proposed by NSDC in 2009 , more research at local school sites should be conducted to explore, assess, and evaluate the driving forces behind an organization's capacity to support individual learning during a systemic change in professional development. Specifically, researchers should design future studies which evaluate local schools' collective commitment and cultural norms, as this critical aspect of organizational capacity could potentially affect how 
"school people" (Elmore, 2004, p. 215) interact and collaboratively learn which fuels, propels, and sustains the "continuous cycle of learning" (NSDC, 2009).

Additionally, it is recommended that these future studies be conducted at local school sites, which have consistently improved student achievement as defined by the No Child Left Behind Act of 2002. It is important to collect and analyze data from these successful schools to determine not only what is making the difference but also how it is being done. Findings from such future studies will potentially impact student achievement in other schools, add to the existing body of literature, and further refine the concept of systemic thinking in the public schools as emphasized in the new definition of professional development: "Every school in a system benefits from expertise that resides within all schools in the system, not just their system" (S. Hirsch, personal communication, December 31, 2009).

As stated by Guskey (2000) and the NSDC (2009), learning occurs at the school site. For it is at the local level where changes can be implemented that potentially directly affects student achievement. Along with the contextual nature of professional development and learning, evaluative studies, too, are contextual. As indicated in the review of literature, wellknown large-scale studies such as Reading First and Title I (NCEE, 2008a) continue to be developed, conducted, and funded at the district, state, and national level. Through various media, findings from large-scale federally funded studies continue to be discussed, reported, and published across the educational arena. However, researchers and all those involved in public education must not take lightly research opportunities local school sites provide, regardless of how contextual potential findings might seem. As aforementioned in the literature review, Shaha et al. (2004) stated, "As a caution, too often those [individuals] undertaking evaluations from which results might be shared allow their perceptions regarding 
the smallness of a district or its unique ethnic mix to undermine their capability of impacting the broader educational arena by sharing their findings" (p. 4). Additionally, the Institute of Educational Sciences emphasized the importance of evaluation at the local level through its annual National Center for Educational Research competition (NCER, 2008).

Findings that explore collective commitment and cultural norms which impact interaction and collaborative learning toward defining learning goals, implementing strategies, providing coaching, and assessing the effectiveness of professional development efforts (NSDC, 2009) are not to be underestimated, even in the smallest of schools across America. Without collective commitment and positive cultural norms, commitment to student success cannot be achieved thus breaking the continuous cycle of learning for teachers, which could eventually and tragically impact student achievement. Therefore, in future studies, it is recommended that researchers reference the works of others in the field such as Barth, Guskey, Elmore, Hargreaves, Huberman, and McCabe to develop guiding questions around collective commitment and cultural norms in the context of what NSDC deemed the attributes of high achieving schools: "great leaders, collaborative learning, and great professional learning" (S. Hirsch, personal communication, December 31, 2009).

\section{Recommendations for Practice}

In order to strengthen the continuous cycle of learning, perceptions of collective commitment and cultural norms must be frequently assessed and addressed through open, honest communication among those that interact and collaborate toward improving student achievement by analyzing data, defining learning goals, implementing strategies, providing coaching, and assessing the effectiveness of professional efforts (NSDC, 2009). As Sparks 
(1996) emphasized, in order for an intervention such as a system wide change in professional development to make a difference, the culture of a school first must change.

Therefore, it is recommended that change agents or an outside source conduct an assessment of school culture before the implementation of a system wide intervention. Without an initial formal assessment of collective commitment and cultural norms, it is difficult to predict how the interdependent relationship between organizational capacity and individual capacity will affect the interaction and collaborative learning of all knowledge workers (Pava, 1986, p. 208) involved in the continuous cycle of learning. This potentially leaves student achievement to chance.

Findings from the initial assessment must be openly shared and discussed with the ultimate goal of determining common ground to support student achievement. A program should then be designed utilizing participatory planning and differentiated instruction in order to incorporate what each teacher needs to know and learn to improve classroom instruction. Involve those members of the population most resistant to collective commitment and cultural norms. Make them see how the new learning will directly benefit their students. Create leadership roles that make the status quo feel important and needed. With the new definition of professional development, local educators can access models that describe what learning should look like at the school site (NSDC, 2009). Expectations, roles, and purposes should be clearly defined and reexamined often.

As a program progresses, it is recommended that change agents make frequent feedback a priority. Through a formative evaluation process, the level of collective commitment and cultural norms should be measured throughout the life of the program. This should be done in the context of interaction and collaborative learning which includes 
analyzing data, defining learning goals, implementing strategies, providing coaching and assessing the effectiveness of professional development efforts (NSDC, 2009). Based on feedback, change agents should recognize and feel comfortable redefining an element or elements of the program perceived as preventing a continuous cycle of learning which has the potential to affect student achievement. Sometimes these adjustments may be as simple as changing the medium of presentation or reconfiguring tables and chairs. At other times, adjustments may present problems of a more challenging and complex nature such as differentiating instruction based on teacher expertise or knowledge. However if districts do not gather feedback through formative evaluative measures, again student achievement is potentially left to chance.

Finally, to emphasize and encourage a continuous level of collective commitment, establish a sense of shared leadership by moving away from a top down authoritative approach. "Tap into teacher expertise" as one participant in this study stated. As change agents, take time to discover or rediscover the experiences, creativity, and resourcefulness of the faculty or school people (Elmore, 2004, p. 215). Individual capacity will be strengthened as will the organization's capacity, particularly the aspect of collective commitment and cultural norms which impacts the interaction and collaborative learning needed to maintain a continuous cycle of learning.

\section{FinAl Remarks}

In an era of infinite school reform, through the recommendations for future practice and research, it is hoped that "school people" (Elmore, 2004, p. 215) who are in essence the "knowledge workers" (Pava, 1986, p. 208) of our society will continue their tireless efforts 
toward developing and refining best practices through collective commitment and cultural norms. Therefore, throughout their academic lives, all students in all public schools across America will benefit from the highest quality of instruction provided by new and seasoned teachers working within a system of highly developed organizational capacity. 


\section{REFERENCES}

Adelman, H. S., \& Taylor, L. (2007). Systemic change for school improvement. Journal of Educational and Psychological Consultation, 17(1), 55-77.

Alexander, N. A. (2006). Being on track for No Child Left Behind: Examining the organizational capacity of Massachusetts public eighth-grade programs. Educational Policy, 20(2), 399-428.

Alliger, G., \& Janak, E. (1989). Kirkpatrick's levels of training criteria: Thirty years later. Personnel Psychology, 42(2), 331-342.

Alvarado, A. (1998). Professional development is the job. American Educator, 22(4), 18-23.

American Psychological Association. (2002). Publication manual of the American Psychological Association (5th ed.). Washington, DC: Author.

Banathy, B. H. (1992). A systems view of education: Concepts and principles for effective practice. Englewood Cliffs, NJ: Educational Technology Publications.

Barth, R. (1990). Improving schools from within: Teachers, parents, and principals can make a difference. San Francisco, CA: Jossey-Bass.

Barth, R. (2002). The culture builder. Educational Leadership, 59(8), 6-11.

Berman, P., \& McLaughlin, M. (1978). Federal programs supporting educational change: Implementing and sustaining innovations. Santa Monica, CA: The Rand Corporation.

Bernfield, G., Blasé, K., \& Fixsen, D. (2006). Towards a unified perspective on human service delivery systems: Application of the teaching-family model. Behavior Analyst Today, 7(2), 168-187.

Berry, B., Turchi, L., Johnson, D., Hare, D., Owens, D. D., \& Clements, S. (2003). The impact of high-stakes accountability on teachers ' professional development: Evidence from the south. Retrieved July 22, 2008, from http://www.teachingquality.org

Blasé, J., \& Blasé, J. (2002). Breaking the silence: Overcoming the problem of principals' mistreatment of teachers. Thousand Oaks, CA: Corwin Press.

Brandt, R. (1994). Establishing staff development as a professional function. Journal of Staff Development, 15(4), 2-8. 
Burden, K., \& Atkinson, S. (2008). Evaluating pedagogical affordances of media sharing web 2.0 technologies: A case study. Retrieved August 12, 2008, from http://www.ascilite.org.au/conferences/melbourne08/procs/burden-2.pdf

Cohen, D. K. (1995). What is the system in systemic reform? Educational Researcher, 24(9), 11-17.

Cohen, D. K., \& Ball, D. L. (1999). Instructional capacity and improvement (Policy Report Series RR-43). Philadelphia: Consortium for Policy in Research in Education.

Corcoran, T., \& Christman, J. B. (2002). The limits and contradictions of systemic reform: The Philadelphia story (ED 476 940). Philadelphia: Consortium for Policy Research in Education. Retrieved July 21, 2008, from ERIC database.

Creswell, J. W. (1998). Qualitative inquiry and research design: Choosing among the five traditions. Thousand Oaks, CA: Sage Publications.

Elementary and Secondary Education Act of 1965, Pub. L. No. 107-110. 115 Stat. 1425 (1966).

Elmore, R. (2004). School reform from the inside out: Policy, practice, and performance. Cambridge: Harvard Education Press.

Erickson, F. (1998). Qualitative research methods for science education. In B. J. Fraser \& K. G. Tobin (Eds.). The international handbook of science of education (pp. 11551173). Dordrecht, Netherlands: Kluwer Academic.

Fessler, R., \& Christensen, J. (1992). The teacher career cycle: Understanding and guiding the professional development of teachers. Needham Heights, MA: Allyn and Bacon.

Frechtling, J., \& Sharp-Westat, L. (Eds.). (1997). User-friendly handbook for mixed method evaluations. Darby, PA: Diane Publishing Company.

Fuhrman, S. H. (1994). Challenges in systemic education reform (Policy Briefs Series RB14.) New Brunswick, NJ: Consortium for Policy Research in Education.

Fullan, M. (1993). Change forces: Probing the depths of educational reform. Bristol, PA: The Falmer Press.

Fullan, M. (2003). The moral imperative of school leadership. Thousand Oaks, CA: Corwin Press.

Fullan, M. (2008). Learning about system renewal. Educational Management Administration Leadership, 2(36), 289-303. 
Fullan, M., \& Hargreaves, A. (1992). What's worth fighting over in your school? Toronto, Ontario: Ontario Public School Teachers' Federation.

Garet, M., Birman, B., Porter, A., Desimone, L., \& Herman, B. (1999). Designing effective professional development: Lessons from the Eisenhower Program. Washington, DC: U.S. Department of Education

Glover, T., \& DiPerna, J. (2007). Service delivery for response to intervention: Core components and directions for future research. School Psychology Review, 36, 526540 .

Goals 2000: Educate America Act of 1993, Pub. L. No. 103-227. 108 Stat. 125 (1993).

Green, R., \& Etheridge, C. (1999). Collaborating to establish standards and accountability: Lessons learned about systemic change. Education, 121(4), 821-829.

Guskey, T. R. (1998). Follow-up is key, but it's often forgotten. Journal of Staff Development, 19(2), 7-8.

Guskey, T. R. (2000). Evaluating professional development. Thousand Oaks, CA: Corwin Press.

Guskey, T. R. (2002). Professional development and teacher change. Teachers and Teaching: Theory and Practice, 8(3/4), 381-391.

Guskey, T. R. (2005). Taking a second look at accountability. Journal of Staff Development, 26(1),10-18.

Hall, L. (2007). Inspiration, implementation, and impact: Examining teacher professional development in successful school districts. Retrieved April 24, 2008, from Proquest Digital Dissertations (Publication No. ATT 3426948).

Hargreaves, A. (2004). Inclusive and exclusive educational change: Emotional responses of teachers and implications for leadership. School Leadership \& Management, 24(2), 287-309.

Hiebert, J., Gallimore, R., \& Stigler, J. (2002). A knowledge base for the teaching profession: What would it look like and how can we get one? Educational Researcher, 31(5), 315.

Holly, M. L., \& Mcloughlin, C. S. (Eds.). (1989). Perspectives on teacher professional development. Philadelphia: Taylor \& Francis Inc.

Holton, E. (1996). The flawed four-level evaluation model. Human Resources Development Quarterly, 7(1), 5-21. 
Huberman, M. (1993). The lives of teachers. New York: Teachers College Press.

Institute of Educational Sciences. (2008). About us. Retrieved August, 1, 2008, from http://ies.ed.gov/ncer/aboutus/

Isaac, S., \& Michael, W. (1997). Handbook in research and evaluation (3rd ed). San Diego: Edits.

Janis, I. (1972). Victims of groupthink. Boston: Houghton Mifflin.

Joint Committee on Standards for Educational Evaluation. (1994). The program evaluation standards ( $2^{\text {nd }}$ ed.). Thousand Oaks, CA: Sage.

Joyce, B., Bush, R., \& McKibbin, M. (1982, January). The California staff development study. Palo Alto, CA: Booksend Laboratories.

Joyce, B., Showers, B. R., \& Fullan, M. (2002). Student achievement through staff development (3rd ed.). Alexandria, VA: Association for Supervision and Curriculum Development.

Kaplan, M. (1986). Great Society and its legacy. Durham, NC: Duke University Press.

Killion, J. (2002). Assessing impact: Evaluating staff development. Oxford, OH: National Staff Development Council.

Krathwohl, D., \& Smith, N. (2005). How to prepare a dissertation proposal: Suggestions for students in education and the social and behavioral sciences. Syracuse, NY: Syracuse University Press.

Krueger, R. A. (1988). Focus groups: A practical guide for applied research. Newbury Park, CA: Sage.

Lee, S. (2006). The assessment of the organizational capacity of school districts: An analysis of the Boston Public Schools and the collaborative coaching and learning model. Dissertation Abstracts International, 67(04). Retrieved April 24, 2008, from ProQuest Digital Dissertations (AAT No. 3213552).

Lieberman, A., \& Miller, L. (1999). Teachers-Transforming their world and their work. New York: Teachers College Press.

Lincoln, Y. S., \& Guba, E. G. (1985). Naturalistic inquiry. Beverly Hills, CA: Sage.

Little, J. W. (1993). Teachers, professional development in a climate of educational reform. Educational Evaluation and Policy Analysis, 15(2), 129-151. 
Long, R. (2007, January 16). Senate puts focus on education. Chicago Tribune. Retrieved April 24, 2008, from http://chicagotribune.com

Lortie, D. C. (1975). Schoolteacher: A sociological study. Chicago: University of Chicago Press.

Loucks- Horsley, S., Love, N., Stiles, K., Mundry, S., \& Hewson, P. (1998). Designing professional development for teachers of science and mathematics. Thousand Oaks, CA: Corwin Press.

Loucks-Horsley, S., Love, N., Stiles, K., Mundry, S., \& Hewson, P. (2003). Designing professional development for teachers of science and mathematics $\left(2^{\text {nd }} \mathrm{ed}.\right)$. Thousand Oaks, CA: Corwin Press.

Marriott, D. (2003). Examining an observation-based model of professional development for teachers. Dissertation Abstracts International, 64(04).

McCabe, L. (2001). The inter-relatedness of professional development and school culture in non-urban middle schools. Retrieved April 29, 2008, from ProQuest Digital Dissertations (Publication No. AAT 3012524).

McDonald, J. (2007). The power of protocols: An educator's guide to better practice (2 ${ }^{\text {nd }}$ ed.). New York: Teachers College Press.

McGinnis, J. R., Parker, C., \& Graeber, A. (2003). A cultural perspective of the induction of five reform-minded beginning mathematics and science teachers. Journal of Research in Science Teaching, 41(7), 720-747.

Mertens, D. (2005). Research and evaluation in education and psychology: Integrating diversity with quantitative, qualitative, and mixed methods ( $2^{\text {nd }}$ ed.). Thousand Oaks, CA: Sage.

Miles, M. B., \& Huberman, A. M. (1994). Qualitative data analysis: A sourcebook of new methods $\left(2^{\text {nd }}\right.$ ed.) Thousand Oaks, CA: Sage.

Miller, L. (2006). Professional development in a large school district: An applicationof Guskey's model. Dissertation Abstracts International, 67(06). Retrieved April 24, 2008, from ProQuest Digital Dissertations (Publication No. AAT NR15774).

National Association of Manufacturers. (2001). Investing in teaching. Retrieved April 24, 2008, from http://www.nam.org

National Center for Educational Evaluation and Regional Assistance. (2008a). About us. Retrieved August 1, 2008, from http://ies.ed.gov/ncee/aboutus/ 
National Center for Educational Evaluation and Regional Assistance. (2008b). The impact of professional development models and strategies on teacher practice and student achievement in early reading. Retrieved August 1, 2008, from http://ies.ed.gov/ncee/ projects/evaluation/tq_reading.asp

National Center for Educational Evaluation and Regional Assistance. (2008c). The impact of professional development strategies on teacher practice and student achievement in math. Retrieved August 1, 2008, from http://ies.ed.gov/ncee/projects/ evaluation/tq mathematics.asp

National Center for Educational Evaluation and Regional Assistance (2008d). NCEE projects and programs, 2008. Retrieved August 1, 2008, from http://ies.ed.gov/ncee/projects

National Center for Education Research. (2008). Teacher quality: Reading and writing. Retrieved August 1, 2008, from http://ies.ed.gov/ncer/projects/program.asp? $\operatorname{ProgID}=24$

National Commission on Excellence in Education. (1983). A nation at risk: The imperative for educational reform. Washington, DC: U.S. Department of Education.

National Commission on Teaching and America's Future. (1996). What matters most: Teaching for America's future. New York: Author.

National Defense Education Act of 1958, Pub. L. No. 85-864. 72 Stat. 1580-1605. (1959).

National Education Commission on Time and Learning. (1994). Prisoners of time. Washington, DC: Government Printing Office.

National Staff Development Council. (2001). NSCD standards for staff development. Retrieved April 11, 2008, from www.NSDC.org

National Staff Development Council. (2009). NSCD a new definition of professional development. Retrieved December 31,2009, from www.nsdc.org/standfor/ definition.cfm

Newman, F., King, M., \& Youngs, P. (2000). Professional development that addresses organizational capacity: Lessons from urban elementary schools. American Journal of Education, 108(4), 259-299.

Newman, J. (2006). Alabama district improves by sharpening data and goals. The Journal of the National Staff Development Council, 27(2) 10-14.

No Child Left Behind Act of 2002, Pub. L. No. 107-110. 115 Stat. 1425 (2002). 
O’Day, J., Goertz, M. E., \& Floden, R. E. (1995). Building capacity for educational reform (CPRE Policy Briefs). New Brunswick, NJ: Consortium for Policy Research in Education, Rutgers University.

Office of Educational Research and Improvement. (1994). The Eisenhower professional development program. Washington, DC: U.S. Department of Education.

O'Neill, J. (2008). System change can take education goals from fantasy to reality. Journal of Staff Development, 29(2), 48-50.

Pascoe, D. (2007). What is systems theory? TechTrends, 50(2), 22-23.

Patton, M. (1990). Qualitative evaluation and research methods $\left(2^{\text {nd }}\right.$ ed.). Thousand Oaks, CA: Sage.

Patton, M. (1997). Utilization-focused evaluation: The new century text. Thousand Oaks, CA: Sage.

Pava, C. (1986). Redesigning sociotechnical systems designs: Concepts and methods for the 1990s. Journal of Applied Behavioral Sciences, 22(5), 206-221.

Pennell, J. R., \& Firestone, W. A. (1998). Principal roles in changing oriented professional development: Matching leadership styles to staff characteristics. Paper presented at the annual meeting of the American Educational Research Association, San Diego, CA.

Perrone, V., \& Patton, M. (1976). Does accountability count without teacher support? Minneapolis: University of Minnesota, Minnesota Center for Social Research.

Peterson, K. D., \& Deal, T. E. (1998). How leaders influence the culture of schools. Educational Leadership, 56(1), 28-30.

Reeves, D. (2006). The learning leader: How to focus school improvement for better results. Alexandria, VA: Association for Supervision and Curriculum Development.

Riehl, C., \& Sipple, J. (1996). Making the most of time and talent: Secondary school organizational climates, teaching task environments, and teacher commitment. American Educational Research Journal, 33(4), 873-901.

Robb, L. (2008). Differentiating reading instruction: How to teach reading to meet the needs of each student. New York: Scholastic, Inc.

Salant, P., \& Dillman, D. A. (1994). How to conduct your own survey. New York: John Wiley \& Sons. 
Scriven, M. S. (1983). Pros and cons about goal-free evaluation. Evaluation Comment, 3(4), 1-7.

Seltzer, M., \& Rose, M. (2006). Constructing analyses: The development of thoughtfulness in working with quantitative methods. In C. Conrad \& R. Serlin (Eds.), The Sage handbook for research in education: Engaging ideas and enriching inquiry. Thousand Oaks, CA: Sage.

Senge, P. (2006). The fifth discipline: The art and practice of the learning organization. New York: Currency Doubleday.

Shaha, S. H., Lewis, V. K., O’Donnell, T. J., \& Brown, D. H. (2004). Evaluating professional development: An approach to verifying program impact on teachers and students. The Journal of Research in Professional Learning, 1(1), 1-18.

Sparks, D. (1994). A paradigm shift in professional development. Journal of Staff Development, 15(4), 26-29.

Sparks, D. (1996). A new form of staff development is essential to high school reform. The Educational Forum, 60, 260-266.

Sparks, D. (2002). Designing powerful professional development for teachers and principals. Oxford, OH: National Staff Development Council.

Sparks, D., \& Hirsh, S. (1997). A new vision for staff development. Alexandria, VA: Association for Supervision and Curriculum Development.

Speck, M., \& Knipe, C. (2001). Why can't we get it right? Designing high-quality professional development for standards-based schools. Thousand Oaks, CA: Corwin Press.

Speck, M., \& Knipe, C. (2005). Why can't we get it right? Designing high-quality professional development for standards-based schools ( $2^{\text {nd }}$ ed.). Thousand Oaks, CA: Corwin Press.

Spicer, K. (2008). State of professional development in the era of accountability: Teachers' perceptions. Dissertation Abstracts International, 68(12). Retrieved August, 24, 2008, from ProQuest Digital Dissertations (Publication No. AAT 3294799).

Steinaker, N. W., \& Bustillos, T. A. (2007). A handbook for writing formal papers: From concept to conclusion ( $3^{\text {rd }}$ ed.). Boston: Pearson Custom Publishing.

Stiggins, R. (2007). Five assessment myths and their consequences. Education Week, 27(8), 28-29. Retrieved April 24, 2008, from http://www.edweek.org/go/commentary 
Stufflebeam, D. L., Madaus, G. F., \& Kellaghan, T. (2000). Evaluation models: Viewpoint on educational and human services evaluation. Boston: Kluwer.

Stufflebeam, D. L., \& Shinkfield, A. (2007). Evaluation theory, models, and applications. San Francisco: Jossey-Bass.

U.S. Government Accountability Office. (2007, July). Government auditing standards (Publication No. GAO-07-7316). Washington, DC: Government Printing Office.

Weiss, R. S. (1994). Learning from strangers: The art and method of qualitative interview studies. New York: Free Press.

Whyte, S. F., \& Whyte, K. K. (1991). Making Mondragon: The growth and dynamics of the worker cooperative complex ( $2^{\text {nd }}$ ed.). New York: ILR Press.

Woods, P., Troman, G., \& Boyle, M. (1997). Restructuring schools, restructuring teachers. Buckingham: Open University Press.

Zmuda, A., Kuklis, R., \& Kline, E. (2004). Transforming schools: Creating a culture of continuous improvement. Alexandria, VA: Association for Supervision and Curriculum Development. 
APPENDIX A

PARTICIPANT PROFILE 
Participant Profile

Please answer the following questions based on your position at the start of the 2007-08 academic school year. Your responses will be used to form the focus groups of the study. Please create a 5-7 letter password and write it in the upper right hand corner of this survey. This password will be used to alert you of an invitation to join a select focus group.

1.How may total years teaching experience did you have at the start of the 2007-08 school year? Include any experience outside of the district.

2. What level of education did you have at the start of the 2007-08 school year?

Bachelors

Masters

Masters plus

3. Place an X by the ONE category, which best describes your consumer type.

Gourmet omnivore

Passive Consumer

Reticent Consumer

4. Place an $X$ by the ONE category, which best described you during the 2007-08 school year.

Induction

Stability

Career Wind Down

5. Place and $\mathrm{X}$ by the $\mathrm{ONE}$ career stage which best described you during the 2007-08 school year.

Competency Building

Enthusiastic and Growing

Career Frustration 


\section{APPENDIX B}

QUESTIONNAIRE TO ASSESS ORGANIZATIONAL

SUPPORT 
Questionnaire to Assess Organizational Support

Directions. Please indicate the degree to which you agree or disagree with each statement below. Indicate your answer on the blank line next to the item.

$\begin{array}{lllllc}1 & 2 & 3 & 4 & 5 & 6 \\ \text { Strongly } & \text { Moderately } & \text { Slightly } & \text { Slightly } & \text { Moderately } & \text { Strongly } \\ \text { gree } & \text { Agree } & \text { Agree } & \text { Disagree } & \text { Disagree } & \text { Disagree }\end{array}$

1.___ Our professional development programs and activities are aligned with our school mission, goals, and objectives.

2. Funding for professional development is a line item in our school budget.

3. The administration, faculty, and other staff members of our school work together to plan professional development activities.

4. ___ Leaders in our school advocate, encourage, and support professional development through incentives and resources.

5. The administration and faculty of our school have studied the change process to assist in planning and implementing effective professional development programs and activities.

6.___ A norm of experimentation exists at our school that permits educators to try new instructional practices without fear of criticism should initial efforts fail.

7.____ District-level personnel help guide our professional development planning efforts and assist in implementation.

8.___ Provisions for follow-up support are included in all of our professional development plans.

9. A norm of continuous improvement exists in our school that recognizes that learning about best practices in our profession is never finished.

10._We have ready access to expertise when implementation problems or difficulties are encountered.

11. The resources required to implement new practices are considered during planning and built into our school budget.

12.___ District level professional development programs and activities are thoughtfully planned and complement our school-level efforts.

Source: Guskey (2000, p. 170). 


\section{APPENDIX C}

SCRIPT TO ADMINISTER THE SURVEY 
Script to Administer the Survey

A doctorate student is researching how a school supports its teachers during new professional development programs. Your responses will help the researcher gain insight as to how different subgroups of the teacher population perceive the support offered by the school. All of your responses will be confidential.

This is a two-part survey. The first part, labeled participant profile contains 5 questions that will further describe the teacher population. Please refer to the yellow handout when answering participant profile questions 3,4 , and 5 . Just a reminder to answer the questions based on the 2007-08 academic school year. Take a moment now to look over the first part of the survey and yellow reference sheet. Are there any questions before we continue with directions for part two of the survey?

Now turn to part two of the survey labeled, Questionnaire to Assess Organizational Support. You will use the scale at the top of the page when answering the 12 questions. By placing a 1 next to a statement means you strongly agree with the statement. If you place a 6 next to the statement, then you strongly disagree. Take a moment now to look over this part of the survey. Do you have any questions? You will have approximately 15 minutes to complete the two-page survey. When you are finished, please place it in the yellow envelope. The researcher and I will be available to answer any questions as they arise during the process. 
APPENDIX D

REFERENCE GUIDE FOR PARTICIPANT PROFILES 
Reference Guide for Participant Profiles

Please use this guide as a reference for answering questions 3, 4, and 5 of the Participant Profile.

\section{Question 3: Which best describes your consumer type?}

Gourmet Omnivore- I am mature, persistent, and highly active at work and at home. I often encourage those around me to join in the fun or even some times force people to join in the fun. For example, if I am an avid photographer, I can't stop talking about it and want others to get involved. I am able to transfer ideas and lessons learned from my personal life into my classroom.

Passive Consumer- My activity level at work and home depends on what I am doing and whom I am spending my time with... I am like a chameleon and can adapt quickly to whatever is going on.... I am good-natured and will work hard- but only if others around me are working hard too.

Reticent Consumer-I feel oppressed by systems at work and at home. On the job, I generally loathe the higher-ups and don't care much for the high activity and energy level of my colleagues. I spend a lot of time and energy building walls around myself. At work I think people are naïve to the ways of the system and culture. Professionally and personally, I am sort of an expert on ignoring the positives and voicing the negatives of many situations and events.

\section{Question 4: Which best described you during the 2007-08 school year?}

Induction- I am striving for acceptance from students, colleagues, supervisors, and the community. I am working toward establishing a comfort level in everyday problems. I might have recently changed grade levels, schools, or am new to the profession.

Stability-I put a fair day's work for the pay. I do what's expected but not much else. I participate in staff development and other activities only at a surface level.

Career Wind Down- I am soon retiring or I am not old enough to retire but am thinking of finding another career. I may have bitter feelings about teaching or I may look back with fond memories. 
Question 5: Which best described your career stage during the 2007-08 school year?

Competency Building-I am striving to improve what I do in the classroom. I am curious about new materials and strategies. I am receptive to new ideas and often volunteer to attend conferences. I am probably in a graduate program or thinking about starting one soon.

Enthusiastic and Growing-I am confident about my teaching and continue to grow professionally. My overall job satisfaction and enthusiasm levels are high. For the most part, I look forward to work and interacting with my students. I might already be involved or am thinking about working on some ideas for professional development at our school.

Career Frustration- I am burned out. This job frustrates me and I wonder why I ever entered the profession. I wouldn't advise anyone to become a teacher. 
APPENDIX E

\section{PROTOCOL FOR FOCUS GROUPS' GUIDING} INTERVIEW QUESTIONS 
Protocol for Focus Groups' Guiding Interview Questions

\section{Group 1}

1) From the survey, the group as a whole slightly or moderately disagrees with the following statement. "The administration, faculty, and other staff members of our school work together to plan professional development activities." Why do you not agree with this statement? What group or who planned the professional development activities last year? What were the results or consequences for you as a learner? During last year (07-08) were you asked to help plan professional development? If so, what did you plan? Was your plan implemented? How might your professional development experience been different if administrators, faculty and other staff had worked together to plan the activities?

2) From the survey, $75 \%$ of your group moderately disagreed with the following survey item: "District level professional development programs and activities are thoughtfully planned and complement our school-level efforts." What words or phrases come to mind when you hear this statement read aloud? Can you describe a program or activity that was not thoughtfully planned? Can you describe a program or activity that did not necessarily complement your school level efforts?

3) All in this group either slightly or strongly agreed with the following statement:

"A norm of continuous improvement exists in our school that recognizes that learning about best practices in our profession is never finished." What kinds of things would a newcomer to the school observe, notice, or recognize to support your perceptions? In classrooms, during professional development, and team meetings, etc? Who best supports or where does the norm of continuous improvement stem from?

4) From the survey, $75 \%$ of the group disagreed with this statement. "A norm of experimentation exists at our school that permits educators to try new instructional practices without fear of criticism should initial efforts fail." What kinds of things were you thinking about when you disagreed with this statement? Can you provide specific examples? What might cause a teacher at this site to worry about being criticized if something new failed? Can you give an example of how the emphasis on success at your school might discourage a teacher from trying something new? Could or how might personnel evaluation procedures interfere with attempts to try a change in your teaching? What might be possible consequences of trying and failing at your school?

5) From the survey, $75 \%$ agree that district-level personnel help guide professional development planning efforts and assist in implementation. What examples can you give of this? How does this impact you as a learner?

6) From the survey, all the group members disagreed with this statement. "Provisions for follow-up support are included in all of our professional development plans." What kinds of follow up support would you expect to receive during a system wide change like you experienced last year? Did you ask for follow-up support during the school year? If so, what 
were the results? How might your experience have been improved if follow-up support was included in the professional development plans? Describe what do you think is the greatest consequence when follow up support is lacking in a system wide change to a school's professional development.

7) From the survey, $75 \%$ answered in disagreement to "We have ready access to expertise when implementation problems or difficulties are encountered." Can you give a specific time when this occurred? Describe the problem or difficulty you encountered. If your problem was solved...how? Who helped? Can you take one of those examples and walk me through how you would like it to have been solved?

\section{Group 2}

1) From the survey, the group as a whole slightly or moderately disagrees with the following statement, "The administration, faculty, and other staff members of our school work together to plan professional development activities." What makes you disagree with this statement? What groups were involved in the planning? What were the results or consequences for you as a learner? During last year (07-08) were you asked to help plan professional development? If so, what did you plan? Was your plan implemented? How might your professional development experience been different if administrators, faculty and other staff had worked together to plan the activities?

2) $80 \%$ of the group either moderately or slightly agreed with this statement, "District level professional development programs and activities are thoughtfully planned and complement our school-level efforts. What words or phrases come to mind when you hear this statement read aloud? Can you describe a program or activity that was thoughtfully planned? Can you describe a program or activity that complemented your school level efforts? What were the results or consequences for you as a learner?

3) $80 \%$ of this group either slightly or strongly agreed with the following statement, "A norm of continuous improvement exists in our school that recognizes that learning about best practices in our profession is never finished." What kinds of things would a newcomer to the school observe, notice, or recognize to support your perceptions? In classrooms, during professional development, and team meetings, etc? Who best supports or where does the norm of continuous improvement stem from? Can you site one specific example that a school wishing to improve this aspect could model?

4) $80 \%$ of the group members disagreed with this statement, "Provisions for follow-up support are included in all of our professional development plans." What kinds of follow up support would you expect to receive during a system wide change like you experienced last year? Did you ask for follow-up support during the school year? If so, what were the results? How might your experience have been improved if follow-up support was included in the professional development plans? Describe what do you think is the greatest consequence when follow up support is lacking in a system wide change to a school's professional development? 
5) $80 \%$ agree that district-level personnel help guide professional development planning efforts and assist in implementation. What examples can you give of this? How does this impact you as a learner? How might this affect your learners?

6) From the survey, $60 \%$ of the group agreed with this statement, "A norm of experimentation exists at our school that permits educators to try new instructional practices without fear of criticism should initial efforts fail." What kinds of things were you thinking about when you agreed with this statement? What might cause a teacher at this site to keep on trying new practices without fear and despite failure? Can you give an example of how the emphasis or recognition of success at your school might encourage a teacher to try something new? Could or how might personnel evaluation procedures be conducive with attempts to try a change in your teaching? What might be possible consequences of trying and failing at your school?

7) From the survey, $60 \%$ disagreed that the administration and faculty of the school have studied the change process to assist in planning and implementing effective professional development programs and activities. What are some words and phrases that come to mind after hearing this statement read aloud? From your perspective, if administrators and faculty did not study the change process, how did this affect you as a learner and participant in this system wide change? What part about this sytemwide change was most difficult and could have been prevented if those involved had a better knowledge of the change process?

8) From the survey, $60 \%$ disagreed with this statement, "Leaders in our school advocate, encourage, and support professional development through incentives and resources." How did this impact your learning experiences? If not by offering incentives and resources, what are some ways that leaders advocate, encourage, and support professional development? (For example by modeling, etc.) As learners and teachers, how do you expect or want leaders to encourage a new program?

9) From the survey, $60 \%$ agreed with this statement, "Our professional development programs and activities are aligned with our school mission, goals, and objectives." Can you provide examples of this? How did this impact your attitude and learning toward the program? In what ways did this impact your students?

10) From the survey, $60 \%$ answered in agreement to "We have ready access to expertise when implementation problems or difficulties are encountered." Can you give a specific time when this occurred? Describe the problem or difficulty you encountered. Can you take one of those examples and walk me through how ready access to expertise helped to solve the problem? Did this impact your learners? How?

\section{Group 3}

1) From the survey, all disagreed with the statement, "Leaders in our school advocate, encourage, and support professional development through incentives and resources." How did this impact your learning experiences in professional development? If not by offering 
incentives and resources, what were some ways that leaders advocated, encouraged, and support professional development? (For example by modeling, etc.) As learners and teachers, how do you expect or want leaders to encourage a new program like you experienced in professional development last year?

2) From the survey all disagreed with the statement, "Provisions for follow-up support are included in all of our professional development plans." What kinds of follow up support would you expect to receive during a system wide change like you experienced last year? Did you ask for follow up support during the school year? If so, what were the results? How might your experience have been improved if follow up support was included in the professional development plans? Describe what you think is the greatest consequence when follow up support is lacking in a system wide change to a school's new professional development program.

3) From the survey, $75 \%$ of you agreed with the statement. "A norm of continuous improvement exists in our school that recognizes that learning about best practices in our profession is never finished." What kinds of things would a newcomer to the school observe, notice, or recognize to support your perceptions? In classrooms, during professional development, and team meetings? Who best supports or where does the norm of continuous improvement stem from?

4) From the survey, 75\% of your survey group disagreed with the statement, "District level professional development programs and activities are thoughtfully planned and complement our school level efforts." What words of phrases come to mind when you hear this statement read aloud? Can you describe a program or activity that was not thoughtfully planned? Can you describe a program or activity that did not necessarily complement your school level efforts?

\section{Group 4}

1) From the survey, $75 \%$ of you slightly agreed with this statement, "Our professional development programs and activities are aligned with our school mission, goals, and objectives." Can you provide examples of this? How did this impact your attitude and learning toward the program? In what ways did this impact your students?

2) From the survey, the group $100 \%$ slightly, moderately, or strongly disagreed with the following statement, "The administration, faculty, and other staff members of our school work together to plan professional development activities." What makes you disagree with this statement? What groups were involved in the planning? What were the results or consequences for you as a learner? How might your professional development experience been different if administrators, faculty and other staff had worked together to plan the activities?

3) From the survey, $75 \%$ disagreed with this statement. "Leaders in our school advocate, encourage, and support professional development through incentives and resources." How 
did this impact your learning experiences? As learners and teachers, how do you expect or want leaders to encourage a new program?

4) From the survey, $75 \%$ disagreed that the administration and faculty of the school have studied the change process to assist in planning and implementing effective professional development programs and activities. What are some words and phrases that come to mind after hearing this statement read aloud? From your perspective, if administrators and faculty did not study the change process, how did this affect you as a learner and participant in this system wide change? What part about this sytemwide change was most difficult and could have been prevented if those involved had a better knowledge of the change process?

5) From the survey, 75\% of the group disagreed with this statement, "A norm of experimentation exists at our school that permits educators to try new instructional practices without fear of criticism should initial efforts fail." What kinds of things were you thinking about when you disagreed with this statement? Can you provide specific examples? What might cause a teacher at this site to worry about being criticized if something new failed? Can you give an example of how the emphasis on success at your school might discourage a teacher from trying something new? What might be possible consequences of trying and failing at your school?

6) From the survey, $75 \%$ agree that district-level personnel help guide our professional development planning efforts and assist in implementation. What examples can you give of this? How does this impact you as a learner?

7) All in this group either slightly or strongly agreed with the following statement, "A norm of continuous improvement exists in our school that recognizes that learning about best practices in our profession is never finished." What kinds of things would a newcomer to the school observe, notice, or recognize to support your perceptions? In classrooms, during professional development, and team meetings, etc? Who best supports or where does the norm of continuous improvement stem from?

8) $75 \%$ of your group slightly or moderately disagreed with the following survey item: "District level professional development programs and activities are thoughtfully planned and complement our school-level efforts." What words or phrases come to mind when you hear this statement read aloud? Can you describe a program or activity that was not thoughtfully planned? Can you describe a program or activity that did not necessarily complement your school level efforts?

\section{Group 5}

1) From the survey, 67\% disagreed with this statement, "Leaders in our school advocate, encourage, and support professional development through incentives and resources." How did this impact your learning experiences? If not by offering incentives and resources, what are some ways that leaders advocate, encourage, and support professional development? (For 
example by modeling, etc.) As learners and teachers, how do you expect or want leaders to encourage a new program?

2) From the survey, $67 \%$ disagreed that the administration and faculty of the school have studied the change process to assist in planning and implementing effective professional development programs and activities. What are some words and phrases that come to mind after hearing this statement read aloud? From your perspective, if administrators and faculty did not study the change process. how did this affect you as a learner and participant in this system wide change? What part about this sytemwide change was most difficult and could have been prevented if those involved had a better knowledge of the change process?

3) From the survey, $67 \%$ of the group disagreed with this statement, "A norm of experimentation exists at our school that permits educators to try new instructional practices without fear of criticism should initial efforts fail." What kinds of things were you thinking about when you disagreed with this statement? Can you provide specific examples? What might cause a teacher at this site to keep on trying new practices without fear and despite failure? Can you give an example of how the emphasis or recognition of success at your school might encourage a teacher to try something new? Could or how might personnel evaluation procedures be conducive with attempts to try a change in your teaching? What might be possible consequences of trying and failing at your school?

4) From the survey, 67\% disagreed with this statement. "District-level personnel help guide our professional development planning efforts and assist in implementation." Can you describe a certain activity during last year that led you to disagree with the statement? How did this lack of guidance in planning and implementation from district level personnel affect you as a learner?

5) From the survey, $100 \%$ of the surveyed teachers in this group disagreed with this statement. "Provisions for follow-up support are included in all of our professional development plans." What kinds of follow up support would you expect to receive during a system wide change like you experienced last year? Did you ask for follow-up support during the school year? If so, what were the results? How might your experience have been improved if follow-up support was included in the professional development plans? Describe what do you think is the greatest consequence when follow up support is lacking in a system wide change to a school's professional development?

6) From the survey, $83 \%$ of this group either slightly or strongly agreed with the following statement: "A norm of continuous improvement exists in our school that recognizes that learning about best practices in our profession is never finished."

What kinds of things would a newcomer to the school observe, notice, or recognize to support your perceptions? In classrooms, during professional development, and team meetings, etc? Who best supports or where does the norm of continuous improvement stem from? Can you site one specific example that a school wishing to improve this aspect could model? 
7) From the survey, $83 \%$ agreed with this statement, "Our professional development programs and activities are aligned with our school mission, goals, and objectives." Can you provide examples of this? How did this impact your attitude and learning toward the program? In what ways did this impact your students?

One on One interview

1) "The administration, faculty, and other staff members of our school work together to plan professional development activities." What made you disagree with this statement? What groups were involved in the planning? What were the results or consequences for you as a learner? During last year (07-08) were you asked to help plan professional development? If so, what did you plan? Was your plan implemented? How might your professional development experience been different if administrators, faculty and other staff had worked together to plan the activities?

2) "The administration and faculty of our school have studied the change process to assist in planning and implementing effective professional development programs and activities." What are some words and phrases that come to mind after hearing this statement read aloud? From you perspective, if administrators and faculty did not study the change process, how did this affect you as a learner and participant in this system wide change? What part about this sytemwide change was most difficult and could have been prevented if those involved had a better knowledge of the change process?

3) What kinds of things were you thinking about when you disagreed with this statement? "A norm of experimentation exists at our school that permits educators to try new Instructional practices without fear of criticism should initial efforts fail." Can you provide specific examples? What might cause a teacher at this site to worry about being criticized if something new failed? Can you give an example of how the emphasis on success at your school might discourage a teacher from trying something new? Could or how might personnel evaluation procedures interfere with attempts to try a change in your teaching? What might be possible consequences of trying and failing at your school?

4) You agreed in the survey that a norm of continuous improvement exists in the school that recognizes that learning about best practices in our profession is never finished. What kinds of things would a newcomer to the school observe, notice, or recognize to support your perceptions? In classrooms, during professional development, and team meetings, etc? Who best supports or where does the norm of continuous improvement stem from? Can you site one specific example that a school wishing to improve this aspect could model? What advice would you give to a teacher going through a system wide change in his/her professional development? What advice would you give to a professional development planner implementing a systemwide change in professional development? 


\section{Administrator Interview Protocol}

\section{As you are interviewed- please reflect upon the 07-08 school year only.}

1.) What role did you play in planning professional development activities? Describe collaboration efforts with colleagues during this time.

2.) Can you provide an example of how a professional development activity was planned and how that same activity complemented school-level efforts.

3.) During this system wide change, what provisions for follow-up support to staff were included in the professional development plans? Can you give a specific example?

4.) Before the implementation of this new PD program, how did you as a leader prepare for this system wide change? For example what change models/theories did you explore? Did you collaborate with other administrators who recently implemented a system wide change?

5.) How would you describe your leadership style? In what ways did you as a leader encourage and support professional development during the 07-08 school year?

6.) How would you describe the overall culture of this school? Can you compare it to other places where you have worked in a leadership capacity?

7.) Would you say that a norm of continuous improvement exists at the school which recognizes that learning about best practices in the teaching profession is never finished? If so, what kinds of things would a newcomer to the school observe in professional development? In classrooms? In collaborative meetings?

8.) What kinds of things might a new teacher or administrator observe that would reflect teachers trying new instructional practices without fear of criticism?

9.) How were school personnel (administrators, teachers) recognized for their successes during this system wide change?

10.) Did the program alter organizational procedures? If so, in what ways?

Is there anything I should have asked you but didn't about this system wide change in professional development during the $07 / 08$ school year? 
APPENDIX G

POST CODING FOR PARTICIPANT

PROFILE 


\section{Post Coding for Participant Profile}

Question 1 on Participant Profile (Years teaching)

$1-3$ years $=1 \quad 4-7$ years $=2 \quad 8-11$ years $=3 \quad 12-15$ years $=4 \quad 15+$ years $=5$

Question 2 on Participant Profile (Education level)

Bachelors $=1 \quad$ Masters $=2 \quad$ Masters plus $=3$

Question 3 on Participant Profile (Consumer type)

Gourmet Omnivore $=1$ Passive Consumer $=2$ Reticent Consumer $=3$

Question 4 on Participant Profile (Teacher Career Stage A)

Induction $=1 \quad$ Stability $=2$ Career Wind Down $=3$

Question 5 on Participant Profile (Teacher Career Stage a)

Competency Building = 1 Enthusiastic and Growing $=2$ Career Frustration = 3 